\title{
A Review of Ice Particle Shapes in Cirrus formed In Situ and in Anvils
}

DOI:

10.1029/2018JD030122

\section{Document Version}

Accepted author manuscript

Link to publication record in Manchester Research Explorer

\section{Citation for published version (APA):}

Lawson, P., Gallagher, M., Woods, S., \& Connolly, P. (2019). A Review of Ice Particle Shapes in Cirrus formed In Situ and in Anvils. Journal of Geophysical Research-Atmospheres. https://doi.org/10.1029/2018JD030122

\section{Published in:}

Journal of Geophysical Research-Atmospheres

\section{Citing this paper}

Please note that where the full-text provided on Manchester Research Explorer is the Author Accepted Manuscript or Proof version this may differ from the final Published version. If citing, it is advised that you check and use the publisher's definitive version.

\section{General rights}

Copyright and moral rights for the publications made accessible in the Research Explorer are retained by the authors and/or other copyright owners and it is a condition of accessing publications that users recognise and abide by the legal requirements associated with these rights.

\section{Takedown policy}

If you believe that this document breaches copyright please refer to the University of Manchester's Takedown Procedures [http://man.ac.uk/04Y6Bo] or contact uml.scholarlycommunications@manchester.ac.uk providing relevant details, so we can investigate your claim.

\section{OPEN ACCESS}


Lawson R. Paul (Orcid ID: 0000-0003-0840-7780)

Woods Sarah (Orcid ID: 0000-0003-2174-8889)

Jensen Eric J. (Orcid ID: 0000-0002-7514-4012)

Erfani Ehsan (Orcid ID: 0000-0002-7364-1912)

Gallagher Martin (Orcid ID: 0000-0002-4968-6088)

Connolly Paul James (Orcid ID: 0000-0002-3294-7405)

Whiteway James A. (Orcid ID: 0000-0002-0999-1627)

Schmitt Carl G (Orcid ID: 0000-0003-3829-6970)

McFarquhar Greg (Orcid ID: 0000-0003-0950-0135)

Um Junshik (Orcid ID: 0000-0002-7886-9043)

Protat Alain (Orcid ID: 0000-0002-8933-874X)

Lance Sara (Orcid ID: 0000-0002-2396-2582)

Stith Jeffrey (Orcid ID: 0000-0002-6451-5455)

Korolev Alexei (Orcid ID: 0000-0003-3877-8419)

Toon Owen Brian (Orcid ID: 0000-0002-1394-3062)

Krämer Martina (Orcid ID: 0000-0002-2888-1722)

\section{A Review of Ice Particle Shapes in Cirrus formed In Situ and in Anvils}

R. P. Lawson ${ }^{1}$, S. Woods' ${ }^{1}$ E. Jensen ${ }^{2}$, E. Erfani ${ }^{11,17}$, C, Gurganus ${ }^{1}$, M. Gallagher ${ }^{3}$, P. Connolly $^{3}$, J. Whiteway ${ }^{4}$, A. J. Baran ${ }^{5,6}$, P. May ${ }^{7}$, A. Heymsfield ${ }^{8}$, C. G. Schmitt ${ }^{8}$, G. McFarquhar', J. Um ${ }^{10}$, A. Protat ${ }^{7}$, M. Bailey ${ }^{11}$, S. Lance ${ }^{12}$, A. Muehlbauer ${ }^{13}$, J. Stith ${ }^{8}$, A. Korolev $^{14}$, O. B. Toon ${ }^{15}$, M. Krämer ${ }^{16}$

${ }^{1}$ Stratton Park Engineering Company, Inc., Boulder, Colorado, USA.

${ }^{2}$ NASA Ames Research Center, Moffett Field, California, USA.

${ }^{3}$ University of Manchester, Manchester, UK.

${ }^{4}$ Centre for Research in Earth and Space Science, York University, Toronto, Ontario, Canada.

${ }^{5}$ Met Office, Exeter, UK.

${ }^{6}$ School of Physics, Astronomy and Mathematics, University of Hertfordshire, Hatfield, Hertfordshire, UK.

${ }^{7}$ Australian Bureau of Meteorology, Melbourne, Victoria, Australia.

${ }^{8}$ National Center for Atmospheric Research, Boulder, Colorado, USA.

${ }^{9}$ Cooperative Institute for Mesoscale Meteorological Studies, University of Oklahoma, Norman, Oklahoma, USA.

${ }^{10}$ Department of Atmospheric and Environmental Sciences, Pusan National University, Busan, South Korea

${ }^{11}$ Desert Research Institute, Reno, NV, USA.

${ }^{12}$ Atmospheric Sciences Research Center, University at Albany, Albany, NY, USA.

${ }^{13}$ FM Global Research, Norwood, MA, USA.

${ }^{14}$ Environment Canada, Toronto, Ontario, Canada.

This article has been accepted for publication and undergone full peer review but has not been through the copyediting, typesetting, pagination and proofreading process which may lead to differences between this version and the Version of Record. Please cite this article as doi: 10.1029/2018JD030122 


\title{
${ }^{15}$ Department of Atmospheric and Oceanic Sciences and Laboratory for Atmospheric and Space Physics, University of Colorado Boulder, Boulder, Colorado, USA.
}

\author{
${ }^{16}$ Forschungszentrum Jülich, Institut für Energie und Klimaforschung, Jülich, \\ Germany. \\ ${ }^{17}$ Current Affiliation: Department of Atmospheric, Oceanic, and Earth Sciences, George \\ Mason University, Fairfax, VA, USA
}

Corresponding author: Dr. R. Paul Lawson (plawson@specinc.com)

Key Points:

- There is a distinct difference in the shapes of cirrus ice particles formed in situ and cirrus generated as the result of convective anvils.

- The shapes of ice particles in Tropical Maritime anvil cirrus are characteristically different from ice particles in Mid-Latitude convective anvils.

- Numerical simulations of the generation of in situ and anvil cirrus can incorporate ice particle shape information to improve radiative transfer parameterizations.

\begin{abstract}
Results from twenty-two airborne field campaigns, including more than ten million highresolution particle images collected in cirrus formed in situ and in convective anvils, are interpreted in terms of particle shapes and their potential impact on radiative transfer. Emphasis is placed on characterizing ice particle shapes in Tropical Maritime and MidLatitude Continental anvil cirrus, as well as in cirrus formed in situ in the upper troposphere, and subvisible cirrus in the upper tropical troposphere layer. There is a distinctive difference in cirrus ice particle shapes formed in situ compared to those in anvils that are generated in close proximity to convection. More than half the mass in cirrus formed in situ are rosetteshapes (polycrystals and bullet rosettes). Cirrus formed from fresh convective anvils is mostly devoid of rosette-shaped particles. However, small frozen drops may experience regrowth downwind of an aged anvil in a regime with $R H_{\text {ice }}>\sim 120 \%$, and then grow into rosette shapes. Identifiable particle shapes in Tropical Maritime anvils that have not been impacted by continental influences typically contain mostly single plate-like and columnar crystals and aggregates. Mid-Latitude Continental anvils contain single rimed particles, more and larger aggregates with riming, and chains of small ice particles when in a highly electrified environment. The particles in subvisible cirrus are $<\sim 100 \mu \mathrm{m}$ and quasi-spherical with some plates and rare trigonal shapes. Percentages of particle shapes and power laws relating mean particle area and mass to dimension are provided to improve parameterization of remote retrievals and numerical simulations.
\end{abstract}




\section{Introduction}

The shapes of cirrus ice particles have been shown to have significant influence on the Earth's radiation budget (Stephens et al., 1990; Mishchenko et al., 1996; McFarquhar et al., 2002; Stephens 2005; Jensen et al., 2009; Lawson et al., 2010; Feng et al., 2011; Baran 2012; Yang et al., 2015, 2018; Hartmann 2016; Hartmann and Berry, 2017; Um et al., 2018; Loeb et al., 2018). According to Baran (2012), "space-based measurements reveal that cirrus covers about $30 \%$ of the mid-latitudes at any given time, while in the tropics, the coverage can be $60 \%-80 \%$ at any given time." Guignard et al. (2012) report that about $25 \%$ of the earth is covered by subvisible cirrus (SVC), which is found mostly in the Tropical Tropopause Layer (TTL). Jensen et al. (2009), Lawson et al. (2010), Baran (2012) and others show that the net radiative effect of cirrus clouds depend on horizontal and vertical cloud dimensions, and the size distribution and shape of ice particles throughout the cloud. Choi and Ho (2006) show that in the Tropics optically thin clouds (i.e., optical depth < 10) have a warming effect and optically thick clouds a cooling effect. Their data suggest that $60 \%$ of the clouds in the tropics are optically thin, and thus the overall radiative effect is a warming of the atmosphere. Modeling results from Fig. 4 of in Fu et al., (2002) show a net warming effect for tropical cirrus with tops $>\sim 13 \mathrm{~km}$ with an optical depth $<10$, and a net cooling effect for lower clouds at the same optical depth, which is in general agreement with Choi and Ho (2006). The data from Choi and Ho (2006) suggest that $60 \%$ of the clouds in the tropics are optically thin, and thus the overall radiative effect is a warming of the atmosphere. Hartmann et al. (2018) simulated tropical convection and found that anvils initially thicken and have a net cloud radiative cooling effect (i.e., the atmosphere cools), followed by the anvil rising and thinning, producing a net radiative warming effect that approximately balanced the initial cooling. However, the results have yet to be corroborated by observations of initial anvil thickening followed by thinning and lifting.

The majority of cirrus clouds in the tropics appear to be the result of thunderstorm outflow (i.e., detrained cloud), or are otherwise associated with convection (Massie et al., 2002; Riihimaki et al., 2012), including lifting from gravity waves that form as a result of convective blocking (Jensen et al., 2016), or regrowth of seed particles advected downwind (Gallagher et al., 2012). Cirrus that is associated with convective outflow is commonly referred to as "anvil cirrus" (Lawson et al., 2003, 2010; Heymsfield et al. 2017; Jensen et al., 2018). While there are 27 terms associated with cirrus and cirriform clouds in the online version of the AMS Glossary of Meteorology (http://glossary.ametsoc.org/wiki/Main_Page), there is no mention of cirrus formed as the result of convection and thunderstorm outflow. In this paper we refer to anvil cirrus as cloud associated with convection and thunderstorm outflow that is above the $-30{ }^{\circ} \mathrm{C}$ level. Previous studies have shown that ice particles larger than about $200 \mu \mathrm{m}$ will sediment out of anvil cirrus in a few hours (Mace et al., 2006; Jensen et al., 2018; Woods et al. 2018). Satellite images suggest that anvil cirrus spreads out and can expand over the course of 12 hours or more (Luo and Rossow, 2004; Mace et al., 2006), so continued growth of smaller ice particles and/or nucleation of new ice must be occurring.

Cirrus that forms at temperatures colder than about $-30{ }^{\circ} \mathrm{C}$, as opposed to fresh anvil cirrus where the large majority of the ice particles are formed at warmer temperatures in convective updrafts, is referred to here as "in situ" cirrus. In situ cirrus can be generated via several mechanisms, including synoptic lifting, orographic lifting, gravity waves and regeneration of "seed" ice that has formed from homogenous freezing of small drops and advected out of an anvil. The freezing process can be through either heterogeneous or homogeneous nucleation (Cziczo et al., 2013; Jensen et al., 2013). 
Several airborne field campaigns have investigated the properties of ice particles formed in situ and in anvil cirrus. The advent of the cloud particle imager (CPI) in 1997 facilitated the acquisition of extensive datasets of high-resolution imagery of ice particle shapes (e.g., Korolev et al., 1999; Stith et al., 2002, 2014; Lawson et al., 2001, 2003, 2006a, 2008, 2010; Whiteway et al., 2004; Connolly et al., 2005, Gallagher et al., 2005, 2012; Jensen et al., 2009, 2018, Baran et al., 2009, 2011; Heymsfield et al., 2017; Woods et al., 2018). A review paper by Baran (2012) explores multiple aspects of how cirrus clouds contribute to climate, but does not present a detailed discussion of particle shape. Krämer et al. (2016) also present results from a comprehensive study of multiple investigations of cirrus, but without an assessment of particle shape. A recent review of cirrus clouds by Heymsfield et al. (2017) focuses on nucleation processes, size distributions and ice water content, with a brief discussion of particle shapes, but without emphasis on high-resolution imagery. The Heymsfield et al. (2017) review does recommend, however, that the dominant shapes of cirrus ice particles as a function of cloud dynamics and geographic location be addressed in the future. This review paper has been generated partly in response to that recommendation. The twenty-two airborne field campaigns discussed here emphasize analyses of the dominant shapes of cirrus particle images recorded by the CPI. The datasets were collected in anvil and in situ cirrus at locations ranging from Polar regions to the Tropics. Data were collected over a myriad of surfaces, including over the open ocean, land in the mid-latitudes and over ocean that has been influenced by nearby land. High altitude data collected in SVC sampled in the upper TTL are also discussed.

The structure of this paper is as follows: Section 2 describes methodology, including airborne platforms, instrumentation, software used to automatically classify particle shapes and nomenclature used to define cloud types. Section 3 provides an introduction to typical particle shapes in anvil and in situ cirrus, and a physical explanation for why the shapes are distinctly different. Section 4 presents representative results from the twenty-two field campaigns. Section 5 provides a tabulation of the percentages of ice particle shapes in the various cirrus cloud types, with derived power laws that relate mean values of ice particle area and mass to particle dimension as a function of particle shape. Section 6 is a summary and discussion of results. A list of all acronyms used in this paper is found in Appendix A. An explanation of the least squares fits to data points is presented in Appendix B.

\section{Methodology}

\subsection{Instrumentation}

The CPI makes it possible to collect high-resolution digital images of cloud particles without having them impact a surface, such as Formvar or oil-coated film strips. The CPI records images of particles on an 8-bit, high-speed digital camera as the particles pass through the sample volume of the instrument. The motion of the particles is "frozen" by a pulsed laser and only the portion of the 1 megapixel camera with particle images is recorded. The nominal pixel resolution in the sample volume is $2.3 \mu \mathrm{m}$, but the actual resolution is about $5 \mu \mathrm{m}$ due to optical blur. Thus, the gross shape of particles larger than about $50 \mu \mathrm{m}$ in maximum dimension can be determined (Woods et al. 2018), and the shapes of some smaller particles can be distinguished from spheres (e.g., water drops) if they have an aspect ratio > 2:1. However, some images, such as budding rosettes, cannot be distinguished from irregular shapes unless they are larger than about $100 \mu \mathrm{m}$. Throughout the manuscript, particle sizes are referenced by maximum dimension, unless otherwise noted. 
Data from the 2D-S probe (Lawson et al., 2006c) is used in discrete instances in this paper. The CPI has a relatively small sample area of $2 \mathrm{~mm} \times 2 \mathrm{~mm}$. Thus, particles larger than about $1 \mathrm{~mm}$ are seldom entirely viewed by the probe, due to their random positioning in the sample area. The 2D-S will fully image particles up to $1.2 \mathrm{~mm}$, with no limit on the image in the direction of travel of the particle. Also, the 2D-S is used in the selected instances when particle size distributions are shown in this paper. The $2 \mathrm{D}-\mathrm{S}$ records images with $10-\mu \mathrm{m}$ pixel resolution, but the concentration of particles in the 10 to $20 \mu \mathrm{m}$ range contains the most uncertainty. Unless otherwise noted, particle mass from CPI and 2D-S imagery is computed in this paper from the particle cross-sectional area of each individual image using the area-to-mass relationship from Baker and Lawson (2006b). 2D-S size distributions and number concentrations shown in this paper are compared with size distributions from the fast cloud droplet probe (FCDP). The FCDP measures the sizes of particles from 2 to $50 \mu \mathrm{m}$ via forward scattering and Mie theory (Lawson et al., 2017; Woods et al., 2018). As described in Woods et al. (2018), size distribution measurements are deemed reasonable when there is good overlap between the two probes in the 10 to $30 \mu \mathrm{m}$ region.

There is some use of historical data in this paper from the 2D-C (two-dimensional cloud particle imaging probe) and the CIP (cloud imaging probe) in this paper. However, as pointed out by Heymsfield et al., (2017) and Gurganus and Lawson (2018), historical measurements of size distributions of small ice particles $(<\sim 75 \mu \mathrm{m})$ using 2D-C (Knollenberg 1970) and CIP (Baumgardner et al., 2001) probes have been problematic due to poor response of cloud particle probes in that size range..

The 2D-S probe uses anti-shattering probe tips and particle inter-arrival time to minimize shattering (Lawson, 2011). The CPI is not immune to shattering. Shattered images can generally be identified when there are several small images within a single frame (Um and McFarquhar, 2011); however, when there is only a single image in a frame there is uncertainty whether it is a natural ice particle or an artifact. The shape analyses in this paper generally rely on particles larger than $50 \mu \mathrm{m}$, which excludes most shattered particles. In figures where smaller particles are used in an analysis, the CPI data are sorted to eliminate frames with more than one image.

\subsection{Software to Automatically Classify Particle Shape}

High-speed real time data processing makes it possible to store large quantities of digital images from a single cloud sampling pass. Up to a thousand images per second are recorded in clouds with small particles. Software routines have been developed by various investigators to automatically classify the shapes of ice particles recorded by the CPI (e.g., Lawson et al., 2006b, and Um and McFarquhar 2009; Schmitt and Heymsfield 2010). Lawson et al. (2006b) provides a description of how several parameters, including particle length, width, area, perimeter, roundness, area ratio and perimeter harmonics are used to classify shapes. Perimeter harmonics are accomplished by converting perimeter into a time series, taking the Fourier transform and analyzing harmonic frequencies.

A similar, but mathematically different approach using fractal dimension, is described in Schmitt and Heymsfield (2010). The ice particle shape (i.e., habit) classification software works best if it is "tuned" for the type of cloud particles that are typically found within a specific cloud type, such as anvil or in situ cirrus. For example, stellar dendrites and rosettes are difficult to distinguish, but stellar shapes are formed at temperatures warmer than $-20^{\circ} \mathrm{C}$ 
and typically found in anvils, whereas rosettes are formed at temperatures colder than $-40^{\circ} \mathrm{C}$ (Bailey and Hallett 2009) and typically found in cirrus formed in situ. Lawson et al. (2006b) show a comparison of cirrus particles $>50 \mu \mathrm{m}$ classified manually compared with automatic classification. Their analysis shows the following discrepancies in the automatic method compared with manual classification: spheroids 5\%; columns: $8 \%$; plates: 27\%; budding rosettes: $20 \%$; rosette shapes: $11 \%$; small irregulars: $11 \%$; and large irregulars: $13 \%$. CPI images show that there are ubiquitous ice particles smaller than $50 \mu \mathrm{m}$ in most ice clouds. These particles typically appear to be quasi-spherical in shape in CPI images. However, it is often not possible to determine if these small particles are spherical, quasi-spherical, small hex-plates, droxtals, or some other undefined shape. Investigators have used various terminologies to classify these small particle images, including spheroids, quasi-spheroids, spheres and unclassified, for example. In this paper we adopt the term used by the investigator and do not attempt to redefine the classifications. An example of the shapes of particles classified from in situ cirrus using the methodology described in Lawson et al. (2006b) is shown in Figure 1.

\subsection{Airborne Platforms and Nomenclature Defining Cloud Types}

The emphasis of this paper is on the shape of cirrus ice particles with some implications on radiative transfer. The data were collected in convective anvils and in situ cirrus in several geographic locations using multiple airborne platforms. Included are measurements in Tropical Maritime, tropical continental and Mid-Latitude Continental anvils and in situ cirrus in the mid and upper troposphere, up to temperature levels of about $-60^{\circ} \mathrm{C}$. Additional measurements in the TTL up to $-90{ }^{\circ} \mathrm{C}$ are also discussed. Platforms include a WB-57F, DC-8, Global Hawk, Gulfstream V, Proteus, Egrett, Citation, Convair 580, Sabreliner, C-130 and two Learjets. The operators of the research aircraft are shown in Appendix A.

This paper investigates ice particle shapes in Tropical Maritime and Mid-Latitude Continental cirrus generated in situ, and from convection (i.e., anvil cirrus). Here, we consider Tropical Maritime anvils that are not influenced by proximate land masses. Thus, projects that focused on convection that was influenced by nearby land masses, such as studies over the Tiwi Islands, downwind of Darwin, Australia, and projects downwind of Central America, are not pure Tropical Maritime convection. We will see that Tropical anvils influenced by land masses share characteristics of both maritime and continental convection, and are sometimes highly electrically charged. Cirrus that is regenerated in situ downwind of anvil outflow is also considered. The characteristics of ice particles in cirrus formed in situ are compared with anvil cirrus. The characteristics of cirrus generated from Mid-Latitude Continental anvils are contrasted with cirrus formed in Tropical Maritime anvils. Limited measurements of the microphysical properties of SVC are presented.

As pointed out by Heymsfield et al. (2017) and Gurganus and Lawson (2018), measurements of size distributions of small ice particles $(<\sim 75 \mu \mathrm{m})$ using 2D-C (Knollenberg, 1970) and CIP (Baumgardner et al., 2001) probes have been problematic due to poor response of cloud particle probes in that size range, and artifacts from ice crystal shattering (Lawson, 2011; Korolev et al., 2013). We do not emphasize size-distribution data in this paper. We only present size distributions when we feel the measurements are reliable, and mainly for the purpose of comparing differences in cirrus cloud types. The size distribution measurements that are presented are based primarily on the 2D-S probe (Lawson 
et al., 2006c), which has been shown to be most accurate for particle sizes $\geq 30 \mu \mathrm{m}$ (Gurganus and Lawson 2018). The primary focus of the paper is on ice particle shapes.

\section{Overview of Particle Shapes in Anvil and In Situ Cirrus}

Graupel particles, hailstones and supercooled liquid water are rarely observed in thunderstorm anvils, except at $\mathrm{T} \geq-37{ }^{\circ} \mathrm{C}$ within a few $\mathrm{km}$ downwind of strong, active convection (Lawson et al., 1998). Images of ice particles in thunderstorms that consist primarily of single frozen drops and graupel are typically observed in the upshear region of convective updrafts. On the other hand, ice particles observed in the downshear region of convective outflow are typically single crystals, frozen drops and aggregates, as described below. Figure 2 shows an example of 2D-S images in the upshear and downshear regions of a strong convective turret that was embedded in an anvil. The data were collected from a NASA DC- 8 penetration of the turret at $-47{ }^{\circ} \mathrm{C}$ off the west coast of Costa Rica during the NASA TC4 project. Graupel particles, which except for particles with very low density, have fall velocities $>\sim 1 \mathrm{~m} \mathrm{~s}^{-1}$ (Heymsfield and Wright 2014), rapidly sediment from the outflow as soon as they are no longer supported by an updraft. Therefore, higher density graupel particles are not observed more than about $10 \mathrm{~km}$ from active convection in thunderstorm anvils, and this leads to the rapid decrease in IWC as a function of distance from the center of convection (Lawson et al., 2010). Reports of large graupel and hailstones falling from thunderstorm anvils are generally associated with vigorous Mid-Latitude Continental storms, which are often supercells. Very strong updrafts can form overshooting tops that eject large graupel and hailstones that can be advected several $\mathrm{km}$ downwind and fall through the anvil outflow. This is not a typical occurrence and is not discussed in detail in this paper, where the focus is on in situ cirrus and the outflow regions of anvils from about $10 \mathrm{~km}$ to thousands of $\mathrm{km}$ downwind of active convection.

The shapes of ice particles in the outflow regions of thunderstorm anvils (i.e., anvil cirrus) are typically markedly different than particles observed in cirrus formed in situ. Several investigators have reported that cirrus formed in situ consists largely of bullet rosettes and polycrystals. Weickmann (1947) was first to note the presence of bullet rosettes (threedimensional clusters of prismatic crystals joined at a common center) in cirrus. Heymsfield (1986) used replicator data to show a few high-resolution images of bullet rosettes. Later, CPI imagery produced enhanced cirrus datasets with millions of images of bullet rosettes and polycrystals formed in situ in cirrus (e.g., Sassen et al., 2001; Heymsfield et al., 2002; Gallagher et al., 2005; Lawson et al., 2006a, 2010; Um and McFarquhar 2007; Um et al., 2015; Stith et al., 2014; Woods et al., 2018). Figure 3 shows examples of CPI images of bullet rosettes and aggregates of bullet rosettes formed in situ in mid-latitude cirrus. The shapes of the bullet rosettes are in striking contrast to the shapes of single crystals and aggregates of crystals typically found in maritime and continental anvils, also shown in Figure 3.

The generation of rosette-shapes is attributable to rapid freezing of water and/or solution drops and continued growth in an ice supersaturated environment. Bailey and Hallett (2009) show results of laboratory studies that indicate that "pure" bullet rosettes generally form at temperatures $<-38{ }^{\circ} \mathrm{C}$. Their results show that rosette-shaped polycrystals, which may have one or more branches with plate-like growth and side planes, typically occur at temperatures from about -20 to $-40{ }^{\circ} \mathrm{C}$. Polycrystals tend to form in regions that are ( 20 to $60 \%)$ supersaturated with respect to ice; whereas single crystals tend to form at lower supersaturations. This may be because side plane growth has been observed 
to only take place in conditions where riming is occurring (Baker and Lawson 2006a). Examples of both pure rosettes and rosette-shaped polycrystals are shown in Fig. 4 (Bailey and Hallett 2009).

The notable difference in the shapes of ice crystals and aggregates in anvils compared to in situ cirrus is readily explained from basic cloud physics. As elucidated previously, the shapes of in situ cirrus ice particles that are not irregular and are large enough to be identified in CPI images are typically bullet rosettes and polycrystals, with some columns and very few plates. On the other hand CPI images in both Maritime and Continental fresh anvils are typically devoid of rosettes. The CPI images in tropical marine anvils that are not highly electrified are typically plates, double plates, columns and irregulars, with some needles, stellars and dendrites (Fig. 3). We note here that while plates and columns are the preferred habit in mixed-phase clouds within the temperature range from about -8 to $-12{ }^{\circ} \mathrm{C}$, plates and columns are formed at all temperatures when $R H_{\text {ice }}$ is $<\sim 110 \%$ (Bailey and Hallett 2009). In Tropical Maritime updrafts where glaciation typically occurs prior to $-20{ }^{\circ} \mathrm{C}$ (Lawson et al. 2015, 2017), the plates and columns observed in the anvil may also have grown at colder temperatures after liquid water has been depleted.

The images in highly electrified Mid-Latitude Continental anvils are often chains of frozen drops, small crystals and aggregates (e.g., Lawson et al 2003; Connolly 2005; Gallagher 2012; Stith et al., 2014). The primary explanation for the lack of bullet rosettes and polycrystals in Tropical Maritime anvils is that the large majority of ice crystals are formed and grow in convective updrafts prior to reaching the homogeneous freezing level ($38{ }^{\circ} \mathrm{C}$ ). For example, Lawson et al. (2017) found that about $90 \%$ of the supercooled liquid water (SLW) has been frozen or evaporated when updraft temperatures reach $-20{ }^{\circ} \mathrm{C}$ in Tropical Maritime updraft cores, in agreement with the conceptual model of Stith et al. (2004, their Fig. 14). Thus, the ice crystals observed in Tropical Marine anvils typically grow in habit regimes that are conducive to producing plates, columns, stellars and dendrites. On the other hand, small cloud droplets are often transported up to the homogeneous freezing level in strong updrafts formed in Mid-Latitude Continental convection (Rosenfeld and Woodley 2000; Lawson et al., 2017). The high concentrations of small droplets in the updrafts can either participate in riming or, after homogeneous freezing, can form aggregates (e.g. Stith et al. 2014; 2016). Anvils generally form at temperatures colder than $-38{ }^{\circ} \mathrm{C}$ so all SLW is frozen and the ice rapidly depletes the supersaturated fraction of water vapor in the anvil, driving RHice down to 100\% (Diao et al. 2015; Jensen et al., 2017), which inhibits formation and growth of polycrystals and rosettes (Bailey and Hallett 2009).

The table accompanying Fig. 3 suggests that aggregates are observed much more frequently in mid-latitude and Florida continental anvils than the Tropical Maritime anvils observed near Kwajalein. Several investigators have observed a large degree of aggregated CPI images in the outflow of continental convection (e.g., Lawson et al., 2003; Whiteway et al., 2004; Connolly et al., 2005, Gallagher et al., 2012). Gallagher et al. (2012) observed a high percentage of aggregates in the outflow of continental anvils near Darwin off of the northwest coast of Australia. As is typical with these intense thunderstorms (called "Hector" thunderstorms), there is considerable lightning and large anvils that spread downwind over the ocean. Gallagher et al. (2012) modeled an event and determined that the aggregation efficiency most consistent with the data was on the order of 0.5 , which is significantly higher than the typical value of 0.1 (Field and Heymsfield 2003). 
Aggregates and chains of aggregates consisting of frozen drops and small crystals are often observed in Mid-Latitude Continental clouds. On the other hand, chains are rarely observed in Maritime Tropical anvils (Fig. 3), unless the anvil is highly electrified, which is not typical. The chains of frozen drops and small crystals observed in Mid-Latitude Continental anvils have been attributed to high electric fields (Lawson et al., 2003; Connolly et al., 2005; Gallagher et al., 2012; Stith et al., 2014; Um et al., 2018), implied from the laboratory work of Saunders and Wahab (1975). This is supported by the correlation between the degree of aggregation and the in-anvil concentration of lightning-produced NOx, suggesting that the aggregation and electrification occurred in the same regions of the cloud (Stith et al., 2016).

Jensen et al. (2009), Lawson et al. (2010) and others show that particle size distributions in aged anvil cirrus increase in size from small, mostly frozen cloud drops near cloud top, to ice particles of hundreds of microns in mid-cloud, to aggregates that can exceed $1-\mathrm{mm}$ in size near cloud base. Figure 5 shows $2 \mathrm{D}-\mathrm{S}$ measurements in aged anvil cirrus from the TC4 project that was flown out of Costa Rica in July - August, 2007 (Jensen et al 2009). The four PSDs are from four levels in the aged anvil cirrus and show the typical increase in maximum particle size with decreasing altitude in the cloud.

2D-S and CPI images of aggregates falling from the base of a Tropical Maritime anvil, and from an electrified Mid-Latitude Continental anvil are shown in Figure 6. As seen in Fig. 6, the sizes of aggregates at the base of the Mid-Latitude Continental anvil are larger and resemble snowflakes, whereas the aggregates from the Tropical Maritime anvil are generally more "blocky". In general, the images appear to be larger versions of those shown in Fig. 3, where the Tropical Maritime CPI images are plates, columns and blocky crystals that are stuck together, whereas the Mid-Latitude Continental images are interlaced chains of small frozen drops and larger rimed particles.

Cloud drops that freeze homogeneously in convective updrafts may either sublimate if they are advected into air subsaturated with respect to ice, or grow if advected into a region supersaturated with respect to ice. Drops that freeze homogeneously $\left(\mathrm{T} \leq-38^{\circ} \mathrm{C}\right)$ and grow are likely to form rosettes (Bailey and Hallett 2009), which are readily identifiable from other ice shapes in anvils (Gallagher et al., 2012). Measurements of relative humidity with respect to ice $\left(R H_{\text {ice }}\right)$ are useful in determining if ice advected downwind in anvils will experience new growth, or not. However, $R H_{\text {ice }}$ measurements at temperatures colder than about $-40{ }^{\circ} \mathrm{C}$ require sophisticated in situ instrumentation (Ravishankara 2012). Furthermore, it is not sufficient to measure $R H_{\text {ice }}$ only where the ice crystals are observed; instead, measurements along the advected path of the ice during its growth process are required. Alternatively, since there is a clear distinction in particle shapes generated in situ and in fresh anvils, rosettes can be confidently used as a surrogate for new crystal growth in aged anvils.

Based on the following explanation, we do not make the distinction between in situ origin cirrus and liquid origin cirrus, which has been suggested by Wolf et al., (2018). Supercooled drops in anvil cirrus freeze and grow prior to reaching the homogeneous freezing temperature $\left(-38{ }^{\circ} \mathrm{C}\right)$, or freeze at the homogeneous freezing temperature. When drops freeze prior to reaching $-38{ }^{\circ} \mathrm{C}$ they grow rapidly in a water-saturated environment and exhibit shapes consistent with environmental temperature and supersaturation. When drops freeze at $-38{ }^{\circ} \mathrm{C}$ in an anvil, $R H_{\text {ice }}$ is near $100 \%$ (Diao et al. 2015; Jensen et al., 2017) and there is little or no subsequent growth. Supercooled drops that freeze and form ice particles in cirrus can be pure water or solution drops containing salts, which can freeze at temperatures colder than $-38{ }^{\circ} \mathrm{C}$. Supercooled drops in the updrafts of convective storms 
typically have a mean diameter $>\sim 10 \mu \mathrm{m}$ (Lawson et al. 2017). On the other hand, solution drops in cirrus can be tiny, perhaps even submicron, which depresses their freezing temperature well below $-38^{\circ} \mathrm{C}$ when they contain even traces of salts. As shown later, $R H_{\text {ice }}$ in cirrus formed in situ can reach values up to $170 \%$ where continued growth of frozen drops is enhanced. This is emphasized by the observation that pure rosettes are almost always observed at temperatures colder than $-38{ }^{\circ} \mathrm{C}$ (Bailey and Hallett 2009; Baker and Lawson 2006a).

\section{Results from Field Campaigns}

Several field campaigns that focused on the investigation of cirrus formed in situ and from thunderstorm anvil outflow have been staged in various locations around the globe. Due to the need for high resolution images needed to identify ice habits, twenty-two field campaigns from which CPI data are available are discussed in this paper. Over 10 million CPI images have been collected from the twenty-two field campaigns, but there is no effort to present a statistical analysis that relates particle shape with environmental parameters. This is because the development of particle shape is strongly dependent on the time history of environmental conditions experienced by the particle during its growth cycle, and these data are rarely available. That is, an ice particle may nucleate at one temperature and relative humidity, and then experience several different temperature and relative humidity regimes before it is observed. The projects discussed here are presented in roughly chronological order with emphasis on summaries of findings. A summary of composite results is presented at the conclusion of findings from the individual field campaigns.

\subsection{Environment Canada FIRE.ACE Project}

Environment Canada (EC) was one of the first institutions to operate a CPI, which was installed on the Canadian National Research Council Convair 580 research aircraft. The data discussed here are the first results from the FIRE.ACE project that included CPI data. The EC FIRE.ACE project took place in the Arctic during April 1998. While the EC investigations were not focused on cirrus clouds, Korolev et al. (1999) visually inspected over 95,000 CPI images in ice clouds with $-45<\mathrm{T}<0{ }^{\circ} \mathrm{C}$. As shown in Korolev et al. (1999) Table 1 , only $8.4 \%$ of CPI images $>40 \mu \mathrm{m}$ in the temperature range from -40 to -45 ${ }^{\circ} \mathrm{C}$ were pristine, with the remainder being irregular in shape. The predominant shapes of the larger particles at temperatures colder than about $-30{ }^{\circ} \mathrm{C}$ in the in situ cirrus were rosetteshaped polycrystals and pure bullet rosettes (Korolev 2018 - Personal Communication).

\subsection{NASA TEFLUN-A, TEFLUN-B and KWAJEX Projects}

The SPEC Learjet participated in the TEFLUN-A project and investigated thunderstorm anvils in the Southeast U.S. in April - May 1998. The University of North Dakota (UND) Citation studied convective storms in southern Florida in August 1998 (TEFLUN-B), and near the Kwajalein Atoll in July - August 1999 (KWAJEX). The NASA TEFLUN-A\&B and KWAJEX projects were some of the first projects that revealed the difference in particle shapes in Tropical Maritime and Mid-Latitude Continental convective anvils.

The Learjet focused on stratiform outflow regions generated by convective squall lines and produced the first dataset of CPI images in Continental thunderstorm anvils. An example of a Learjet flight track through a stratiform outflow region is shown in Fig. 7. 
Analysis of CPI images from both TEFLUN-A\&B in anvils near active convection showed that particles $>\sim 50 \mu \mathrm{m}$ were not typical of in situ cirrus (i.e., rosette-shaped polycrystals and bullet rosettes - Fig. 3), but instead mostly a combination of irregular shapes and aggregates. Most of the ice particles were irregular in shape and rimed (Fig. 7). In both TEFLUN projects, CPI images of particles sampled far downwind from the active convection occasionally showed examples of polycrystals with side planes, suggesting regrowth via vapor deposition.

The KWAJEX project took place in the vicinity of the Kwajalein Atoll in the Central Pacific. As shown in Figs. 3 and 7, particles in KWAJEX maritime anvils generally display different characteristics than seen in continental anvils. This is partially explained by the long-standing observation that supercooled liquid water in maritime updrafts is typically depleted at warmer temperatures than in continental convection (e.g., Koenig 1963; Mason 1996; Stith et al., 2002; Lawson et al., 2015, 2017). The coalescence process in Tropical Maritime updrafts is very efficient and broadens the drop spectra out to millimeter-diameter drops. Lawson et al. (2015) show that a secondary ice process rapidly glaciates supercooled water in the updrafts. In contrast, Mid-Latitude Continental convection is typically more electrified and contains smaller $(<\sim 50 \mu \mathrm{m})$ drops that do not freeze until much colder temperatures are reached (Rosenfeld and Woodley 2000; Lawson et al., 2017). This is a result of a combination of: (a) warmer and lower cloud bases in maritime tropical convection than in mid-latitude continental, (b) a different updraft vertical profile in continental versus maritime-tropical convection that results in less transit time to homogeneous freezing temperatures in the continental case, and (c) a generally higher concentration of small CCN in the continental cases. Thus, the small surpercooled drops are available for riming and forming aggregates. As a result, ice particles in Tropical Maritime anvils (Kwajalein images in Figs. 3 and 7) generally appear to contain more single crystals, fewer rimed particles, and fewer chain aggregates of small particles than Mid-Latitude Continental convection.

\subsection{NASA-DOE EOS, ACTIVE, EMERALD-I\&II, TWP-ICE, CRYSTAL-FACE and DC3 Projects}

These projects are grouped together because they focused primarily on anvil cirrus and revealed the first CPI imagery of chains of small frozen droplets and ice crystals. The SPEC Learjet participated in the EOS project and conducted flights in Eastern Colorado and Western Oklahoma during June - July 2001. The data collected by the SPEC Learjet revealed the first documentation of chains of small frozen drops and ice particles that was related to highly electrified anvils (Lawson et al., 2003). Figure 8 shows a photograph of a MidLatitude Continental anvil that was penetrated in three locations by the Learjet. Plotted below the photo, the particle concentration measured by a 2DC probe (Knollenberg 1970) decreases with distance from the primary convection. The anvil was highly electrified, which was verified by the crew that witnessed multiple lightning strikes during the cloud penetrations. CPI images revealed a high percentage of aggregates and chains of small ice particles, also shown in Fig. 8.

The EMERALD-II field project took place in November - December 2002 and targeted anvils generated from strong convection over the Tiwi Islands, which are on $25 \mathrm{~km}$ north of the Australian coast. Convective storms that form over Australia and Tiwi Islands near Darwin are known to be vigorous and extremely electrical. Whiteway et al. (2004), Connolly et al. (2005) and Gallagher et al. (2012) discuss the formation of chains of small hexagonal ice crystals in the outflow of these "Hector" thunderstorms. We define the Hector 
convection as Tropical, due to its geographic location, but not Tropical Maritime, because it is strongly influenced by Australia and nearby islands. Figure 9 shows examples of chains of mostly hexagonal ice crystals from Connolly et al. (2005) in juxtaposition with a photograph of aggregated ice crystals formed in a high electric field in the laboratory (Saunders and Wahab 1975). Baran (2012) also shows CPI images from a convective anvil that formed over the Tiwi Islands on 16 November 2005 during the ACTIVE project. The CPI images are very similar to CPI imagery reported from the EMERALD-II project, and are labeled Tropical in the figures, not Tropical Maritime.

The CRYSTAL-FACE project was staged from Key West, Florida in July 2002. The project employed multiple aircraft collecting observations ranging from cloud base $(\sim 1 \mathrm{~km})$ to $17 \mathrm{~km}$. The NASA WB-57 flew near anvil tops while the UND Citation sampled both growing convection and anvils during the project. Figure 10 shows an example of a vertical cross section of radar reflectivity during anvil transects of the WB-57 at $-65{ }^{\circ} \mathrm{C}$ and the Citation at $-49{ }^{\circ} \mathrm{C}$. Examples of CPI images in Fig. 10 show similar characteristics to particle shapes in other continental anvils (e.g., Figs. 3, 8 and 9).

The EMERALD-I and TWP-ICE projects were both staged out of Adelaide, Australia. EMERALD-I sampled primarily in situ cirrus (Whiteway et al., 2004), while TWP-ICE focused on the evolution of cloud systems from the initial convective cells through to the decaying and self-maintaining cirrus (May et al., 2008). EMERALD-I was held in September 2001 prior to the Hector storms that dominated weather events later in the year, which were the focus of EMERALD-II and TWP-ICE. Figure 11a shows examples of CPI images sampled in frontal cirrus between 10 and $12 \mathrm{~km}\left(-52<\mathrm{T}<-34{ }^{\circ} \mathrm{C}\right)$ by the Egrett on 19 September 2001. The images were visually sorted into habits. Interestingly, the rosettes and budding rosettes were only observed near cloud top in the frontal cirrus.

During TWP-ICE, the Scaled Composites Proteus aircraft made intensive airborne measurements of in situ cirrus, aged anvil cirrus and fresh anvils between 21 January and 14 February 2006. Figures 11b and c show examples from May et al. (2009) of CPI images recorded in a fresh anvil (Fig. 11b), and aged anvil cirrus that has experienced regrowth downwind of convection (Fig. 11c). Figure 11d shows chains of hexagonal-shaped particles sampled by the Proteus in a highly-electrified anvil (Um and McFarquhar 2009). The shapes of CPI images shown in Fig. 11 support the patterns observed in previous field projects.

The DC3 project took place in the late spring and early summer of 2012. Stith et al (2014) report results from two flights conducted by the NSF Gulfstream V (operated by NCAR) in anvils located over eastern Colorado. They found a high incidence of chain aggregates of frozen drops in both highly electrified anvils. The occurrence of well-defined pristine crystals (e.g., columns and plates) was less than $0.04 \%$ by number. Single frozen droplets and frozen droplet aggregates (FDAs) were the dominant habits with fractions of $73.0 \%$ by number and $46.3 \%$ by projected area, respectively (Um et al. (2018)). Figure 12 shows examples of CPI images sampled in an electrified anvil from Um et al. (2018).

Figure 13 shows habit histograms from Protat et al. (2011) of CPI images collected in aged anvil cirrus with in situ particle growth (Fig. 13a), and in a fresh anvil (Fig. 13b). The images were sampled by the Proteus during the TWP-ICE project. The automatic habit classification scheme is from Um and McFarquhar (2009), which uses different criteria than the scheme described in Lawson et al. (2006b), and the habit abbreviations are shown in the caption to Fig. 13. In the aged anvil with in situ particle growth (Fig. 13a 29 January 2006), $50 \%$ of particles $>100 \mu \mathrm{m}$ are unclassified, and the other half are mostly bullet rosettes with 
a few plates and aggregates of plates. In the 100 to $300 \mu \mathrm{m}$ range, $40 \%$ of the particles are unclassified (UC) the remaining images are essentially bullet rosettes (BRs), aggregates of plates (APs), and aggregates of columns (ACs). For particles $>300 \mu \mathrm{m}$, the fraction of unclassified particles is much smaller, and the dominant particles are BRs and aggregates of bullet rosettes (ABRs). Thus, this automatic habit classification for cirrus particles $>\sim 50$ $\mu \mathrm{m}$ formed in situ is very similar to examples of CPI images shown previously, and earlier habit classifications of in situ cirrus (Lawson et al., 2006b).

In contrast, the flight on 2 February 2006 (Fig. 13b) was performed in a fresh anvil produced by deep convection that was forming over the Tiwi Islands. For particles ranging from 50 to $100 \mu \mathrm{m}$, columns and plates dominate the nonspherical habits, while bullet rosettes dominated for the flight in aged anvil with cirrus formed in situ (Figs. 13a). For particles $>100 \mu \mathrm{m}$ in Fig. 13, the difference between the aged anvil with in situ cirrus and the fresh anvil is even more obvious. There is a predominance of plates and aggregates of plates observed in the fresh anvil, while budding rosettes, aggregates of budding rosettes, and aggregates of columns (that could also be rosettes) dominated in the aged anvil cirrus.

\subsection{NASA MIDCIX, DOE SPARTICUS and NASA FIRE-II Projects}

The NASA MIDCIX project utilized the NASA WB-57 and took place in April May 2004 in the south-central United States in the vicinity of the Southern Great Plains Atmospheric Radiation Measurement Central Facility near Lamont, Oklahoma. One objective of the project was to investigate the size distribution of in situ cirrus. The WB-57 was able to profile cirrus from cloud top to near cloud base on several occasions. The SPEC Learjet also flew three missions in conjunction with the WB-57. The SPARTICUS project was staged out of Boulder, Colorado from January - June 2010. The SPEC Learjet flew approximately 150 hours and investigated mostly synoptically-generated in situ cirrus, with limited flights in orographic and anvil cirrus. The extensive SPARTICUS dataset confirmed MIDCIX measurements of particle habits and size distributions in cirrus.

Figure 14 shows measurements of mass particle size distributions, examples of CPI images and classification of habits from SPARTICUS data separated into three temperature ranges. The left panel shows a vertical profile of mass size distributions based on the $2 \mathrm{D}-\mathrm{S}$ probe from several transects of cirrus clouds. The red trace in each of the size distribution panels shows the mean size distribution of the individual cirrus transects. The mean values of total particle concentration decreases with increasing temperature. As explained by Jensen et al. (2009), Woods et al. (2018) and Mitchell et al., (2018), and shown in Figs. 5 and 20, this is expected as particles sediment they may aggregate, grow via vapor diffusion if $R H_{\text {ice }}>$ $100 \%$ or sublimate if $R H_{\text {ice }}<100 \%$. Since the particles fall through regions with sub and supersaturated $R H_{\text {ice}}$, small particles will tend to sublimate and large particles will either grow, or slowly get smaller with rounded edges. Modeling work by Spichtinger and Gierens (2009) suggests that particle sedimentation will reduce $R H_{\text {ice }}$ in lower cloud regions to below the threshold for homogeneous ice nucleation, thus contributing to the reduction in total particle concentration in those regions. Also, the potential for new nucleation decreases with increasing temperature, so the appearance of new, small particles decreases with increasing temperature. As a result, progressing from coldest to warmest temperature regions, data in Fig. 14 show that the large end of the size distribution increases progressively from about 1 to $3 \mathrm{~mm}$. As expected, the ice water content (IWC) increases with increasing temperature due mainly to growth from vapor diffusion. While very small percentages of columns and plates are found in all three temperature ranges in Fig. 14, the most striking feature seen in the images and the histograms of particle shapes is the preponderance of rosettes and budding 
rosettes. Rosettes and budding rosettes comprise more than half of the number of particles > $50 \mu \mathrm{m}$, and over three-quarters of the area and mass.

Another way of viewing the relationship between particle size and habits from in situ cirrus data sampled in SPARTICUS is shown in Fig. 15. In this figure, all CPI images are classified, including images with particles $<50 \mu \mathrm{m}$. The automatic habit classification cannot reliably distinguish some perfectly spherical ice particles from quasi-spherical ice when image sizes are $<50 \mu \mathrm{m}$. Therefore, the "spheres" category includes small ice particles that may be irregular in shape, spherical, quasi-spherical (spheroids) droxtal shaped, or even hexagonal. Figures 14 and 15 highlight the observation that the smallest particles (spheres and irregulars) are the most prolific and the largest particles are rosettes and aggregates. The warmest temperature range in Figs. 14 and 15 is colder than $-38^{\circ} \mathrm{C}$, so the largest particles are typically rosettes and aggregates, instead of polycrystals with side planes and aggregates.

Muhlbauer et al. (2014) used an atmospheric state classification based on large-scale meteorology determined from the ECMWF reanalysis and states of cloudiness determined from the millimeter-wavelength cloud radar observations at the ARM SGP site. It was concluded that almost half of the cirrus cloud occurrences in the vicinity of the ARM SGP site during SPARTICUS was explained by three distinct synoptic regimes, namely, upper level ridges, mid-latitude cyclones with frontal systems, and subtropical flows with nearby jet-streams. They found that probability density functions of cirrus microphysical properties, such as PSDs and IWC, exhibited striking differences among the different synoptic regimes. CPI images sorted into representative shapes for these three synoptic regimes are shown in Fig. 16 (Lance et al., 2013).

The images in Fig. 14 and histograms in Fig. 15 suggest that a large number of rosette aggregates are present within all temperature ranges $(205-235 \mathrm{~K})$, with the largest aggregates found in the warmest temperature region $(225-235 \mathrm{~K})$. Aggregation of rosettes was previously reported by Kajikawa and Heymsfield (1989). Heymsfield et al. (2002) shows CPI images with increasing aggregation of rosettes during quasi-Lagrangian descending spirals in cirrus formed in situ. Figure 17 shows an example from the FIRE-II field program where aggregation increases with decreasing altitude, and aggregates with up to five rosettes are observed at the lowest altitude (Heymsfield et al., 2002). The top of the spiral $(9.5 \mathrm{~km})$ was at $-50{ }^{\circ} \mathrm{C}$ and the bottom was at $-26{ }^{\circ} \mathrm{C}$, which is warmer than the formation temperature of rosettes (Bailey and Hallett 2009), so these particles must have fallen from aloft.

Heymsfield (1975) proposed that the tops of cirrostratus clouds were a generation region with small particles. Heymsfield and Miloshevich (1995) suggested that the tops of mountain generated cirrus were a generation region when $R H_{\text {ice }}$ exceeded $110 \%$. More extensive measurements collected during SPARTICUS show that the tops of mountain generated cirrus may contain high concentrations of small ice, or alternatively, contain budding rosettes and rosettes that are several hundreds of microns in dimension. Since rosettes grow from a frozen drop, it is reasonable to conclude that small frozen drops that remain in an ice supersaturated environment will produce rosettes that will remain near cloud top if there is sufficient $R H_{\text {ice }}$ and vertical velocity. A vertical velocity of about 20 to $30 \mathrm{~cm}$ $\mathrm{s}^{-1}$ is required to sustain a rosette of a few hundreds of microns (Heymsfield and Iaquinta 2000). This magnitude of vertical velocity is not possible to measure in the upper troposphere, but is certainly reasonable in regions with orographic influences and/or gravity waves (Baker and Lawson 2006a; Jensen et al., 2016). 
Figure 18 shows measurements of 2D-S size distributions and CPI images from SPEC Learjet measurements in cirrus near Lubbock, Texas, downwind of the Rocky Mountains. The wind during this flight was from the southwest and ranged from 40 to $60 \mathrm{~m} \mathrm{~s}^{-1}$. The Learjet made stair-step climbs from $-49{ }^{\circ} \mathrm{C}$ up to cloud top at $-59^{\circ} \mathrm{C}$. The ice particles at cloud top were almost entirely $<100 \mu \mathrm{m}$ and in concentrations $>2,000 \mathrm{~L}^{-1}$. High particle concentrations in orograhically generated cirrus (i.e, wave clouds) often produce high concentrations of ice in the downwind regions (Baker and Lawson 2006a). The distance downwind of wave clouds where high cirrus ice concentrations are observed will be a function of particle size, wind speed, relative humidity and dispersion of the particles. High ice particle concentrations were rarely encountered in the SPARTICUS dataset, except in cirrus generated orographically, in the tops of anvils near active convection and in some Ridge Crest (Mishra et al., 2014; Mitchell et al. 2018). Thus, while it is likely that the cold tops of cirrus are the most favorable nucleating region (Mitchell et al. 2018), it is not possible to say whether this is the only nucleating region.

\subsection{NASA ATTREX and POSIDON Projects in TTL Cirrus}

The ATTREX and POSIDON projects focused on measurements of cirrus in the tropical tropopause layer (TTL) from about 13 to $18 \mathrm{~km}$. The Global Hawk uninhabited aerial vehicle (UAV) deployed from Guam and flew in excess of 30 hours over the western Pacific during the ATTREX 2014 field campaign. The Global Hawk made a series of sawtooth maneuvers that allowed it to sample cirrus from convective outflow, in situ and subvisible cirrus. Sampling was done well away from active convection, but the cirrus was often initially generated from convection and regenerated from moisture in the region. The result was typically a combination of aged and in situ cirrus.

Instrumentation on the Global Hawk included a SPEC Hawkeye probe, which combines the SPEC FCDP, CPI and 2D-S probes (Woods et al., 2018). The agreement in the overlap region (10 to $45 \mu \mathrm{m})$ of the FCDP and 2D-S size distributions was good, which encouraged Woods et al. (2018) to report a combined size distribution with a break point of about $35 \mu \mathrm{m}$. The two water vapor measurements on the aircraft were in good agreement (always within a factor of two), even at values less than 10 ppmv (Jensen et al., 2015).

Figure 19 shows average measurements of $R H_{\text {ice }}$ and total ice particle concentration from about -63 to $-85^{\circ} \mathrm{C}$ adapted from Woods et al (2018), which are in general agreement with measurements shown in Luebke et al. (2016). Note: Woods et al. (2018) include data from -60 to $-40^{\circ} \mathrm{C}$, but the Global Hawk only spent about 12 minutes sampling cloud in this temperature region, and the particle concentration data are not statistically representative of the region. Particle concentration is fairly consistent, ranging from 100 to $200 \mathrm{~L}^{-1}$ between about -63 and $-82{ }^{\circ} \mathrm{C}$, while $R H_{\text {ice }}$ increases steadily from $100 \%$ to $120 \%$. The only anomaly is the concentration at the coldest temperature $\left(-85^{\circ} \mathrm{C}\right)$, which jumps to about 500 $\mathrm{L}^{-1}$. Both concentration and $R H_{\text {ice }}$ values are averages and the peak values of $R H_{\text {ice }}$ sometimes reached the value for homogeneous nucleation of about $160 \%$ at $-85{ }^{\circ} \mathrm{C}$ (Koop et al., 2000). The jump in ice concentration at $-85{ }^{\circ} \mathrm{C}$ is most likely associated with a region where homogeneous nucleation was occurring in some regions. Jensen et al. (2013) showed an example of homogeneous nucleation in a thin cirrus layer at $-83{ }^{\circ} \mathrm{C}$ where ice concentrations were 2,000 to $10,000 \mathrm{~L}^{-1}$. Similar high ice concentrations have also been observed by Krämer et al., (2009). Jensen et al. (2013) found that ice concentrations at the same temperature but outside the isolated regions of homogeneous nucleation are on the order of $200 \mathrm{~L}^{-1}$. Figure 20 shows particle size distributions over the temperature range from 
about -63 and $-82{ }^{\circ} \mathrm{C}$ corresponding to the data shown in Fig. 19. The trend showing larger particles at warmer temperatures in Fig. 20 is consistent with results from previous projects (e.g., MIDCIX, SPARTICUS, TC4).

Figure 21 shows examples of CPI images that were sampled during ATTREX and classified using an automatic habit classification from Woods et al. (2018). Figure 22 shows results of the image classification in the temperature regions spanning -40 and $-90{ }^{\circ} \mathrm{C}$. Figure 22a includes all CPI images and Fig. 22b shows a histogram of only faceted crystals. Korolev et al. (1999) reported that over $95 \%$ of CPI images in ice clouds warmer than -45 ${ }^{\circ} \mathrm{C}$ are not faceted.

Data from Woods et al. (2018) show similar results at colder temperatures. Habit classification in the TTL $\left(-60\right.$ and $\left.-90{ }^{\circ} \mathrm{C}\right)$ is dominated by spheroids, small irregulars and images $<30 \mu \mathrm{m}$. About $60 \%$ of the particles in the TTL region are smaller than $50 \mu \mathrm{m}$. As the temperature warms in the TTL region, the large majority of the images are classified as spheroids and small irregulars. Visual inspection of the small irregulars suggests that a significant fraction of these may be budding rosettes. Particles larger than $30 \mu \mathrm{m}$ that cannot be classified into one of the habit categories are separated into small $(<200 \mu \mathrm{m})$ and large $(>200$ $\mu \mathrm{m})$ irregulars, which includes polycrystals. The particles in the temperature region from -40 and $-60{ }^{\circ} \mathrm{C}$ are strikingly different, being dominated by small and large irregulars, budding rosettes and rosettes. The dominance of budding rosettes and rosettes within the temperature range from -40 and $-60{ }^{\circ} \mathrm{C}$ is more readily identified in Fig. 22b, which shows the habit classification for only faceted crystals. The overall picture presented in Fig. 22b is one where solution drops freeze in the TTL and then grow into rosettes as they fall through the temperature region between -60 and $-40{ }^{\circ} \mathrm{C}$. Albeit, there is no evidence that the particles originating in the TTL are the same particles observed in the lower regions.

The POSIDON project utilized the WB-57 and was also staged out of Guam. The WB-57 was able to penetrate closer to convection than the Global Hawk and sampled both warmer and colder temperatures. Also, the WB-57 had more flexibility to maneuver near storms while the Global Hawk was programmed to fly only climbs and descents, and was not allowed to fly near storms. On one particular flight, the WB-57 departed Guam on 12 October 2016 at 0125 UTC, flew southwest to Palau and returned to Guam. Shortly after takeoff, the crew was requested to descend and penetrate an anvil that was on their route to Palau. Figure 23a shows Himawari 8 satellite water vapor imagery of the storm indicating a region where convection was active approximately three hours earlier, as evidenced by the overshooting top at 2300 UTC on 11 October 2016. On the 0100 UTC panel in Fig. 23b, the overshooting top is not evident, but there is still considerable water vapor seen in the imagery. By 0200 the anvil was still visible on the imagery, but was slightly aged and safe for the WB-57 to sample (Fig. 23c). At 0220 the aircraft started a descent through the decaying anvil from $56,000 \mathrm{ft}(17.1 \mathrm{~km})$ at $-86{ }^{\circ} \mathrm{C}$ to $47,000 \mathrm{ft}(14.3 \mathrm{~km})$ at $-66{ }^{\circ} \mathrm{C}$, and then climbed back to $56,000 \mathrm{ft}$ at 0244 .

Figure 24a shows infrared imagery from the Himawari 8 satellite at 0200 UTC and the flight track of the WB-57 from Guam to Palau, and return to Guam. Note that the WB-57 flew almost the identical flight track to and from Palau. Figure 24b shows a time series of altitude and temperature as the WB-57 descended and then climbed back through the anvil, which is the circled region in the satellite image in Fig. 24a. Figure 24b also shows a vertical profile of CPI images as a function of temperature. The vertical profiles of CPI images are very similar on both the descent and climb, and similar to vertical profiles of other 
Tropical Marine anvils. Mostly small quasi-spheroids and some small columns are observed near cloud top, followed by larger mostly non-faceted ice, then 60 to $200 \mu \mathrm{m}$ plates and hexagonal columns, and finally plates, column, double plates and aggregates of plates and columns out to about $500 \mu \mathrm{m}$ near the bottom of the profile.

After continuing to Palau and reversing course, the WB-57 flew approximately the same track back towards Guam along which it penetrated a region of cloud where CPI images indicated in situ particle growth. Inspection of satellite images from the previous 12 hours shows that no convection had formed in this area. Figure 25a shows the Himawari 8 infrared satellite image at 0400 UTC where a circled X shows the region of thin cloud where CPI images of rosettes where sampled from 0340 to 0354 UTC. Also shown on the flight track are the mean wind vectors between 56,000 and $43,000 \mathrm{ft}$, which are basically parallel to the WB-57 track from the anvil to Palau. The region with rosettes is approximately the location where small quasi-spherical ice particles observed near cloud top in the original convection would have arrived if advected by the mean wind. A time series of $R H_{\text {ice }}$ in the region where the rosettes are observed (Fig. 25b), shows that the "seed" ice would have experienced $R H_{\text {ice }}$ from about 100 to $160 \%$. Bailey and Hallett (2012) report rosette growth rates of from about 0.1 to $0.15 \mu \mathrm{m} \mathrm{s}^{-1}$ at -60 to $-70{ }^{\circ} \mathrm{C}$ with $R H_{\text {ice }} 120$ to $160 \%$, which is commensurate with the 100 to $300 \mu \mathrm{m}$ rosettes that are observed.

The brightness temperature in the region with rosettes is about $260 \mathrm{~K}$ and the surface temperature is about $295 \mathrm{~K}$. The rosettes were sampled at $217 \mathrm{~K}\left(-56{ }^{\circ} \mathrm{C}\right)$, implying that the cloud layer was thin since the brightness temperature was a combination of cloud and surface temperatures. While it is impossible to state that the region with rosettes was the result of small ice that had advected southwest from the anvil penetrated earlier, the environmental conditions are favorable for supporting this possibility. In addition, inspection of earlier satellite images suggests that there was no significant convection in the area that could have spawned seed particles that grew into rosettes. It is possible, however, that gravity waves generated as a result of convection in the area stimulated heterogeneous or homogeneous formation of in situ cirrus since peak RHice in the region approached the homogeneous nucleation threshold (Jensen et al., 2016, 2013)

Figure 26 shows habit separated size distributions from an automatic particle shape classification of CPI images sampled during the WB-57 descent and climb through the fresh anvil (02:20:00 to 02:44:00 UTC), and penetration of the cirrus formed in situ (03:42:00 03:48:00 UTC) on 12 October 2016. The data in Fig. 26 confirm that no rosettes are observed in the fresh anvil. In contrast, in the cirrus formed in situ, $80 \%$ of the total projected area is composed of rosettes (61\%) and budding rosettes (19\%), and $84 \%$ of the total mass is composed of rosettes (67\%) and budding rosettes (17\%). Um et al. (2015) analyzed large datasets of CPI images from SPARTICUS, TWP-ICE and ISDAC (a study of mainly mixed-phase clouds in the Arctic). They also found a separation of particle types between anvil and in situ cirrus, where automatic habit classification showed that pure bullet rosettes were two to five times less frequent in aged anvil cirrus compared with in situ cirrus. They also found a maximum number concentration of pure bullet rosettes at $-45{ }^{\circ} \mathrm{C}$. These results affirm the pattern seen in previous figures that show comparisons of CPI images in anvils and in situ cirrus.

The CPI accurately images the projected area of ice particles, which is the fundamental property in determining cloud albedo. The data in Fig. 26 show that rosettes in the size range from about 200 to $500 \mu \mathrm{m}$ constitute the majority of the projected area, and 
thus dominate the radiative properties in cirrus formed in situ. Figure 26 provides quantitative evidence that in situ cirrus contains distinctly different particle shapes than fresh anvil cirrus. CPI measurements can be used to confidently distinguish in situ cirrus from fresh anvil cirrus, and conversely, the difference in particle shapes can be parametrized and used in remote retrievals and radiative transfer codes.

\subsection{NASA CR-AVE and TC4 Projects in Subvisible Cirrus}

The CR-AVE project was staged from Costa Rica in January - February 2006 and produced the first comprehensive dataset of CPI images of ice particles in subvisible cirrus (SVC) near the tropopause (Jensen et al., 2008; Lawson et al., 2008). Although the net radiative forcing of optically thin SVC is relatively small, the clouds are generally thought to cover a large horizontal extent and some calculations suggest that they are radiatively significant. For example, McFarquhar et al. (2000) used a nadir-pointing lidar on a Learjet and found that a spatially thin layer of cirrus, with base above $15 \mathrm{~km}$ and a mean thickness of $0.47 \mathrm{~km}$, was observed in the central Pacific tropics $29 \%$ of the time. Based on vertical profiles and a radiative transfer model, they calculate observed heating rates of up to $1.0 \mathrm{~K}$ day $^{-1}$, principally in the infrared, and cloud net radiative forcing of up to $1.2 \mathrm{Wm}^{-2}$.

The WB-57 flew six research flights and sampled SVC in the temperature range from -75 to $-90{ }^{\circ} \mathrm{C}$. CPI images of ice particles in SVC appear to differ in size and shape from most particles in anvil and in situ cirrus. Figure 27 shows average PSDs from the 2D-S and CAS, CPI habits and images from the CR-AVE flights. The particles are all smaller than $200 \mu \mathrm{m}$ and the shapes are mostly quasi-spheroidal with irregulars, plates, columns and rare trigonal crystals. The majority of the projected area and mass is found in particles with sizes between 10 and $50 \mu \mathrm{m}$, which is a significantly smaller size range than found in anvil cirrus. The WB-57 flew one mission in SVC during TC4. Davis et al., (2010) analyzed WB-57 CPI images and remote measurements from the NASA ER-2. They found that the particle shapes and size distribution of ice particles in SVC were very similar to those shown in Fig. 27, reported by Lawson et al. (2008) from the 2006 CR-AVE campaign.

\section{Quantitative Results}

High-resolution CPI imagery facilitates quantitative assessment of relationships between particle length, area and mass as a function of cloud type and particle shape. Since quantitative analysis of data collected in 22 different field campaigns is beyond the scope of this paper, we have performed an analysis of representative cases that are comprised of different cloud types. We feel that the selected cases are representative of the entire dataset, but a more comprehensive analysis would produce more robust statistics.

Table 1 shows a breakdown of percentages of particle shapes as a function of cloud type (in situ cirrus, Tropical Maritime Anvil, Continental Anvil and Electrified Mid-Latitude Continental Anvil) for three moments of particle size. The percentages in Table $\mathbf{1}$ are also shown for all particles and classical particle habits, i.e., without the contribution from irregulars (images that cannot be classified) and spheroids that may be too small to accurately classify. Results from Table 1 substantiate visual inspection of the habits of CPI images associated with the various cloud types shown in figures in this paper, with the caveat that it is difficult to visually ascertain the high percentages of irregulars and small spheroids from the figures. Approximately two-thirds of the number concentration of particles in all cloud types is composed of irregular-shaped particles. This is not a new result. As pointed out in 
Section 4.1, Korolev et al. (1999) analyzed CPI images in the temperature range from - 45 to $-40{ }^{\circ} \mathrm{C}$ and found that over $90 \%$ of the images were irregular in shape (i.e., not pristine as defined in their paper). The shape categories defined in this paper are somewhat less rigorous since we do not require the particles to be "pristine", but the trend is similar in that the large majority of the images cannot be defined by classical habits.

It must be noted that unlike optical array probes that operate continuously (unless they are in overload), the CPI takes triggered snapshots of images, so particle arrival times cannot be used to eliminate shattered ice particles (Lawson 2011). Thus, the high number concentrations of small particles in Table 1 may include artifacts. Also, the sample volume of the CPI is greatly reduced for particles $>\sim 1 \mathrm{~mm}$. Larger particles, mostly aggregates, exist in both anvils and deep cirrus near the bottoms of these clouds (see Figures 5, 6, 14, 17).

The percentages of area and mass concentrations in Table 1 reveal a different picture than the number concentrations, even when the small spheroids are included. Particle area is a primary factor in radiative studies, and particle mass is a property that is germane and must be conserved in numerical simulations. Irregulars still comprise from 50 to $80 \%$ of the total particle area and mass in anvils, but in contrast, budding rosettes and rosettes account for over two-thirds of the area and mass in cirrus formed in situ. On the other hand, rosettes account for less than $1 \%$ of particle area and mass in all anvils. Also notable in Table 1 is the relatively high percentage of chain aggregates in highly electrified Mid-latitude Continental Anvils. The area and mass percentages of columns and plates are $\leq 0.1 \%$ in Continental Anvils, whereas they comprise nearly one-quarter of the area and mass in the Tropical Maritime Anvil (Table 1). This is a distinctive difference that is also revealed by inspection of the CPI images (e.g., Figs. 10, 11c,d, 12, 24)

Figure 28 shows plots of particle maximum dimension $(d)$ versus mass $(m)$ for the various particle habits and cloud types, where the lines are color-coded to indicate the various particle habits. Also shown on each plot is a regression analysis relating $d$ to $m$. Table 2 shows a summary of the regression equations for both $d$ to $m$ and $d$ to $A$, (particle projected area) for the individual particle habits. Table 3 shows the data sources used in Tables 1 and 2. Mass is determined from the $A$ to $m$ relationship found in Baker and Lawson (2006b), except for $d \leq 50 \mu \mathrm{m}$, where $m$ is determined from Eqn. B8 in Erfani and Mitchell (2016) hereafter EM16. Equation B8 in EM16 constrains mass from exceeding the mass of a solid sphere, whereas the Baker and Lawson (2006) formulation does not constrain mass to the theoretical limit, which is needed for particles $d \leq 50 \mu \mathrm{m}$. Figure 28 also shows the $d$ to $m$ line that represents a solid spherical ice particle with a density of $0.917 \mathrm{~g} \mathrm{~cm}^{-3}$. It is customary to assume the theoretical maximum mass to indicate where the regression lines cross the line representing the mass of a spherical ice particle, which is done in Fig. 28.

It is possible to apply various best-fit regression techniques to the data, and the various techniques can produce strikingly different results. The various techniques that we explored, examples of the results that are produced, and how we elected to produce fits shown in this section of the paper, are discussed in Appendix B. We also present a brief discussion in Appendix B of how the analysis techniques themselves can skew the interpretation of the data.

Figure 28 shows there is a consistent trend for all of the habits and cloud types, but there are also subtle differences that can influence parameterizations. For example, electrified anvils contain significantly less in chained aggregates than any other particle habit, and 
electrified anvils seem to be prevalent in mid-latitude storms (Stith et al. 2014). Columns with maximum dimensions from about $100 \mu \mathrm{m}$ to $1 \mathrm{~mm}$ in cirrus formed in situ contain about half the mass of columns in Marine and Mid-latitude Continental Anvils that are not as highly electrified (Table 1 and Fig. 28). As shown in Fig. 29, this is due to the higher aspect ratio of columns formed in situ compared with Tropical Marine and Continental Anvils (also see Krämer et al., 2016). This implies that columns in cirrus formed in situ grow at a higher ice supersaturation than columns in Tropical Marine anvils (see Bailey and Hallett 2009 Fig. 2).

The data in Fig. 28 are plotted on log-log axes, which tends to compress the scatter in the plots. That said, the scatter in the plots is not extreme, and even though distinct trends can be seen for some of the particle shapes, the line for all particles (black dashed line) for each cloud type can be a good representation. This is important for remote recoveries and numerical simulations, where classification of particle shapes may be intractable. Also, note that the large occurrence of irregulars in all of the cloud types makes it challenging to use a database based on ray-tracing of classical particle shapes.

In Fig. 30a,b we compare our analysis of CPI images with previous studies found in the literature. EM16 report $d$ to $m$ measurements from SPARTICUS in situ cirrus (Fig. 30a) and Mid-latitude Continental Anvil clouds (Fig. 30b) using 2D-S and CPI data. EM16 show that when plots of $d$ to $m$ in log-log space consider only particles $>\sim 200 \mu \mathrm{m}, 1^{\text {st }}$ order fits to the data intersect the mass value of a solid ice sphere, which is a physical limit. To improve the fit to their data, in their Fig. 3 EM16 fit a $2^{\text {nd }}$ order polynomial, which curves to follow the actual data points and is not limited by the spherical ice mass limit.

In Fig. 30a,b we show $1^{\text {st }}$ order polynomial fits for in situ cirrus and anvils taken from the literature (Brown and Francis 1995; Heymsfield et al., 2010; Cotton et al., 2013), a $1^{\text {st }}$ order polynomial fit to data from EM16, and data from this study. The $1^{\text {st }}$ order fit to the EM16 data is not shown in their paper because they highlight the improved fit provided by a $2^{\text {nd }}$ order polynomial. The coefficients for the $1^{\text {st }}$ order fits were kindly provided to us by Dr. Erfani. Only $1^{\text {st }}$ order polynomial fits to $d$-to- $m$ plots of cirrus data are shown in the literature until the work of EM16. We decided to show only $1^{\text {st }}$ order fits in Fig. 30a,b so that plots from the older literature can be compared with the newer results from EM16 and the present studies. As pointed out above, EM16 show that when ice particles $<\sim 200 \mu \mathrm{m}$ are included, a higher-order polynomial improves the fit to the data. The merits of $1^{\text {st }}$ and $2^{\text {nd }}$ order polynomial fits to cirrus data are further discussed in Appendix B.

In Figs. 30a,b, the Brown and Francis (1995) $d$ to $m$ relationship, which is often cited in the literature, is based on micro-photographs of falling ice crystals and melted drops from data reported by Locatelli and Hobbs (1974), and comparisons of 2DC measurements with a total water content evaporator flown in cirrus clouds. The Heymsfield et al., (2010) study is based on six airborne field campaigns, five of which were in tropical and extra-tropical environments, and uses 2DC, CIP and PIP probes in all but one study where 2D-S data are incorporated. The Heymsfield et al., (2010) gives one relationship for both convective and in situ cirrus, however, the study focuses mainly on convectively generated ice clouds with IWC $>1 \mathrm{~g} \mathrm{~m}^{-3}$ over the temperature range from 0 to $-60{ }^{\circ} \mathrm{C}$; IWC was dominated by particles from $100 \mu \mathrm{m}$ to $2 \mathrm{~mm}$. Cotton et al., (2013) investigated six in situ cirrus clouds over northern Scotland and focused on the contribution of small ice particles (mean size of 40 to $500 \mu \mathrm{m})$ with low IWC $\left(0.001-0.05 \mathrm{~g} \mathrm{~m}^{-3}\right)$ using a combination of several cloud probes, including a Nevzorov IWC probe (Korolev et al. 1998), CDP, CIP, PIP, 2DC, and SID-2 (Cotton et al., 2010). 
All of the power-law fits shown in Figs. 30a,b are truncated when they intersect the theoretical maximum value for a spherical ice particle. The Brown and Francis (1995), Heymsfield et al., (2010) and Cotton et al., (2013) fits shown in Fig. 30a are not reproduced in Fig. 30b for the sake of clarity, but can be inferred by comparison from the solid magenta line in each panel that represents the mass of spherical ice particles. Figure 30a shows that there has been a continuous migration of smaller masses as a function of particle size as studies have proceeded in time. There are several possible explanations, none of which can be validated without extensive re-analysis of the older datasets. The studies previous to EM16 and the present study incorporated data from warmer cloud temperatures where riming may have taken place. The measurement techniques were different in the earlier studies compared with the latter analyses. The incorporation of actual data at the smaller particle sizes may have shifted the weighting of the best-fit lines. This is exemplified by the comparison shown in Appendix B, where, due to its ability to bend, the second-order polynomial introduced by EM16 is a better fit to the data points near the extremities of the scatterplot. Finally, the differences could be explained solely on different characteristics of the particles in each dataset, or by the type of regression analysis that is used to fit the data points. Overall, the best agreement is between the power-law fits to the data presented by EM16 and the present study.

Table 4 contains data extracted from Figs. 13, 15 and 26 that shows up to 19 size intervals with the numerical percentage of each particle shape given for each size interval. The results showing the percentages of various habits for in situ cirrus and different anvil cirrus in Tables 1 and 4, and the power law relationships shown on the plots in Figs. 28 and 30, can be used in parameterizations of remote retrievals and numerical models (Mitchell et al., 2008). For example, data in Table 4 is useful for calculating cloud optical properties, and data in Table 1 can be combined with scattering phase functions from Yang et al. (2015) and applied to remote retrievals from the CALIPSO lidar to compute asymmetry parameter and other radiative functions. Global climate models such as CAM5 apply different microphysical parameterizations to different geographic locations (NCAR 2012). Power laws that relate $d$ to $A$ and $d$ to $m$ (Figs. 28 and 30) can be applied to cirrus formed in situ and convective anvils formed in different geographic locations.

\section{Summary and Discussion}

Based on CPI images, when sorted by number concentration the majority of ice particles in all cirrus clouds, whether generated in situ or from convective outflow, are either too small to categorize (i.e., $<\sim 30 \mu \mathrm{m}$ ) or are irregular in shape (Woods et al., 2018).

High-density graupel particles, which are typically observed in strong updrafts of both maritime and continental convection, sediment out of anvils within about $10 \mathrm{~km}$ of the active convection (Mace et al., 2006; Heymsfield and Wright 2014; Jensen et al., 2018; Woods et al., 2018). The particle shapes shown in the CPI images in this paper (except for the graupel images shown in Fig. 2), are those found in anvils at distances greater than about $10 \mathrm{~km}$.

In situ cirrus and aged anvil cirrus contain small $(<\sim 30 \mu \mathrm{m})$ particles in concentrations of tens to hundreds per liter throughout the cloud, except perhaps near the base of deep ice layers. The small particles are presumably due to new nucleation or remain from competitive growth of larger particles (Jensen et al., 2009; Woods et 
al., 2018). $R H_{\text {ice }}$ in anvils and cirrus, which are not rapidly dissipating or growing, is typically close to $100 \%$ (Krämer et al., 2009; Diao et al., 2015; Jensen et al., 2017).

There is a distinct difference in particle shapes between fresh anvil cirrus and in situ cirrus. Particles that are rosette shaped (i.e., polycrystals when $-38<\mathrm{T}<-30{ }^{\circ} \mathrm{C}$ and bullet rosettes for $-60<\mathrm{T}<-38^{\circ} \mathrm{C}$ ), which are large enough to be recognizable in CPI images, typically comprise more than half the particle mass in cirrus formed in situ (Woods et al., 2018). Rosette shaped particles are rarely found in anvil cirrus unless the observation is in new particle growth far downwind of the convection (Lawson et al., 2003; 2006a; Connolly et al., 2005; Gallagher et al., 2005, 2012). .

The difference in particle shapes in fresh anvil and in situ cirrus is understandable from well-established physics of particle formation and growth. In situ cirrus particles that are formed on frozen drops at cold temperatures $\left(<\sim-38{ }^{\circ} \mathrm{C}\right)$ often develop facets on the drop surface that are favored locations for continued growth (Baker and Lawson 2006). The facets spawn columnar arms if $R H_{\text {ice }}$ is $>\sim 120 \%$, forming rosettes (Bailey and Hallett 2009), which have a distinctive appearance. The ice in anvils is generally formed in updrafts at warmer temperatures where rosettes and polycrystals are not formed (Lawson et al., 2015, 2017). In addition, if supercooled drops are transported into the anvil, the anvil is laden with ice so that $R H_{\text {ice }}$ is < $120 \%$ (Diao et al., 2015; Jensen et al., 2017) and rosettes and polycrystals are not formed.

There is typically a noticeable difference in the shapes of ice particles larger than about $100 \mu \mathrm{m}$ observed in Mid-latitude and Tropical Maritime anvils. Mid-latitude anvils generally contain irregularly-shaped ice particles that are rimed, and rimed aggregates. Tropical Maritime anvils contain a higher percentage of faceted, hexagonally shaped particles, and fewer and smaller aggregates (Lawson et al., 2003; Connolly et al., 2005).

The difference in particle shapes in Mid-Latitude Continental and Tropical Maritime anvils is likely due to warmer cloud base temperatures and broader, less concentrated drop spectra in the updrafts of Tropical Maritime convection, which results in more rapid glaciation and fewer small drops available for riming (Lawson et al., 2015, 2017). Tropical Maritime anvils contain more faceted ice, with aggregates of faceted ice, but fewer aggregates overall and fewer rimed aggregates. Higher concentrations of small drops (up to hundreds per $\mathrm{cm}^{3}$ ) are carried to colder levels in Mid-Latitude Continental updrafts and support the production of rimed aggregates and homogeneous freezing of the small drops (Stith et al., 2014; Um and McFarquhar 2009; Um et al., 2018).

Mid-latitude anvils that have high electrical charge often contain chains of frozen drops and small ice particles. Chains of frozen drops and small ice particles appear much less frequently in Tropical Maritime anvils, except perhaps in highly-electrified Tropical Maritime anvils (Connolly et al., 2005; Um and McFarquhar 2009)

Tropical convective anvils that originate over land, or are somewhat continental in nature, may exhibit some of the characteristics of Mid-Latitude Continental anvils, 
such as higher than average concentrations of small ice and aggregates (Gallagher et al., 2005; 2012; Um and McFarquhar 2009) .

The total concentration of ice particles drops off with distance from active convection in both Tropical Maritime (Woods et al., 2018) and Mid-latitude anvils (Lawson et al., 2010).

Relatively high concentration ( 1 to 10 per $\mathrm{cm}^{-3}$ ) of small, quasi-spherical ice can be observed downwind of in situ cirrus formed orographically, which may or may not form rosette shaped particles (Fig. 18). Small particles that are advected downwind of orographic clouds may grow into rosette shapes if they experience a region with high $R H_{\text {ice. }}$ (e.g., $R H_{\text {ice }}>\sim 120 \%$ ).

Small particles that have frozen homogeneously in convective updrafts may also be advected downwind of anvils and grow into rosette shaped particles in regions with $R H_{\text {ice }}>\sim 120 \%$ (Fig. 25).

Cirrus in the lower TTL (14 to $17 \mathrm{~km}$ ) can be generated from strong convection or formed in situ. Ice particle concentrations are typically tens to hundreds per liter, except where homogeneous nucleation is occurring, where concentrations of very small ice can be one to ten per $\mathrm{cm}^{-3}$. Cirrus observed in the upper TTL $(>\sim 17 \mathrm{~km})$ is generally optically thin, often garnering the name subvisible cirrus (SVC). SVC is composed of quasi-spheroids and plates $<\sim 100 \mu \mathrm{m}$, in concentrations of tens to hundreds per liter (Lawson et al., 2008; Davis et al., 2010; Woods et al., 2018). Thin cloud layers with homogeneous nucleation have been observed to produce small ice in concentrations of 1 to $10 \mathrm{~cm}^{-3}$ (Jensen et al., 2012). Rare instances of trigonal crystals have been observed in SVC (Heymsfield 1986; Lawson et al., 2008).

Quantitative analysis of CPI images are used to generate the percentages of particle habits in various cloud types (in situ cirrus, Tropical Maritime Anvil, Continental Anvil and Electrified Mid-Latitude Continental Anvil), as shown in Table 1. Also, plots of these data with regression analyses to determine best-fit power laws show relationships between $d$ to $m$ and $d$ to $A$. These relationships can be incorporated into parameterizations used in remote retrievals and numerical models.

The data presented in this paper can be used to specify particle size and shape in various types of cirrus clouds, which can be classified using geographic location, altitude and/or temperature, and proximity to active convection. The types of particles in cirrus formed in situ can be generalized (e.g., small quasi spheroids, irregulars and rosettes) or when synoptic meteorology is available, further quantified using synoptic features such as those suggested by Muhlbauer et al. (2014). Anvil cirrus that is generated over the open ocean in the Tropics is considered Tropical Maritime and has particle shapes that are distinctive from Mid-Latitude Continental anvil cirrus. Anvils that are formed in tropical latitudes that are formed over continents and islands are more likely to have a mixture of shapes reflective of Tropical Maritime and Mid-Latitude Continental anvils. Highly electrified convection appears to form chains of frozen drops and small ice crystals in Mid-Latitude Continental anvils, and also in Tropical convection that has not formed over the open ocean. Examples from the SPARTICUS and POSIDON datasets suggest that rosettes can grow downwind from orographic and anvil cirrus, respectively, if small ice is advected downwind into a region with $R H_{\text {ice }}>\sim 120 \%$. 
The availability of newer instruments, such as the CPI, which have now been flown in recent field campaigns, provides information that was not available in earlier reviews of cirrus clouds (e.g. Dowling and Radke, 1990). The information on particle shape provided here can be joined with electromagnetic and physical optics databases, such as described by Yang et al. (2013; 2015; 2018) and Baran et al. (2014), to improve radiative transfer packages used in satellite retrievals and cloud resolving simulations. Numerical models, ranging from some cloud resolving models to global and climate models, do not explicitly include ice particle shapes. Instead, they rely on parameterizations that are readily coded into numerical simulations, such as relationships based on state variables, mean effective ice particle size and ice water content or ice water path (Muhlbauer et al., 2014; Yang et al., 2015). However, as seen in this paper, these variables are typically less prognostic than cloud type, and as pointed out in Baran et al. (2012), these current parameterizations can lead to inconsistencies between radiation and cirrus microphysics schemes, where the two schemes are generally unrelated. A further step is to develop parameterizations of particle size and shape that include geographic location and the type of cloud formation.

\section{Acknowledgements}

The authors thank the extensive support teams that contributed to data collection across all 22 field projects, and the primary sponsor(s) for each field project, as listed in Appendix A. Data from the NASA ATTREX, CR-AVE, CRYSTAL-FACE, MIDCIX, POSIDON, and TC4 projects are available through the NASA ESPO archive: https://espoarchive.nasa.gov/archive/browse. Datasets from the NASA DC3 and SEAC4RS field projects are available from the NASA LaRC archive: https://wwwair.larc.nasa.gov/missions.htm. The DOE ISDAC, SPARTICUS, and TWP-ICE project datasets are available from the DOE ARM archive: https://www.arm.gov/data. The NSF funded CCOPE, FIRE.ACE, FIRE-II, ICE-T datasets are available through the NCAR Earth Observing Laboratory archive: https://www.eol.ucar.edu/all-field-projects-and-deployments. EMERALD $1 \& 2$ and ACTIVE data sets can be obtained from the UK CEDA Data Archive - The Natural Environment Research Council's Research Data Repository for Atmospheric Science and Earth Observation - http://archive.ceda.ac.uk. This review work was funded through NASA Grants NNA15BA18P and NNX14AQ55G and DOE Grant DE-SC0007035. The National Center for Atmospheric Research is sponsored by the National Science Foundation. 


\section{Appendix A}

\section{$\underline{\text { Projects }}$}

\section{Explanation of Acronyms used in this paper.}

\begin{tabular}{|c|c|c|}
\hline ACRONYM & ACRONYM EXPANDED & $\begin{array}{c}\text { PRIMARY } \\
\text { SPONSOR(S) }\end{array}$ \\
\hline ACTIVE & $\begin{array}{l}\text { Aerosol and Chemical Transport in Tropical } \\
\text { Convection }\end{array}$ & UK NERC \\
\hline ATTREX & Airborne Tropical Tropopause Experiment & NASA \\
\hline CCOPE & $\begin{array}{l}\text { Cooperative Convective Precipitation } \\
\text { Experiment }\end{array}$ & NSF/BOR \\
\hline CR-AVE & Costa Rica AURA Validation Experiment & NASA \\
\hline CRYSTAL-FACE & $\begin{array}{l}\text { Cirrus Regional Study of Tropical Anvils and } \\
\text { Cirrus Layers-Florida Area Cumulus Experiment }\end{array}$ & NASA \\
\hline DC3 & Deep Convective Clouds and Chemistry Project & NASA/NSF \\
\hline EOS & Earth Observing System & DOE \\
\hline EMERALD-I \& II & $\begin{array}{l}\text { Egrett Microphysics Experiment with Radiation, } \\
\text { Lidar, and Dynamics }\end{array}$ & UK NERC \\
\hline FIRE.ACE & $\begin{array}{l}\text { First ISCCP Regional Experiment Arctic Cloud } \\
\text { Experiment }\end{array}$ & NASA/DOE \\
\hline FIRE-II & First ISCCP Regional Experiment & NASA \\
\hline ICE-T & Ice in Clouds Experiment-Tropical & NSF \\
\hline ISDAC & Indirect and Semi-Direct Aerosol Campaign & DOE, NASA \\
\hline MIDCIX & Midlatitude Cirrus Cloud Experiment & $\mathrm{DOE}$ \\
\hline POSIDON & $\begin{array}{l}\text { Pacific Oxidants, Sulfur, Ice, Dehydration, and } \\
\text { Convection Experiment }\end{array}$ & NASA \\
\hline SEAC4RS & $\begin{array}{l}\text { Studies of Emissions and Atmospheric } \\
\text { Composition, Clouds and Climate Coupling by } \\
\text { Regional Surveys }\end{array}$ & NASA \\
\hline SCCP & Sierra Cooperative Pilot Project & BOR \\
\hline SPARTICUS & Small Particles in Cirrus Project & $\mathrm{DOE}$ \\
\hline TC4 & $\begin{array}{l}\text { Tropical Composition, Cloud and Climate } \\
\text { Coupling }\end{array}$ & NASA \\
\hline TRMM KWAJEX & $\begin{array}{l}\text { Tropical Rain Measurement Mission Kwajalein } \\
\text { Experiment }\end{array}$ & NASA \\
\hline TRMM TEFLUN-A & $\begin{array}{l}\text { TRMM Texas and Florida Under Flights - A } \\
\text { (Texas) }\end{array}$ & NASA \\
\hline $\begin{array}{l}\text { TRMM } \\
\text { TEFLUN-B }\end{array}$ & $\begin{array}{l}\text { TRMM Texas and Florida Under Flights - B } \\
\text { (Florida) }\end{array}$ & NASA \\
\hline TWP-ICE & $\begin{array}{l}\text { Tropical Warm Pool - International Cloud } \\
\text { Experiment }\end{array}$ & DOE \\
\hline
\end{tabular}




\section{$\underline{\text { Agencies and Institutions: }}$}

\begin{tabular}{|l|l|}
\hline ACRONYM & \multicolumn{1}{c|}{ ACRONYM EXPANDED } \\
\hline ARA & Airborne Research Australia \\
\hline ARM & DOE Atmospheric Radiation Program \\
\hline BOR & U.S. Bureau of Reclamation \\
\hline DOE & U.S Department of Energy \\
\hline EC & Environment Canada \\
\hline ECMWF & European Centre for Medium-Range Weather Forecasts \\
\hline NASA & U.S. National Aeronautics and Space Administration \\
\hline NCAR & U.S. National Center for Atmospheric Research \\
\hline NOAA & U.S. National Oceanic and Atmospheric Administration \\
\hline NRC & National Research Council of Canada \\
\hline NSF & U.S. National Science Foundation \\
\hline SGP & DOE ARM Southern Great Plains (site) \\
\hline SPEC & Stratton Park Engineering Company, Inc. \\
\hline UK NERC & U.K. Natural Environment Research Council \\
\hline UND & University of North Dakota \\
\hline USAF & U.S. Air Force \\
\hline
\end{tabular}

\section{Platforms and Operators:}

\begin{tabular}{|l|l|}
\hline \multicolumn{1}{|c|}{ Platform } & \multicolumn{1}{c|}{ Operator } \\
\hline C-130 & NCAR \\
\hline Citation & UND \\
\hline Convair 580 & NRC \\
\hline DC-8 & NASA \\
\hline Egrett & ARA \\
\hline Global Hawk & NASA \\
\hline Gulfstream V & NCAR \\
\hline Learjet & Aeromet Inc. \\
\hline Learjet & SPEC Inc. \\
\hline Proteus & Scaled Composites \\
\hline Sabreliner & NCAR \\
\hline WB-57F & NASA \\
\hline
\end{tabular}




\section{Instrumentation and Nonemclature:}

\begin{tabular}{|c|c|}
\hline ACRONYM & ACRONYM EXPANDED \\
\hline $2 \mathrm{DC}$ & Two-Dimensional Cloud Probe \\
\hline $2 \mathrm{D}-\mathrm{S}$ & Two-Dimensional Stereo Cloud Probe \\
\hline CALIPSO & Cloud-Aerosol Lidar and Infrared Pathfinder Satellite Obervation \\
\hline CAM5 & Community Atmosphere Model V.5 \\
\hline CDP & Cloud Droplet Probe \\
\hline CIP-100 & Cloud Imaging Probe \\
\hline IWC & Ice water content \\
\hline PIP & Precipitation Imaging Probe \\
\hline $\mathrm{RH}_{\text {ice }}$ & Relative Humidity with respect to ice \\
\hline SID-2 & Small Ice Detector - Version 2 \\
\hline SVC & Subvisible Cirrus \\
\hline & Temperature $\left({ }^{\circ} \mathrm{C}\right)$ \\
\hline TTL & Tropical Tropopause Layer \\
\hline
\end{tabular}

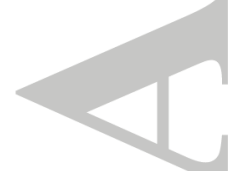

\section{Appendix B}

\section{$1^{\text {st }}$ and $2^{\text {nd }}$ Order Regression Algorithms}

A regression to determine the best fit to a scatterplot of data points can take several forms. A power-law fit of the form $m=\alpha d^{\beta}$ is a straight line on a log-log plot. The power law can also be expressed as a $1^{\text {st }}$ order polynomial of the form $\ln (m)=a_{0}+a_{1} \ln (d)$, and is customarily fit to the logs of the data. Similarly, the $2^{\text {nd }}$ order polynomial introduced by EM16 takes the form $\ln (m)=a_{0}+a_{1} \ln (d)+a_{2}(\ln d)^{2}$ and can be fit to the data. The coefficients for the $1^{\text {st }}$ and $2^{\text {nd }}$ order polynomials are determined by regression analysis to the data points. However, there are several methodologies for performing a regression analysis and they can produce strikingly different best-fit regression lines. Here we show some of the differences produced by various regression techniques, including the technique used in the main body of this paper.

The least-squares regression analyses shown in this paper are generated using the Matlab Curve Fitting Toolbox ${ }^{\mathrm{TM}}$ and Matlab ${ }^{\mathrm{TM}}$ code. Analytical descriptions of the techniques are found on the Matlab ${ }^{\mathrm{TM}}$ website. In this Appendix we provide examples of lines (or curves) that result when five different regression algorithms are applied to various datasets. The five techniques are 1) linear least squares, 2) least absolute residuals, 3) bisquare weights, 4) $1^{\text {st }}$ order polynomial, and 5) $2^{\text {nd }}$ order polynomial (EM16). The first four of the five algorithms result in a straight line on a log-log plot. The $2^{\text {nd }}$ order polynomial technique can result in a curved line on a log-log plot.

Figure B1 shows the results of the five least-squares regression techniques applied to a dataset of ice particle diameter $(d)$ versus mass $(m)$, where the dataset has been modified to demonstrate how the best-fit solutions differ when applied to: Fig. B1a: A dataset of CPI measurements collected in SPARTICUS in situ cirrus where data points range from $10 \mu \mathrm{m}$ to $1 \mathrm{~mm}$, with only a few points at the large end of the size distribution; Fig. B1b: the same dataset as in Fig. B1a but with CPI data points < $70 \mu \mathrm{m}$ excluded; Fig. B1c: The same dataset as in Fig. B1b, but with 2D-S measurements from about 1 to $3 \mathrm{~mm}$ included; Fig. B1d: The same dataset as in Fig. B1a, but with 2D-S measurements from about 1 to $3 \mathrm{~mm}$ included. The examples are chosen to represent situations that have occurred when optical 
cloud probes were not capable of detecting small ice particles (e.g., $<70 \mu \mathrm{m}$ ), and when the cloud probe sample volume limits its ability to provide good sampling statistics of the largest particles.

Most all the fits in Fig. B1a do a reasonably good job of fitting the dataset. The $2^{\text {nd }}$ order polynomial (EM16) appears to provide the best fit to the actual curve in the data points, but the linear fits also provide good fits. However, this is not the case in Fig. B1b where data points $<70 \mu \mathrm{m}$ have been excluded. In this case the $2^{\text {nd }}$ order polynomial fit curves upward at the small and large ends of the dataset, which is an artifact of the fitting routine and does not fit the data well. In Fig. B1c, a large number of 2D-S data points ranging from about 1 to 3 $\mathrm{mm}$ have been added to the CPI measurements shown in Fig. B1b. The 2D-S measurements were collected simultaneously with the CPI data, and both CPI and 2D-S measurements used the same $A$ to $m$ algorithm from Baker and Lawson (2006b) to compute $m$ from each particle image, with the caveat that Eqn. B8 from EM16 was used for particles $<50 \mu \mathrm{m}$.

Fig. B1c is intended to be somewhat representative of the datasets described in Cotton et al., (2013) and Heymsfield et al., (2010). The least squares technique used by Cotton et al., (2013) and Heymsfield et al., (2010) is not reported, so it is unknown how they fit to their data. The message from Fig. B1c is that without measurements of smaller particles, the standard linear least squares fit to the data (dashed cyan line) exceeds the spherical limit (solid magenta line) by a significant amount for particles $<\sim 100 \mu \mathrm{m}$. This is because the linear least squares fit applies abnormally high weights to the largest particles. On the other hand, the other four techniques all provide much better fits to the data points, with the $1^{\text {st }}$ order polynomial and bisquares techniques providing the best fits. Figure B1d shows the results when the entire CPI $+2 \mathrm{D}-\mathrm{S}$ dataset from about $10 \mu \mathrm{m}$ to $3 \mathrm{~mm}$ is fit with the five routines. Even with the small end of the dataset included the linear least squares fit is still biased toward the largest data points and the fit is poor. The bisquares, $1^{\text {st }}$ and $2^{\text {nd }}$ order polynomials provide the best fits.

As demonstrated in EM16, the $2^{\text {nd }}$ order polynomial actually provides the best fit to the data in Fig. B1d, because it follows the gentle convex curve of the data points. However, the ability of the $2^{\text {nd }}$ order polynomial to bend with the data can be problematical if the fit is extended past the range of the dataset, and sometimes even at the extremities of the dataset. This is seen in Fig. B1b where the ends of the $2^{\text {nd }}$ order polynomial bend upward at the extremities of the dataset, and especially in the inset in Fig. B1d. The inset shows the $2^{\text {nd }}$ order polynomial fit for the Marine Anvil columns dataset (see Fig. 28). While the fit is good through the extent of the data points, it bends radically downward for particles that are about $100 \mu \mathrm{m}$ larger than the largest data point. Thus, if only the best-fit $2^{\text {nd }}$ order polynomial equation is used, particles larger than about $200 \mu \mathrm{m}$ will be drastically under sized.

After examining several possible fits to the data, we selected the $1^{\text {st }}$ order polynomial algorithm as the best choice for fitting the data presented in Section 5 (Quantitative Results) in this paper.

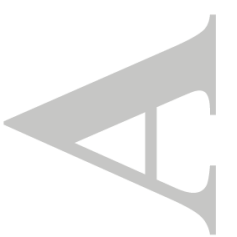




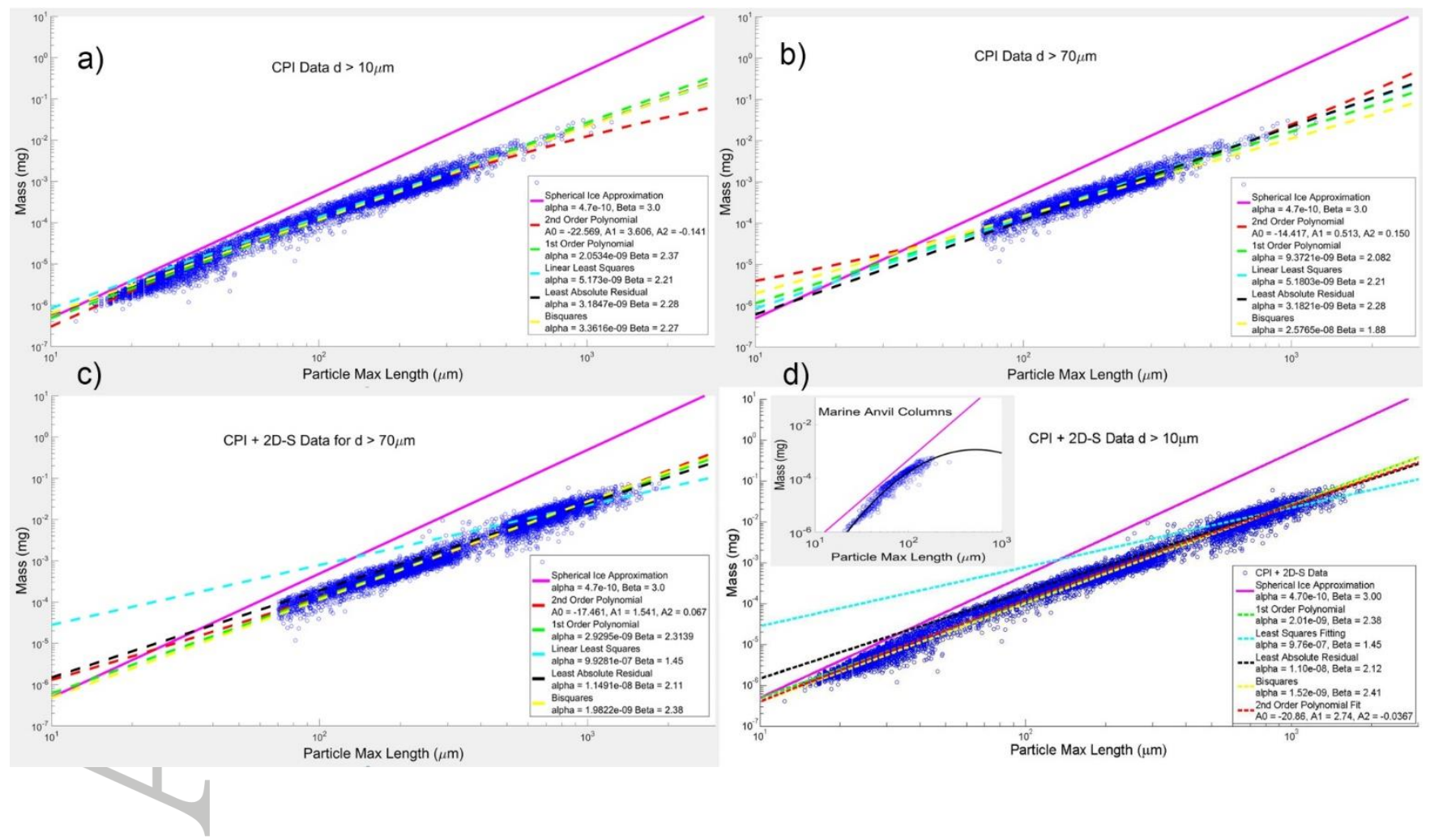

Figure B1. Examples of five least squares best-fit regression techniques applied to an in situ cirrus dataset of $m$ versus $d$ data points using the Baker and Lawson (2006) $A$ to $m$ calculation and EM16 Eqn. B8 for particles $<50 \mu \mathrm{m}$. Panels (a) - (d) are based on CPI images $(10 \mu \mathrm{m}$ to $\sim 1 \mathrm{~mm}$ ) with 2D-S images (500 $\mu \mathrm{m}$ to $3 \mathrm{~mm}$ ) added in panels (c) and (d). The units for the best-fit equations are $d(\mu \mathrm{m})$ and $m$ (mg). (EM16) The inset in (d) also shows an example of Marine Anvil columns and how the $2^{\text {nd }}$ order polynomial bends erroneously outside the range of the data points. 


\section{References}

Bailey, M., \& Hallett, J. (2012). Ice Crystal Linear Growth Rates from $-20^{\circ}$ to $-70^{\circ} \mathrm{C}$ : Confirmation from Wave Cloud Studies. Journal of the Atmospheric Sciences, 69(1), 390-402. https://doi.org/10.1175/JAS-D-11-035.1

Bailey, M. P., \& Hallett, J. (2009). A Comprehensive Habit Diagram for Atmospheric Ice Crystals: Confirmation from the Laboratory, AIRS II, and Other Field Studies. Journal of the Atmospheric Sciences, 66(9), 2888-2899. https://doi.org/10.1175/2009JAS2883.1

Baker, B. A., \& Lawson, R. P. (2006a). In Situ Observations of the Microphysical Properties of Wave, Cirrus, and Anvil Clouds. Part I: Wave Clouds. Journal of the Atmospheric Sciences, 63(12), 3160-3185. https://doi.org/10.1175/JAS3802.1

Baker, B. A., \& Lawson, R. P. (2006b). Improvement in determination of ice water content from two-dimensional particle imagery: Part I: Image to mass relationships. Journal of Applied Meteorology, 45(9), 1282-1290. https://doi.org/10.1175/JAM2398.1

Baran, A. J. (2012). From the single-scattering properties of ice crystals to climate prediction: A way forward. Atmospheric Research, 112, 45-69. https://doi.org/10.1016/j.atmosres.2012.04.010

Baran, A. J., Connolly, P. J., \& Lee, C. (2009). Testing an ensemble model of cirrus ice crystals using midlatitude in situ estimates of ice water content, volume extinction coefficient and the total solar optical depth. Journal of Quantitative Spectroscopy and Radiative Transfer, 110(14), 1579-1598. https://doi.org/10.1016/j.jqsrt.2009.02.021

Baran, A. J., Connolly, P. J., Heymsfield, A. J., \& Bansemer, A. (2011). Using in situ estimates of ice water content, volume extinction coefficient, and the total solar optical depth obtained during the tropical ACTIVE campaign to test an ensemble model of cirrus ice crystals. Quarterly Journal of the Royal Meteorological Society, 137(654), 199-218. https://doi.org/10.1002/qj.731

Baran, A. J., Cotton, R., Furtado, K., Havemann, S., Labonnote, L., Marenco, F., Smith, A., \& Thelen, J. (2014), A self-consistent scattering model for cirrus. II: The high and low frequencies. Quarterly Journal of the Royal Meteorological Society, 140, 10391057. doi:10.1002/qj.2193

Baumgardner, D., Jonsson, H., Dawson, W., O’Connor, D., \& Newton, R. (2001). The cloud, aerosol and precipitation spectrometer: a new instrument for cloud investigations. Atmospheric Research, 59-60, 251-264. https://doi.org/10.1016/S01698095(01)00119-3

Brown, P.R.A. \& Francis, P. N., 1995. Improved measurements of the ice water content in cirrus using a total-water probe. Journal of Atmospheric and Oceanic Technology, 
Choi, Y.-S., \& Ho, C.-H. (2006). Radiative effect of cirrus with different optical properties over the tropics in MODIS and CERES observations. Geophysical Research Letters, 33(21). https://doi.org/10.1029/2006GL027403

Cziczo, D. J., Froyd, K. D., Hoose, C., Jensen, E. J., Diao, M., Zondlo, M. A., et al. (2013). Clarifying the Dominant Sources and Mechanisms of Cirrus Cloud Formation. Science, 340(6138), 1320-1324. https://doi.org/10.1126/science.1234145

Connolly, P. J., Saunders, C. P. R., Gallagher, M. W., Bower, K. N., Flynn, M. J., Choularton, T. W., et al. (2005). Aircraft observations of the influence of electric fields on the aggregation of ice crystals. Quarterly Journal of the Royal Meteorological Society, 131(608), 1695-1712. https://doi.org/10.1256/qj.03.217

Cotton R. J., Osborne S., Ulanowski Z., Hirst E., Kaye P. H., \& Greenaway R. S., (2010). The ability of the small ice detector (SID-2) to characterize cloud particle and aerosol morphologies obtains during flights of the FAAM BAe-146 research aircraft. Journal of Atmospheric and Oceanic Technology, 27(2), 290-303. https://doi.org/10.1175/2009JTECHA1282.1

Cotton, R. J., Field, P. R., Ulanowski, Z., Kaye, P. H., Hirst, E., Greenaway, R. S., et al. (2013). The effective density of small ice particles obtained from in situ aircraft observations of mid-latitude cirrus, Quarterly Journal of the Royal Meteorological Society, 139(676), 1923-1934, doi:10.1002/qj.2058

Davis, S., Hlavka, D., Jensen, E., Rosenlof, K., Yang, Q., Schmidt, S., et al. (2010). In situ and lidar observations of tropopause subvisible cirrus clouds during TC4. Journal of Geophysical Research:

Atmospheres, 115(D10). https://doi.org/10.1029/2009JD013093

Diao, M., Jensen, J. B., Pan, L. L., Homeyer, C. R., Honomichl, S., Bresch, J. F., \& Bansemer, A. (2015). Distributions of ice supersaturation and ice crystals from airborne observations in relation to upper tropospheric dynamical boundaries. Journal of Geophysical Research: Atmospheres, 120(10), 5101-5121. https://doi.org/10.1002/2015JD023139

Diskin, G. S., Podolske, J.R., G. W. Sachse, G. W., \& Slate, T. A. (2002). Open-path airborne tunable diode laser hygrometer. Diode Lasers and Applications in Atmospheric Sensing, A. Fried, Ed., International Society for Optical Engineering. SPIE Proceedings, 4817, 196-204. doi:10.1117/12.453736

Dowling, D. R., \& Radke, L. F. (1990). A Summary of the Physical Properties of Cirrus Clouds. Journal of Applied Meteorology, 29(9), 970-978. https://doi.org/10.1175/1520-0450(1990)029<0970:ASOTPP>2.0.CO;2 
Erfani, E., \& Mitchell, D. L., (2016). Developing and bounding ice particle mass- and areadimension expressions for use in atmospheric models and remote sensing. Atmospheric Chemistry and Physics, 16(7), 4379-4400, doi:10.5194/acp-16-43792016

Feng, Z., Dong, X., Xi, B., Schumacher, C., Minnis, P., \& Khaiyer, M. (2011). Top-ofatmosphere radiation budget of convective core/stratiform rain and anvil clouds from deep convective systems. Journal of Geophysical Research: Atmospheres, 116(D23). https://doi.org/10.1029/2011JD016451

Field, P. R., \& Heymsfield, A. J. (2003). Aggregation and Scaling of Ice Crystal Size Distributions. Journal of the Atmospheric Sciences, 60(3), 544-560. https://doi.org/10.1175/1520-0469(2003)060<0544:AASOIC>2.0.CO;2

Fu, Q., Baker, M., \& D. L. Hartmann (2002). Tropical cirrus and water vapor: an effective Earth infrared iris feedback?, Atmospheric Chemistry and Physics, 2(1), 31-37, https://doi.org/10.5194/acp-2-31-2002

Gallagher, M. W., Connolly, P. J., Whiteway, J., Figueras- Nieto, D., Flynn, M., Choularton, T. W., et al. (2005). An overview of the microphysical structure of cirrus clouds observed during EMERALD-1. Quarterly Journal of the Royal Meteorological Society, 131(607), 1143-1169. https://doi.org/10.1256/qj.03.138

Gallagher, M. W., Connolly, P. J., Crawford, I., Heymsfield, A., Bower, K. N., Choularton, T. W., et al. (2012). Observations and modelling of microphysical variability, aggregation and sedimentation in tropical anvil cirrus outflow regions. Atmospheric Chemistry and Physics, 12(14), 6609-6628. https://doi.org/10.5194/acp-12-66092012

Guignard, A., Stubenrauch, C. J., Baran, A. J., \& Armante, R. (2012). Bulk microphysical properties of semi-transparent cirrus from AIRS: a six year global climatology and statistical analysis in synergy with geometrical profiling data from CloudSatCALIPSO. Atmospheric Chemistry and Physics, 12(1), 503-525. https://doi.org/10.5194/acp-12-503-2012

Gurganus, C., \& Lawson, P. (2018). Laboratory and Flight Tests of 2D Imaging Probes: Toward a Better Understanding of Instrument Performance and the Impact on Archived Data. Journal of Atmospheric and Oceanic Technology, 35(7), 1533-1553. https://doi.org/10.1175/JTECH-D-17-0202.1

Hartmann, D. L. (2016). Tropical anvil clouds and climate sensitivity. Proceedings of the National Academy of $\quad$ Sciences, 113(32), 8897-8899. https://doi.org/10.1073/pnas.1610455113 
Hartmann, D. L., Gasparini, B., Berry, S. E., \& Blossey, P. N. (2018). The life cycle and net radiative effect of tropical anvil clouds. Journal of Advances in Modeling Earth Systems, 10, 3012-3029. https://doi.org/10.1029/2018MS001484

Hartmann, D. L., \& Berry, S. E. (2017). The balanced radiative effect of tropical anvil clouds. Journal of Geophysical Research: Atmospheres, 122(9), 5003-5020. https://doi.org/10.1002/2017JD026460

Heymsfield, A. (1975). Cirrus Uncinus Generating Cells and the Evolution of Cirriform Clouds. Part I: Aircraft Observations of the Growth of the Ice Phase. Journal of the Atmospheric Sciences, 32(4), 799-808. https://doi.org/10.1175/15200469(1975)032<0799:CUGCAT>2.0.CO;2

Heymsfield, A. J. (1986). Ice particles observed in a cirriform cloud at $-83{ }^{\circ} \mathrm{C}$ and implications for polar stratospheric clouds. Journal of the Atmospheric Sciences, 43(8), $\quad$ 851-855. 0469(1986)043<0851:IPOIAC>2.0.CO;2

Heymsfield, A. J., Schmitt, C., Bansemer, A., and Twohy, C. H., (2010). Improved Representation of Ice Particle Masses Based on Observations in Natural Clouds, Journal of the Atmospheric Sciences, 67(10), 3303-3318, doi:10.1175/2010jas3507.1

Heymsfield, A., \& Wright, R. (2014). Graupel and Hail Terminal Velocities: Does a "Supercritical" Reynolds Number Apply? Journal of the Atmospheric Sciences, 71(9), 3392-3403. https://doi.org/10.1175/JAS-D-14-0034.1 Heymsfield, A. J. (1977). Precipitation Development in Stratiform Ice Clouds: A Microphysical and Dynamical Study. Journal of the Atmospheric Sciences, 34(2), 367-381. https://doi.org/10.1175/1520-0469(1977)034<0367:PDISIC>2.0.CO;2

Heymsfield, A. J. (1986). Ice Particle Evolution in the Anvil of a Severe Thunderstorm during CCOPE. Journal of the Atmospheric Sciences, 43(21), 2463-2478. https://doi.org/10.1175/1520-0469(1986)043<2463:IPEITA>2.0.CO;2

Heymsfield, A. J., \& Iaquinta, J. (2000). Cirrus Crystal Terminal Velocities. Journal of the Atmospheric Sciences, 57(7), 916-938. https://doi.org/10.1175/15200469(2000)057<0916:CCTV>2.0.CO;2

Heymsfield, A. J., \& Miloshevich, L. M. (1995). Relative Humidity and Temperature Influences on Cirrus Formation and Evolution: Observations from Wave Clouds and FIRE II. Journal of the Atmospheric Sciences, 52(23), 4302-4326. https://doi.org/10.1175/1520-0469(1995)052<4302:RHATIO>2.0.CO;2

Heymsfield, A. J., Lewis, S., Bansemer, A., Iaquinta, J., Miloshevich, L. M., Kajikawa, M., et al. (2002). A General Approach for Deriving the Properties of Cirrus and Stratiform Ice Cloud Particles. Journal of the Atmospheric Sciences, 59(1), 3-29. https://doi.org/10.1175/1520-0469(2002)059<0003:AGAFDT>2.0.CO;2 
Heymsfield, A. J., Krämer, M., Luebke, A., Brown, P., Cziczo, D. J., Franklin, C., et al. (2017). Cirrus Clouds. Meteorological Monographs, 58, 2.1-2.26. https://doi.org/10.1175/AMSMONOGRAPHS-D-16-0010.1

Jensen, E. J., Pfister, L., Bui, T. V., Lawson, P., Baker, B., Mo, Q., et al. (2008). Formation of large $(\sim 100 \mu \mathrm{m})$ ice crystals near the tropical tropopause. Atmospheric Chemistry and Physics, 8(6), 1621-1633. https://doi.org/10.5194/acp-8-1621-2008

Jensen, E. J., Lawson, P., Baker, B., Pilson, B., Mo, Q., Heymsfield, A. J., et al. (2009). On the importance of small ice crystals in tropical anvil cirrus. Atmospheric Chemistry and Physics, 9(15), 5519-5537. https://doi.org/10.5194/acp-9-5519-2009

Jensen, E. J., Diskin, G., Lawson, R. P., Lance, S., Bui, T. P., Hlavka, D., et al. (2013). Ice nucleation and dehydration in the Tropical Tropopause Layer. Proceedings of the National Academy of $\quad$ Sciences, 110(6), 2041-2046. https://doi.org/10.1073/pnas.1217104110

Jensen, E. J., Pfister, L., Jordan, D. E., Bui, T. V., Ueyama, R., Singh, H. B., et al. (2015). The NASA Airborne Tropical Tropopause Experiment: High-Altitude Aircraft Measurements in the Tropical Western Pacific. Bulletin of the American Meteorological Society, 98(1), 129-143. https://doi.org/10.1175/BAMS-D-1400263.1

Jensen, E. J., Ueyama, R., Pfister, L., Bui, T. V., Alexander, M. J., Podglajen, A., et al. (2016). High-frequency gravity waves and homogeneous ice nucleation in tropical tropopause layer cirrus. Geophysical Research Letters, 43(12), 6629-6635. https://doi.org/10.1002/2016GL069426

Jensen, E. J., Thornberry, T. D., Rollins, A. W., Ueyama, R., Pfister, L., Bui, T., et al. (2017). Physical processes controlling the spatial distributions of relative humidity in the tropical tropopause layer over the Pacific. Journal of Geophysical Research: Atmospheres, 122(11), 6094-6107. https://doi.org/10.1002/2017JD026632

Jensen, E. J., Heever, S. C. van den, \& Grant, L. D. (2018). The Life Cycles of Ice Crystals Detrained From the Tops of Deep Convection. Journal of Geophysical Research: Atmospheres, 123(17), 9624-9634. https://doi.org/10.1029/2018JD028832

Kajikawa, M., \& Heymsfield, A. J. (1989). Aggregation of Ice Crystals in Cirrus. Journal of the Atmospheric Sciences, 46(20), 3108-3121. https://doi.org/10.1175/15200469(1989)046<3108:AOICIC>2.0.CO;2

Knollenberg, R. G. (1970). The Optical Array: An Alternative to Scattering or Extinction for Airborne Particle Size Determination. Journal of Applied Meteorology, 9(1), 86-103. https://doi.org/10.1175/1520-0450(1970)009<0086:TOAAAT>2.0.CO;2 
Koenig, L. R. (1963). The Glaciating Behavior of Small Cumulonimbus Clouds. Journal of the Atmospheric Sciences, 20(1), 29-47. https://doi.org/10.1175/15200469(1963)020<0029:TGBOSC > 2.0.CO;2

Koop, T., Luo, B., Tsias, A., \& Peter, T. (2000). Water activity as the determinant for homogeneous ice nucleation in aqueous solutions. Nature, 406(6796), 611-614. https://doi.org/10.1038/35020537

Korolev, A.V., Strapp, J. W., Isaac, G. A., \& Nevzorov, A. N., (1998). The Nevzorov Airborne Hot-wire LWC-TWC Probe: Principle of operation and performance characteristics. Journal of Atmospheric and Oceanic Technology, 15(6), 1495-1510. https://doi.org/10.1175/1520-0426(1998)015<0708:EOTAOP>2.0.CO;2

Korolev, A. V., Isaac, G. A., \& Hallett, J. (1999). Ice particle habits in Arctic clouds. Geophysical Research Letters, 26(9), 1299-1302. https://doi.org/10.1029/1999GL900232

Korolev, A. V., Emery, E. F., Strapp, J. W., Cober, S. G., \& Isaac, G. A. (2013). Quantification of the Effects of Shattering on Airborne Ice Particle Measurements. Journal of Atmospheric and Oceanic Technology, 30(11), 2527-2553. https://doi.org/10.1175/JTECH-D-13-00115.1

Krämer, M., Schiller, C., Afchine, A., Bauer, R., Gensch, I., Mangold, A., et al., (2009). Ice supersaturations and cirrus cloud crystal numbers, Atmospheric Chemistry and Physics, 9(5), 3505-3522, https://doi.org/10.5194/acp-9-3505-2009

Krämer, M., Rolf, C., Luebke, A., Afchine, A., Spelten, N., \& Costa, A., et al., (2016). A microphysics guide to cirrus clouds - Part 1: Cirrus types, Atmospheric Chemistry and Physics, 16(11), 3463-3483, doi:10.5194/acp-16-3463-2016

Lance, S., Lawson, P., Mo, Q., Jensen, E., \& Muhlbauer, A. (2013, March). SPARTICUS Cirrus particle sizes and habits. Poster presented at the DOE ASR Science Team Meeting, Potomac, Maryland.

Lawson, R. P., Angus, L. J., \& Heymsfield, A. J. (1998). Cloud Particle Measurements in Thunderstorm Anvils and Possible Weather Threat to Aviation. Journal of Aircraft, 35(1), 113-121. https://doi.org/10.2514/2.2268

Lawson, P., Gurganus, C., Woods, S., \& Bruintjes, R. (2017). Aircraft Observations of Cumulus Microphysics Ranging from the Tropics to Midlatitudes: Implications for a "New" Secondary Ice Process. Journal of the Atmospheric Sciences, 74(9), 28992920. https://doi.org/10.1175/JAS-D-17-0033.1

Lawson, R. P. (2011). Effects of ice particles shattering on the 2D-S probe. Atmos. Meas. Tech., 4(7), 1361-1381. https://doi.org/10.5194/amt-4-1361-2011 
Lawson, R. P., Pilson, B., Baker, B., Mo, Q., Jensen, E., Pfister, L., \& Bui, P. (2008). Aircraft measurements of microphysical properties of subvisible cirrus in the tropical tropopause layer. Atmospheric Chemistry and Physics, 8(6), 1609-1620. https://doi.org/10.5194/acp-8-1609-2008

Lawson, R. P., Baker, B. A., Schmitt, C. G., \& Jensen, T. L. (2001). An overview of microphysical properties of Arctic clouds observed in May and July 1998 during FIRE ACE. Journal of Geophysical Research: Atmospheres, 106(D14), 1498915014. https://doi.org/10.1029/2000JD900789

Lawson, R. P., Baker, B. A., \& Pilson, B. L. (2003). In-situ measurements of microphysical properties of mid-latitude and anvil cirrus and validation of satellite retreivals. (pp. 707-710). Presented at the 30th International Symposium on Remote Sensing of Environment, Honolulu, Hawaii.

Lawson, R. P., Baker, B., Pilson, B., \& Mo, Q. (2006a). In Situ Observations of the Microphysical Properties of Wave, Cirrus, and Anvil Clouds. Part II: Cirrus Clouds. Journal of the Atmospheric Sciences, 63(12), 3186-3203. https://doi.org/10.1175/JAS3803.1

Lawson, R. P., Baker, B. A., Zmarzly, P., O’Connor, D., Mo, Q., Gayet, J.-F., \& Shcherbakov, V. (2006b). Microphysical and Optical Properties of Atmospheric Ice Crystals at South Pole Station. Journal of Applied Meteorology and Climatology, 45(11), 1505-1524. https://doi.org/10.1175/JAM2421.1

Lawson, R. P, O’Connor, D., Zmarzly, P., Weaver, K., Baker, B., Mo, Q., \& Jonsson, H. (2006c). The 2D-S (Stereo) Probe: Design and Preliminary Tests of a New Airborne, High-Speed, High-Resolution Particle Imaging Probe. Journal of Atmospheric and Oceanic Technology, 23(11), 1462-1477. https://doi.org/10.1175/JTECH1927.1

Lawson, R. P., Jensen, E., Mitchell, D. L., Baker, B., Mo, Q., \& Pilson, B. (2010). Microphysical and radiative properties of tropical clouds investigated in TC4 and NAMMA. Journal of Geophysical Research: Atmospheres, 115(D10). https://doi.org/10.1029/2009JD013017

Lawson, R. P, Woods, S., \& Morrison, H. (2015). The Microphysics of Ice and Precipitation Development in Tropical Cumulus Clouds. Journal of the Atmospheric Sciences, 72(6), 2429-2445. https://doi.org/10.1175/JAS-D-14-0274.1

Locatelli, J.D. \& Hobbs, P.V. (1974). Fall speeds and masses of solid precipitation particles. Journal of Geophysical Research, 79(15), 2185-2197, https://doi.org/10.1029/JC079i015p02185

Loeb, N. G., Yang, P., Rose, F. G., Hong, G., Sun-Mack, S., Minnis, P., et al. (2018). Impact of ice microphysics on satellite cloud retrievals and broadband flux radiative transfer 
model calculations. Journal of Climate, 31(5), 1851-1864, doi: 10.1175/JCLI-D-170426.1

Luebke, A. E., Afchine, A., Costa, A., Grooss, J.-U., Meyer, J., \& Rolf, C., (2016). The origin of midlatitude ice clouds and the resulting influence on their microphysical properties, Atmospheric Chemistry and Physics, 16(9), 5793-5809, doi:10.5194/acp16-5793-2016

Luo, Z., \& Rossow, W. B. (2004). Characterizing Tropical Cirrus Life Cycle, Evolution, and Interaction with Upper-Tropospheric Water Vapor Using Lagrangian Trajectory Analysis of Satellite Observations. Journal of Climate, 17(23), 4541-4563. https://doi.org/10.1175/3222.1

Mace, G. G., Deng, M., Soden, B., \& Zipser, E. (2006). Association of Tropical Cirrus in the 10-15-km Layer with Deep Convective Sources: An Observational Study Combining Millimeter Radar Data and Satellite-Derived Trajectories. Journal of the Atmospheric Sciences, 63(2), 480-503. https://doi.org/10.1175/JAS3627.1

Mason, B. J. (1996). The rapid glaciation of slightly supercooled cumulus clouds. Quarterly Journal of the Royal Meteorological Society, 122(530), 357-365. https://doi.org/10.1002/qj.49712253003

Massie, S., Gettelman, A., Randel, W., \& Baumgardner, D. (2002). Distribution of tropical cirrus in relation to convection. Journal of Geophysical Research: Atmospheres, 107(D21), AAC 19-1-AAC 19-16. https://doi.org/10.1029/2001JD001293

May, P. T., Allen, G., Vaughan, G., \& Connolly, P. (2009). Aerosol and thermodynamic effects on tropical cloud systems during TWPICE and ACTIVE. Atmospheric Chemistry and Physics, 9(1), 15-24. https://doi.org/10.5194/acp-9-15-2009

May, P. T., Mather, J. H., Vaughan, G., Jakob, C., McFarquhar, G. M., Bower, K. N., \& Mace, G. G. (2008). The Tropical Warm Pool International Cloud Experiment. Bulletin of the American Meteorological Society, 89(5), 629-646. https://doi.org/10.1175/BAMS-89-5-629

McFarquhar, G. M., Heymsfield, A. J., Spinhirne, J., \& Hart, B. (2000). Thin and Subvisual Tropopause Tropical Cirrus: Observations and Radiative Impacts. Journal of the Atmospheric Sciences, 57(12), 1841-1853. https://doi.org/10.1175/15200469(2000)057<1841:TASTTC>2.0.CO;2

McFarquhar, G. M., Yang, P., Macke, A., \& Baran, A. J. (2002). A New Parameterization of Single Scattering Solar Radiative Properties for Tropical Anvils Using Observed Ice Crystal Size and Shape Distributions. Journal of the Atmospheric Sciences, 59(16), 2458-2478. https://doi.org/10.1175/1520-0469(2002)059<2458:ANPOSS>2.0.CO;2

Mishchenko, M. I., Rossow, W. B., Macke, A., \& Lacis, A. A. (1996). Sensitivity of cirrus cloud albedo, bidirectional reflectance and optical thickness retrieval accuracy to ice 
particle shape. Journal of Geophysical Research: Atmospheres, 101(D12), 1697316985. https://doi.org/10.1029/96JD01155

Mishra, S., Mitchell, D. L., Turner, D. D., \& Lawson, R. P. (2014). Parameterization of ice fall speeds in midlatitude cirrus: Results from SPartICus. Journal of Geophysical Research: Atmospheres, 119(7), 3857-3876. https://doi.org/10.1002/2013JD020602

Mitchell, D. L., Rasch, P., Ivanova, D., McFarquhar, G., \& Nousiainen, T. (2008). Impact of small ice crystal assumptions on ice sedimentation rates in cirrus clouds and GCM simulations. Geophysical Research https://doi.org/10.1029/2008GL033552

Mitchell, D. L., A. Garnier, J. Pelon, \& E. Erfani, (2018). CALIPSO (IIR-CALIOP) retrievals of cirrus cloud ice-particle concentrations, Atmospheric Chemistry and Physics, 18(23), 17325-17354, https://doi.org/10.5194/acp-18-17325-2018

Muhlbauer, A., Ackerman, T. P., Comstock, J. M., Diskin, G. S., Evans, S. M., Lawson, R. P., \& Marchand, R. T. (2014). Impact of large-scale dynamics on the microphysical properties of midlatitude cirrus. Journal of Geophysical Research: Atmospheres, 119(7), 3976-3996. https://doi.org/10.1002/2013JD020035

NCAR (2012). Description of the NCAR Community Atmosphere Model (CAM 5.0). National Center for Atmospheric Research Technical Note. NCAR/TN-486+STR

Protat, A., McFarquhar, G. M., Um, J., \& Delanoë, J. (2011). Obtaining Best Estimates for the Microphysical and Radiative Properties of Tropical Ice Clouds from TWP-ICE In Situ Microphysical Observations. Journal of Applied Meteorology and Climatology, 50(4), 895-915. https://doi.org/10.1175/2010JAMC2401.1

Ravishankara, A. R. (2012). Water Vapor in the Lower Stratosphere. Science, 337(6096), 809-810. https://doi.org/10.1126/science.1227004

Riihimaki, L. D., McFarlane, S. A., Liang, C., Massie, S. T., Beagley, N., \& Toth, T. D. (2012). Comparison of methods to determine Tropical Tropopause Layer cirrus formation mechanisms. Journal of Geophysical Research: Atmospheres, 117(D6). https://doi.org/10.1029/2011JD016832

Rosenfeld, D., \& Woodley, W. L. (2000). Deep convective clouds with sustained supercooled liquid water down to $-37.5{ }^{\circ} \mathrm{C}$. Nature, 405(6785), 440-442. https://doi.org/10.1038/35013030

Sassen, K., Comstock, J. M., Wang, Z., \& Mace, G. G. (2001). Cloud and Aerosol Research Capabilities at FARS: The Facility for Atmospheric Remote Sensing. Bulletin of the American Meteorological Society, 82(6), 1119-1138. https://doi.org/10.1175/15200477(2001)082<1119:CAARCA>2.3.CO;2 
Saunders, C. P. R., \& Wahab, N. M. A. (1975). The Influence of Electric Fields on the Aggregation of Ice Crystals. Journal of the Meteorological Society of Japan. Ser. II, 53(2), 121-126. https://doi.org/10.2151/jmsj1965.53.2_121

Schmitt, C. G., \& Heymsfield, A. J. (2010). The Dimensional Characteristics of Ice Crystal Aggregates from Fractal Geometry. Journal of the Atmospheric Sciences, 67(5), 1605-1616. https://doi.org/10.1175/2009JAS3187.1

Spichtinger, P. \& K. M. Gierens (2009). Modelling of cirrus clouds - Part 1b: Structuring cirrus clouds by dynamics, Atmospheric Chemistry and Physics, 9(2), 707-719, https://doi.org/10.5194/acp-9-707-2009

Stephens, G. L. (2005). Cloud Feedbacks in the Climate System: A Critical Review. Journal of Climate, 18(2), 237-273. https://doi.org/10.1175/JCLI-3243.1

Stephens, G. L., Tsay, S.-C., Stackhouse, P. W., \& Flatau, P. J. (1990). The Relevance of the Microphysical and Radiative Properties of Cirrus Clouds to Climate and Climatic Feedback. Journal of the Atmospheric Sciences, 47(14), 1742-1754. https://doi.org/10.1175/1520-0469(1990)047<1742:TROTMA>2.0.CO;2

Stith, J. L., Basarab, B., Rutledge, S. A., \& Weinheimer, A., (2016). Anvil microphysical signatures associated with lightning-produced $\mathrm{NO}_{x}$. Atmospheric Chemistry and Physics. 16(4), 2243-2254. https://doi.org/10.5194/acp-16-2243-2016

Stith, J. L., Avallone, L. M., Bansemer, A., Basarab, B., Dorsi, S. W., Fuchs, B., et al. (2014). Ice particles in the upper anvil regions of midlatitude continental thunderstorms: the case for frozen-drop aggregates. Atmospheric Chemistry and Physics, 14(4), 19731985. https://doi.org/10.5194/acp-14-1973-2014

Stith, J.L., Haggerty, J. Heymsfield, A., \& Grainger, C. A., (2004). Microphysical Characteristics of Tropical Updrafts in Clean Conditions. J. Appl. Meteor., 43(5), 779-794. https://doi.org/10.1175/2104.1

Stith, J. L., Dye, J. E., Bansemer, A., Heymsfield, A. J., Grainger, C. A., Petersen, W. A., \& Cifelli, R. (2002). Microphysical Observations of Tropical Clouds. Journal of Applied Meteorology, 41(2), 97-117. https://doi.org/10.1175/15200450(2002)041<0097:MOOTC>2.0.CO;2

Thornberry, T. D., Rollins, A. W., Gao, R. S., Watts, L. A., Ciciora, S. J., McLaughlin, R. J., \& Fahey, D. W. (2015). A two-channel, tunable diode laser-based hygrometer for measurement of water vapor and cirrus cloud ice water content in the upper troposphere and lower stratosphere. Atmospheric Measurement Techniques, 8(1), 211-224. https://doi.org/10.5194/amt-8-211-2015 
Um, J., \& McFarquhar, G. M. (2007). Single-Scattering Properties of Aggregates of Bullet Rosettes in Cirrus. Journal of Applied Meteorology and Climatology, 46(6), 757-775. https://doi.org/10.1175/JAM2501.1

Um, J., \& McFarquhar, G. M. (2009). Single-scattering properties of aggregates of plates. Quarterly Journal of the Royal Meteorological Society, 135(639), 291-304. https://doi.org/10.1002/qj.378

Um, J., \& McFarquhar, G. M. (2011). Dependence of the single-scattering properties of small ice crystals on idealized shape models. Atmospheric Chemistry and Physics, 11(7), 3159-3171. https://doi.org/10.5194/acp-11-3159-2011

Um, J., McFarquhar, G. M., Hong, Y. P., Lee, S.-S., Jung, C. H., Lawson, R. P., \& Mo, Q. (2015). Dimensions and aspect ratios of natural ice crystals. Atmospheric Chemistry and Physics, 15(7), 3933-3956. https://doi.org/10.5194/acp-15-3933-2015

Um, J., McFarquhar, G. M., Stith, J. L., Jung, C. H., Lee, S. S., Lee, J. Y., et al. (2018). Microphysical Characteristics of Frozen Droplet Aggregates from Deep Convective Clouds. Atmospheric Chemistry and Physics Discussions, 1-33. https://doi.org/10.5194/acp-2018-5

Weickmann, H. K. (1947). Die Eisphase in der Atmosphäre. Dt. Wetterdienst in der USZone.

Whiteway, J., Cook, C., Gallagher, M., Choularton, T., Harries, J., Connolly, P., et al. (2004). Anatomy of cirrus clouds: Results from the Emerald airborne campaigns. Geophysical Research Letters, 31(24). https://doi.org/10.1029/2004GL021201

Wolf, V., Kuhn, T., Milz, M., Voelger, P., Krämer, M., \& Rolf, C., (2018). Ice particle properties of Arctic cirrus, Atmospheric Chemistry and Physics Discussions, https://doi.org/10.5194/acp-2018-386.

Woods, S., Lawson, R. P., Jensen, E., Bui, T. P., Thornberry, T., Rollins, A., et al. (2018). Microphysical Properties of Tropical Tropopause Layer Cirrus. Journal of Geophysical Research: Atmospheres, 123(11), 6053-6069. https://doi.org/10.1029/2017JD028068

Yang, P., L. Bi, Baum, B.A., Liou, K., Kattawar, G. W., Mishchenko, M.I., \& Cole, B. (2013). Spectrally Consistent Scattering, Absorption, and Polarization Properties of Atmospheric Ice Crystals at Wavelengths from 0.2 to $100 \mu \mathrm{m}$. Journal of Atmospheric Science, 70, 330-347, https://doi.org/10.1175/JAS-D-12-039.1

Yang, P., Liou, K.N., Bi, L., Liu, C., Yi, B., \& Baum, B. A., (2015). On the radiative properties of ice clouds: Light scattering, remote sensing, and radiation parameterization. Advances in Atmospheric Sciences, 32(1), 32-63, doi: 10.1007/s00376-014-0011-z. 
Yang, P., Hioki, S., Saito, M., Kuo, C.-P. , Baum, B. A., Liou, K.N. (2018). A review of ice cloud optical property models for satellite remote sensing, Atmosphere 2018, 9(12), 499, doi:10.3390/atmos9120499

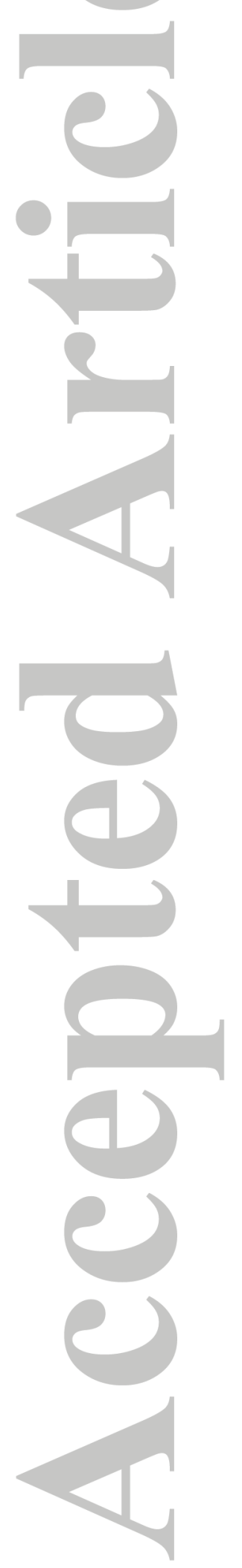




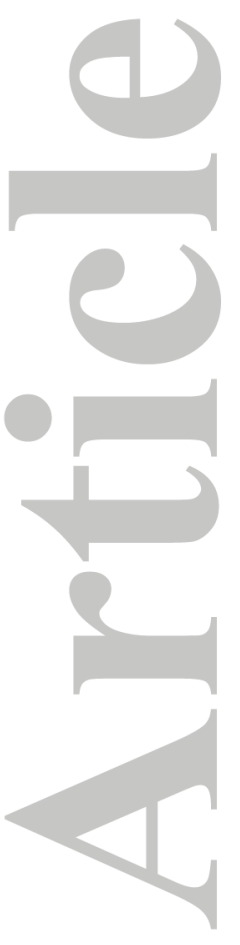

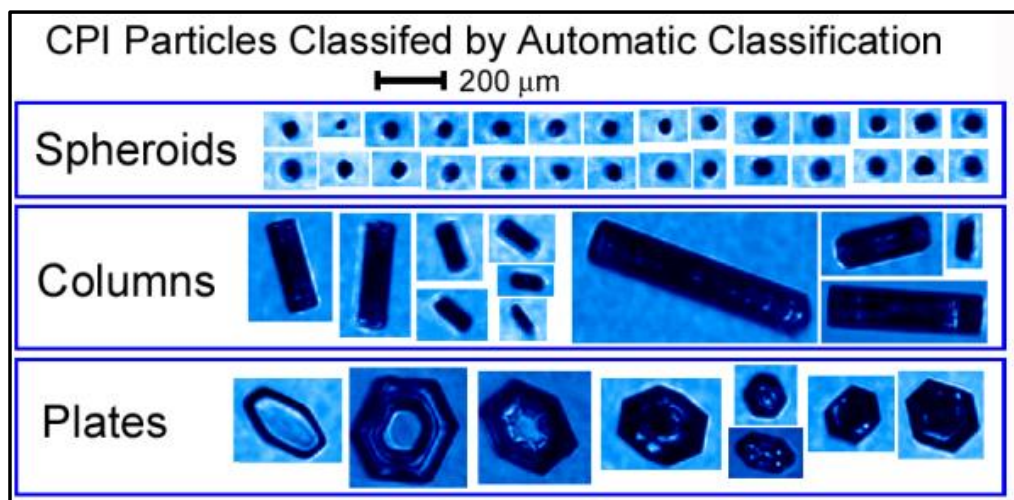
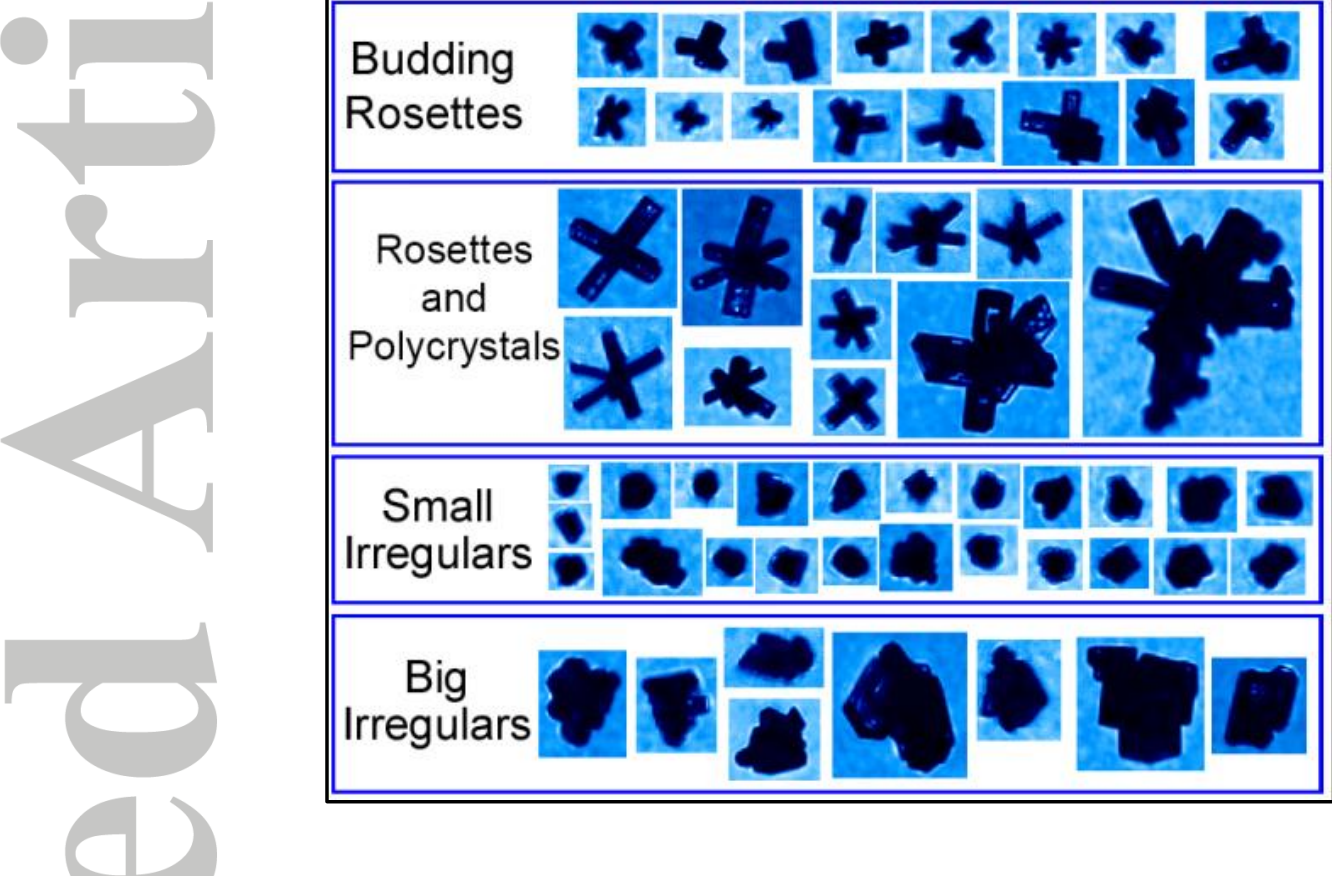

Figure 1. Examples of CPI images sampled in cirrus and classified using an automated software program (from Lawson et al., 2006b). 

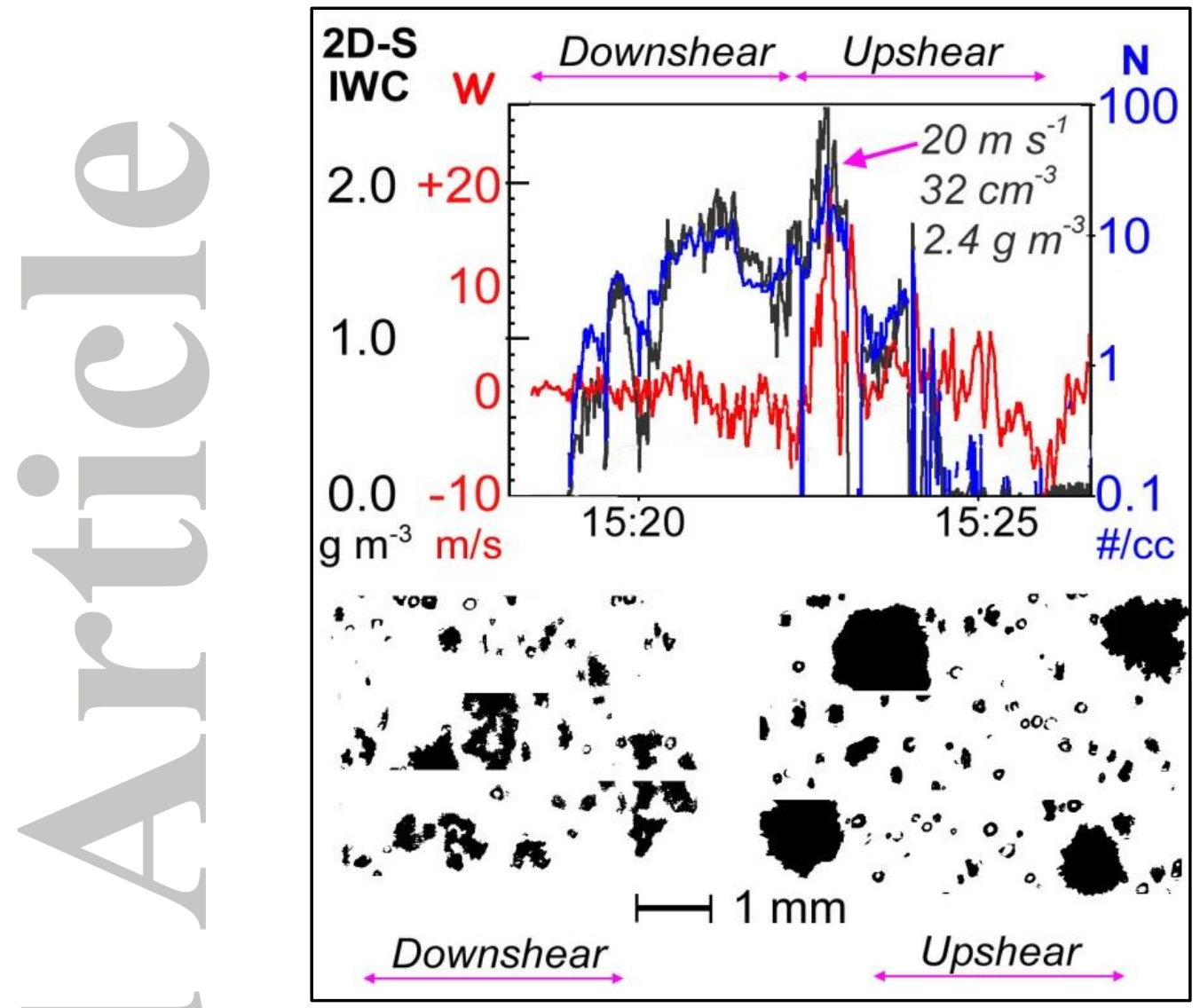

Figure 2. (top) Time series of IWC, vertical air velocity (w) and particle concentration (N) from a DC-8 penetration at $-47^{\circ} \mathrm{C}$ of an embedded turret, and (bottom) examples of 2D-S images. Data collected on 24 July 2007 during the TC4 project (from Lawson et al., 2010). 


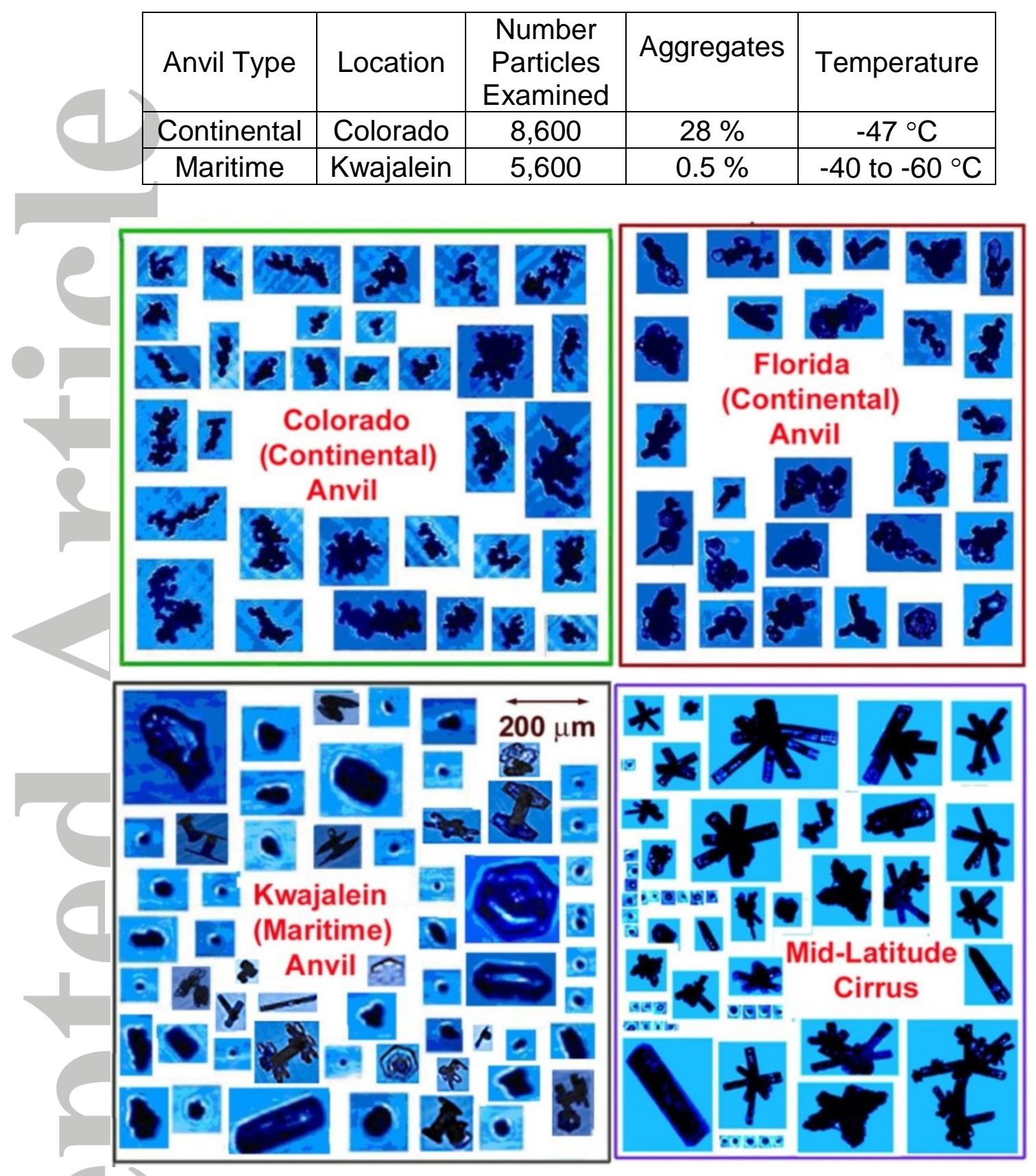

Figure 3. Examples of CPI images collected in Maritime and Continental anvils and Mid-Latitude cirrus formed in situ (from Lawson et al., 2003). 


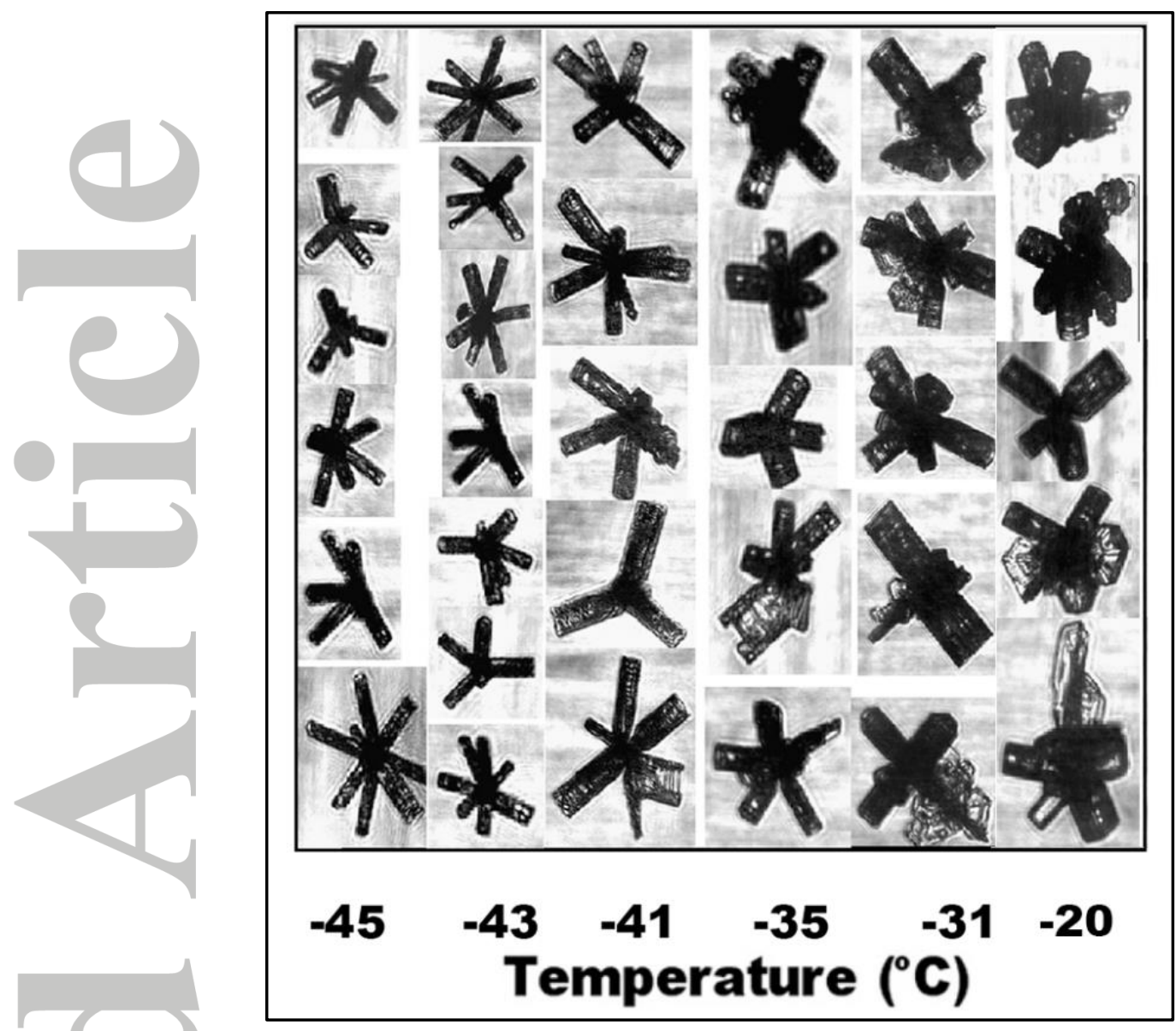

Figure 4. Examples of CPI images typically observed as a function of temperature in cirrus formed in situ (adapted from Bailey and Hallett 2009). 


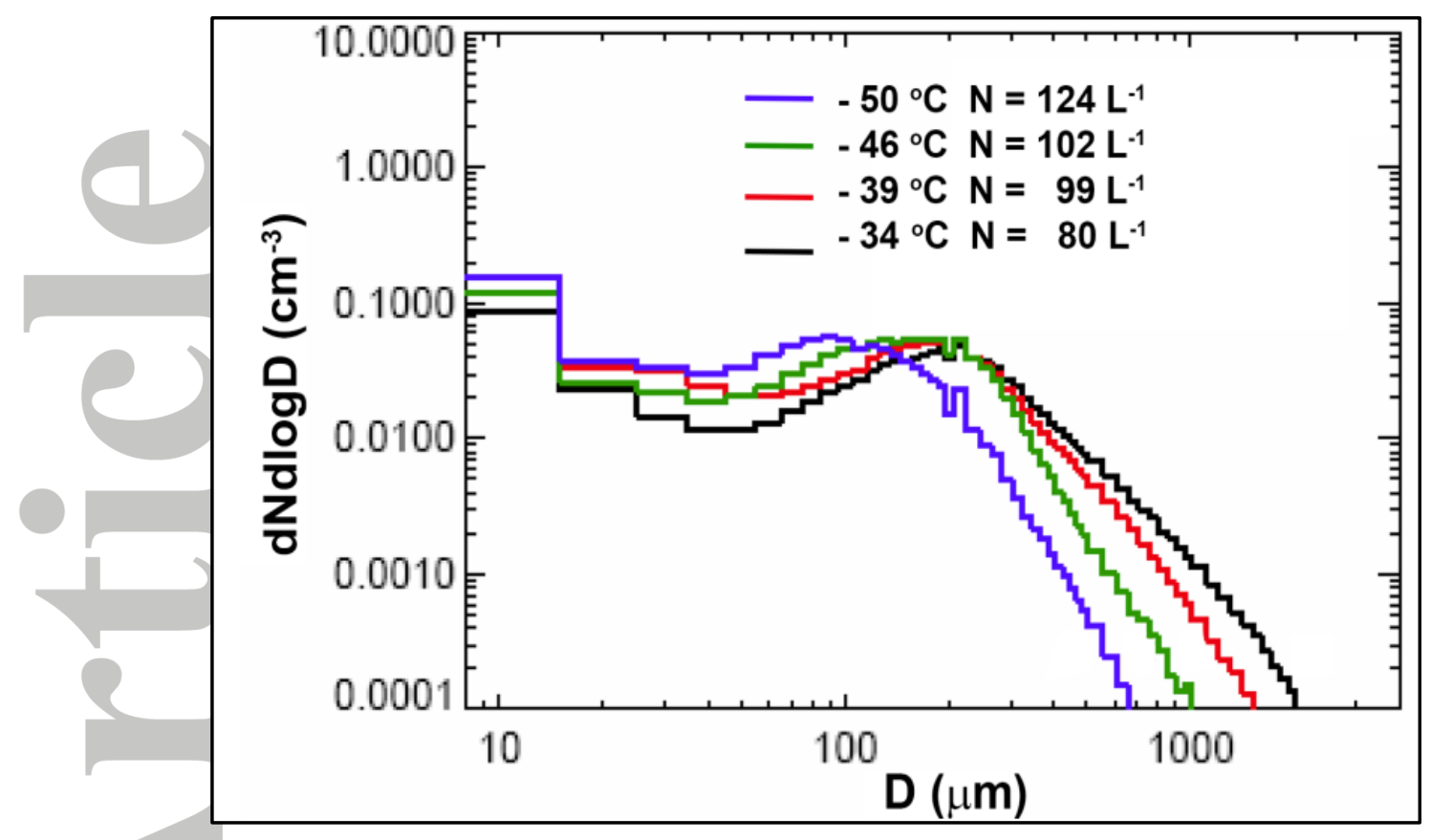

Figure 5. 2D-S particle size distributions and total particle concentration $(\mathrm{N})$ sampled at four temperature levels by the NASA DC-8 in aged anvil cirrus during TC4 (adapted from Jensen et al., 2009). 


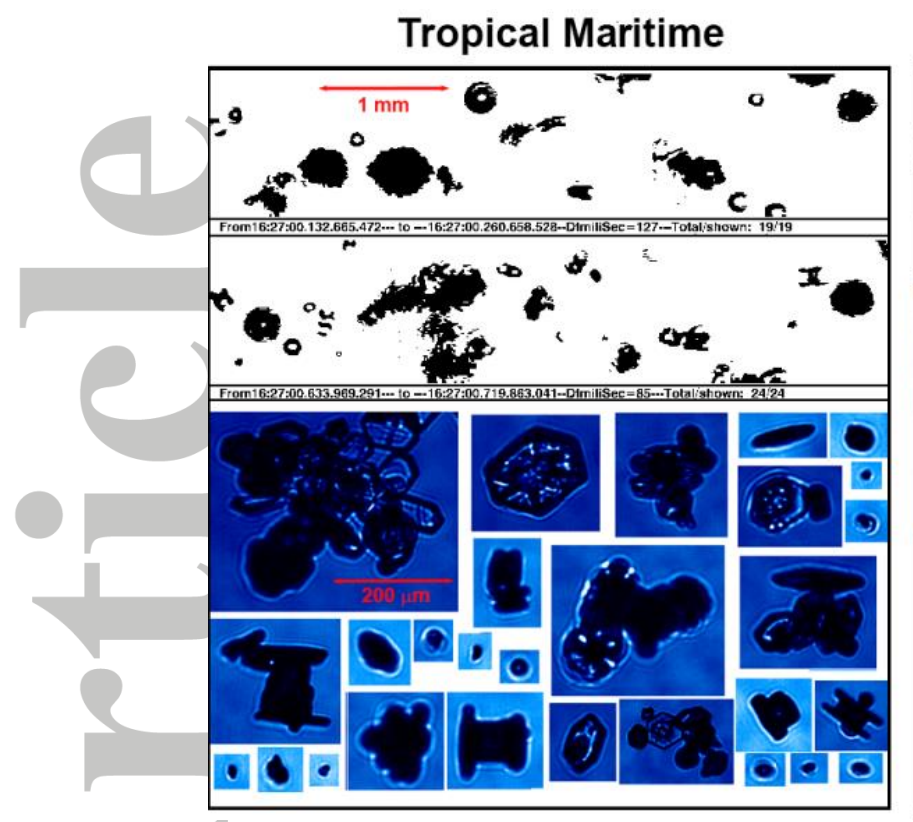

Mid-Latitude Continental

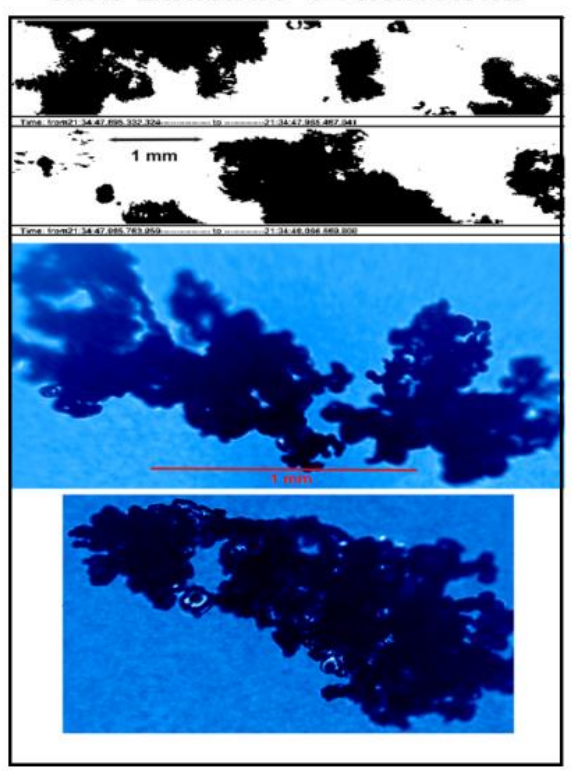

Figure 6. Examples of 2D-S and CPI images sampled at the base of a (left) Tropical Maritime anvil near St. Croix on 15 July 2011 at 16:27:00 UTC by the SPEC Learjet during ICE-T, and by the SPEC Learjet at the base of a (right) Mid-Latitude Continental anvil at 20,000 ft msl $\left(\mathrm{T}=-6.5^{\circ} \mathrm{C}\right)$ in Northeast Colorado on 23 July 2010 at 21:34:47.

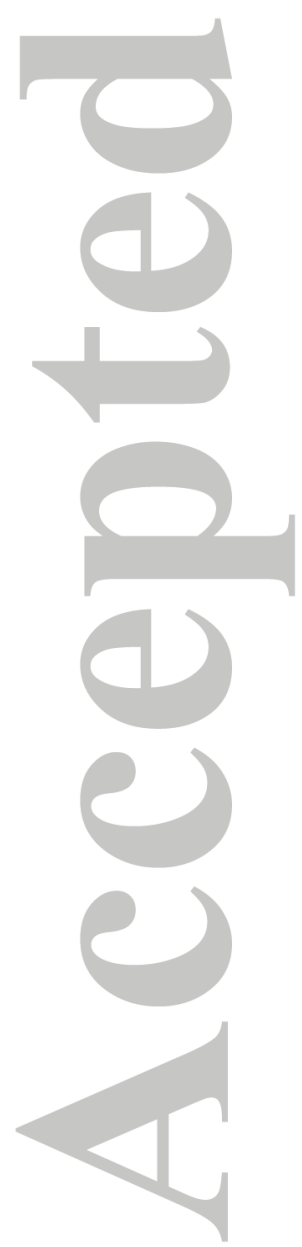



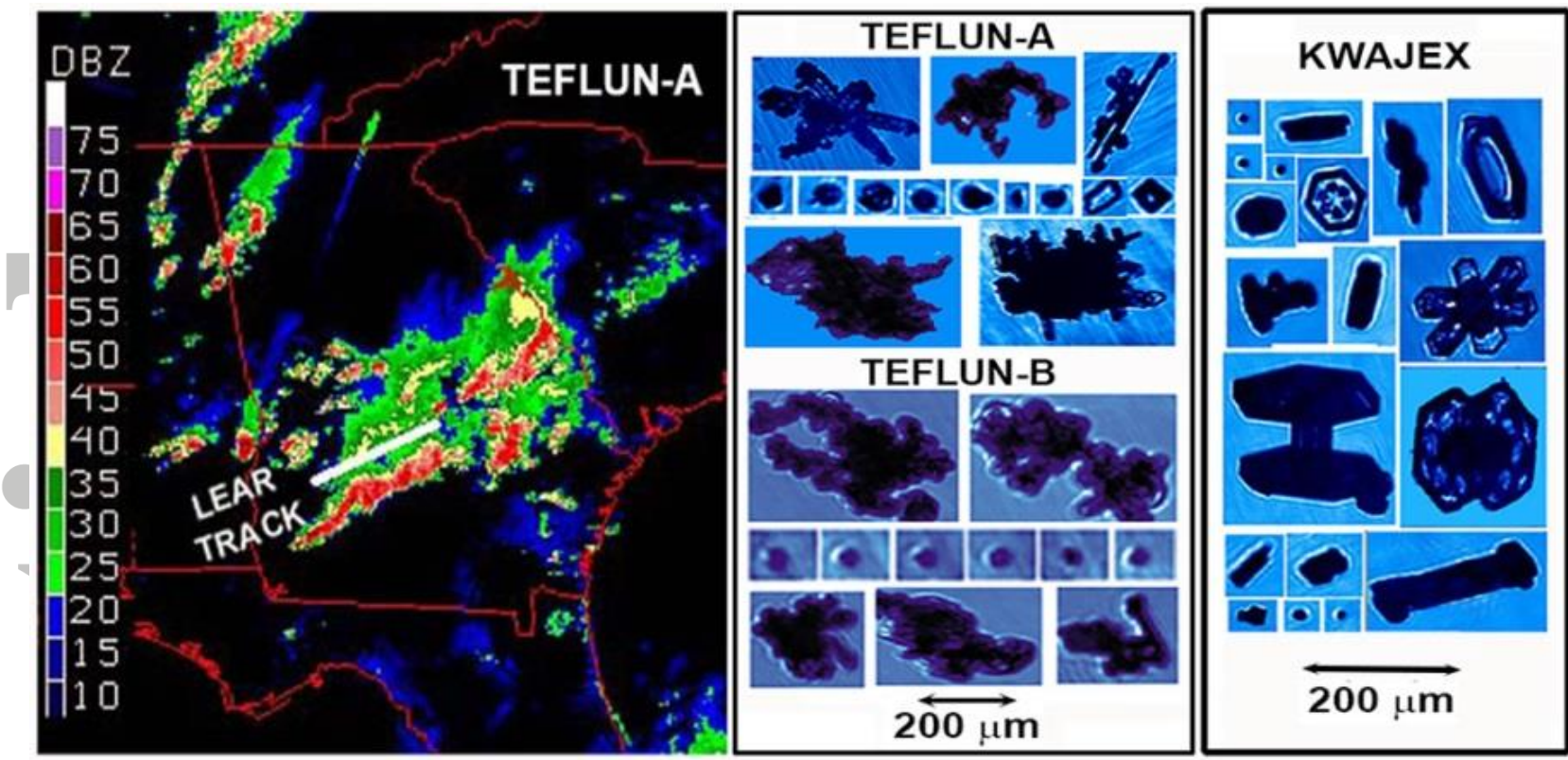

Figure 7. Example of SPEC Learjet flight track overlaid on NexRad radar reflectivity in Georgia; example of images in Continental anvil regions with faceted and rimed ice during TEFLUN-A (SPEC Learjet in Georgia) and TEFLUN-B (UND Citation in south Florida); and example of images in Tropical Maritime anvil during KWAJEX (UND Citation near Kwajalein Atoll).

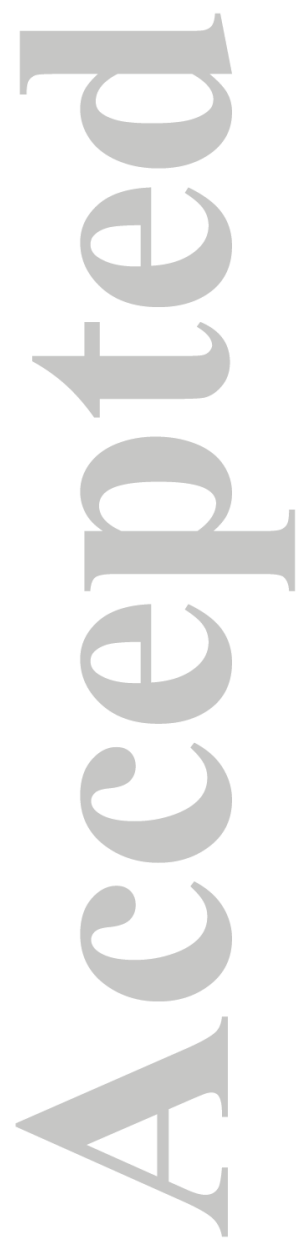




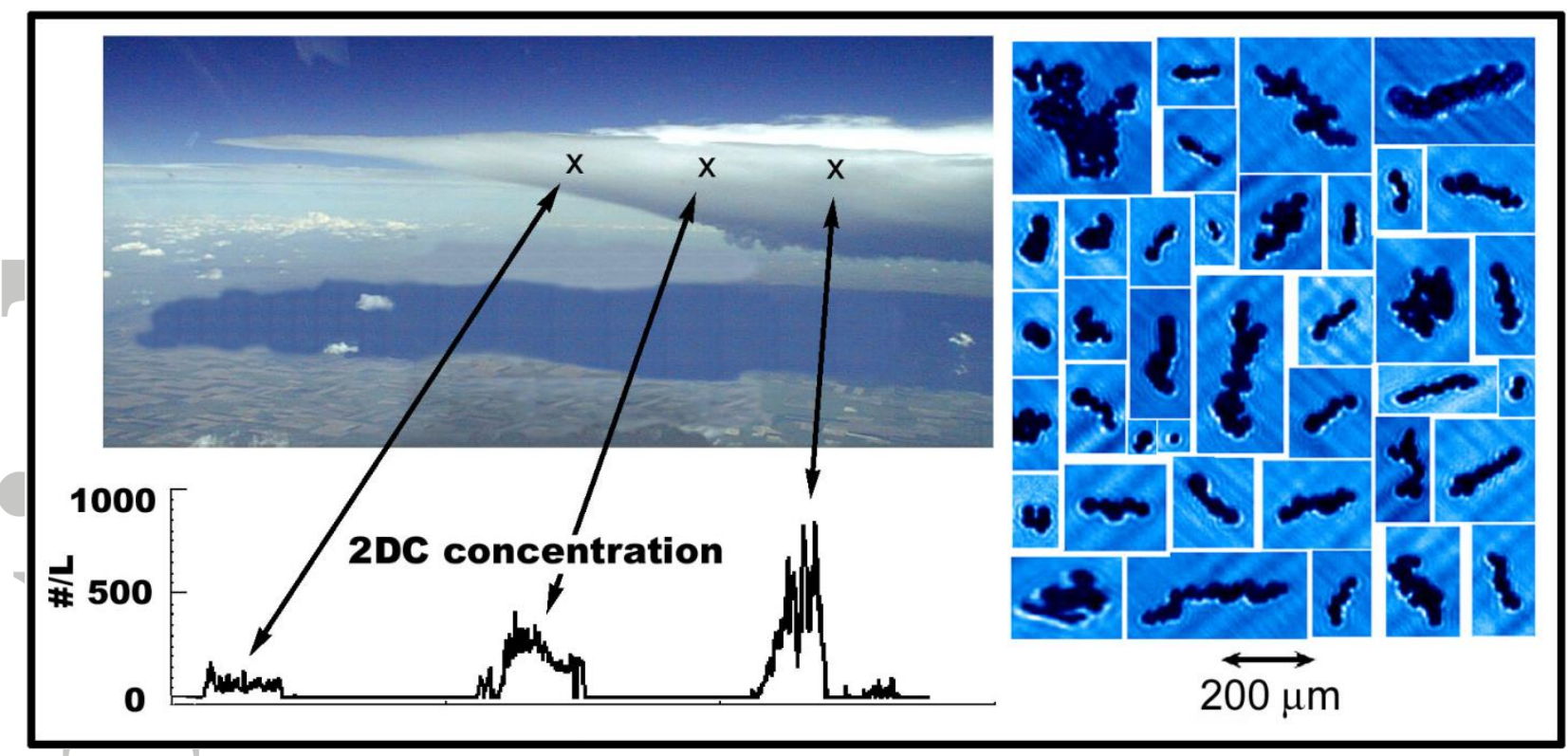

Figure 8. Photograph showing location of penetrations by the SPEC Learjet of an electrified Mid-Latitude Continental anvil at 39,000 ft $\mathrm{msl}\left(\mathrm{T}=-48^{\circ} \mathrm{C}\right)$ on 8 June 2001, time series of 2DC particle concentration and examples of CPI images. 


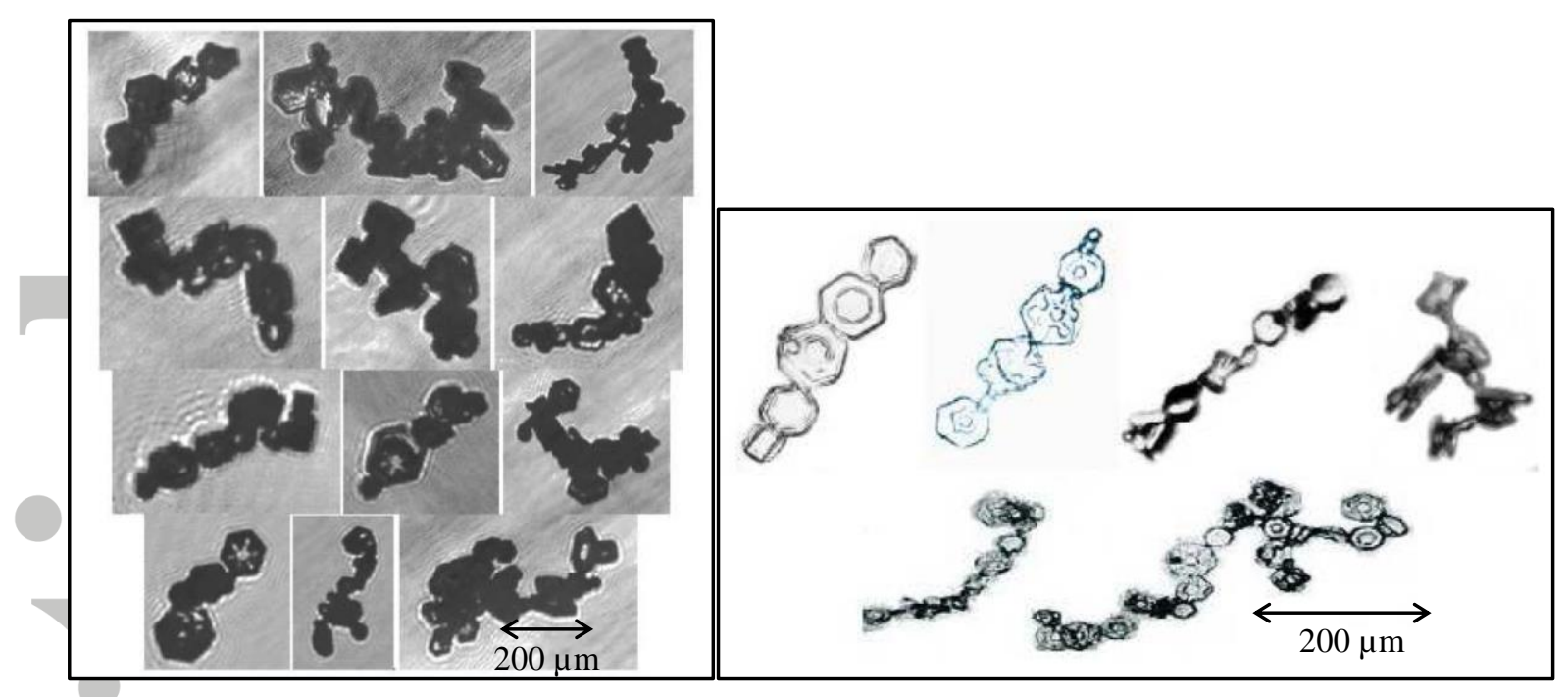

Figure 9. Examples of (left) CPI images of chains of small ice crystals from penetration of an electrified anvil sampled by an ARA Egrett research aircraft during the EMERALD-II project in December 2002, and (right) chains of ice crystals formed in the laboratory (Saunders and Wahab 1975) under a high electric field. Adapted from Connolly et al. (2005).

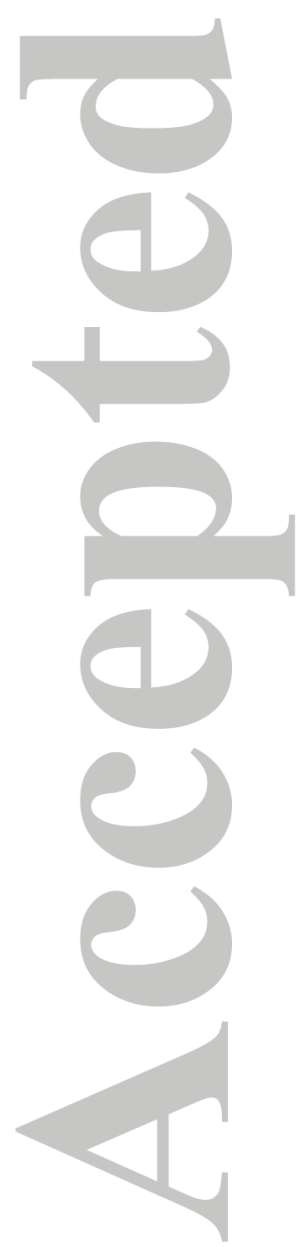




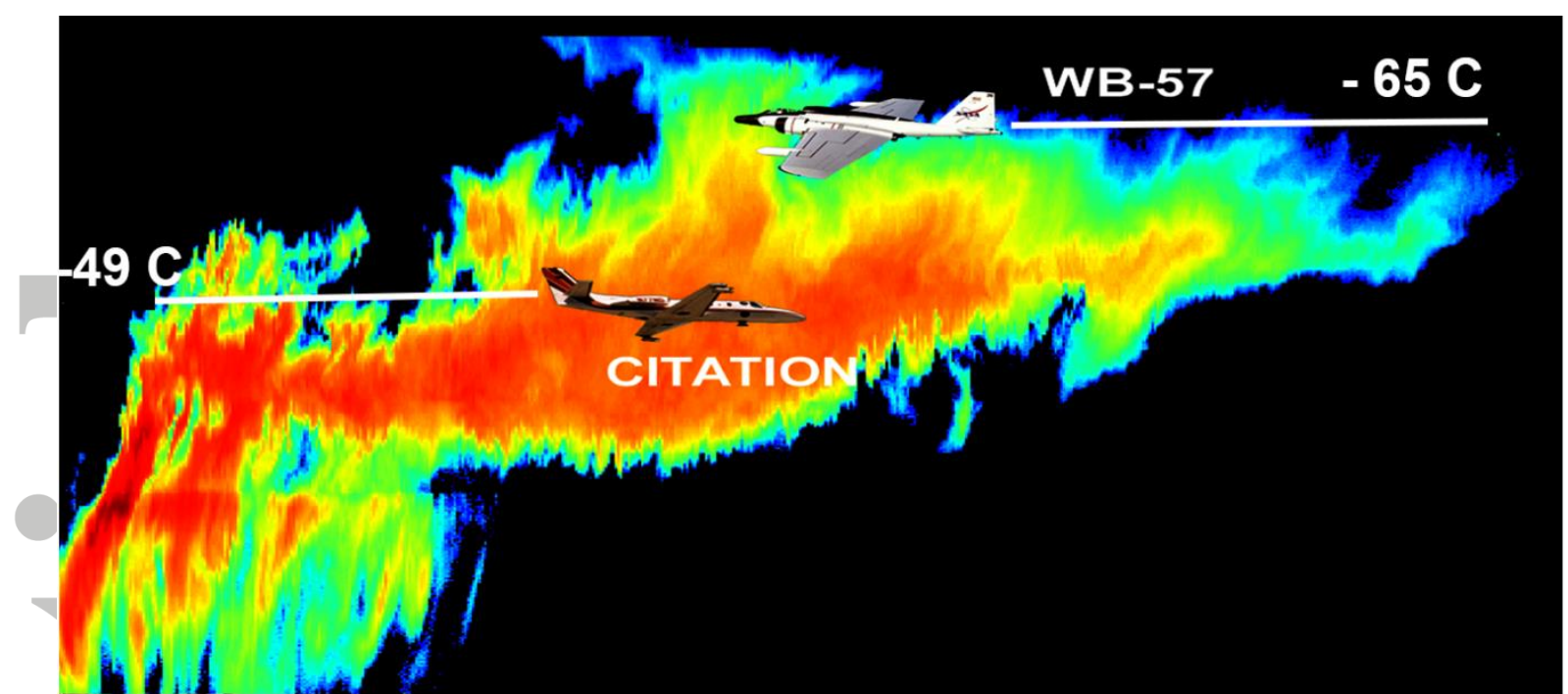

\section{Citation CPI Images}

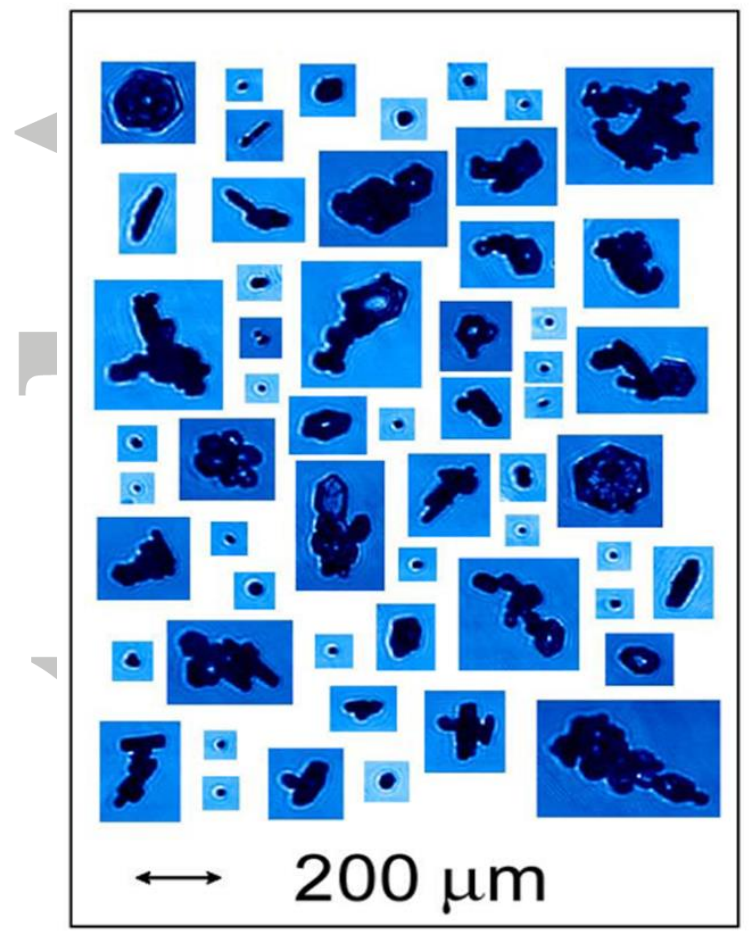

WB-57 CPI Images

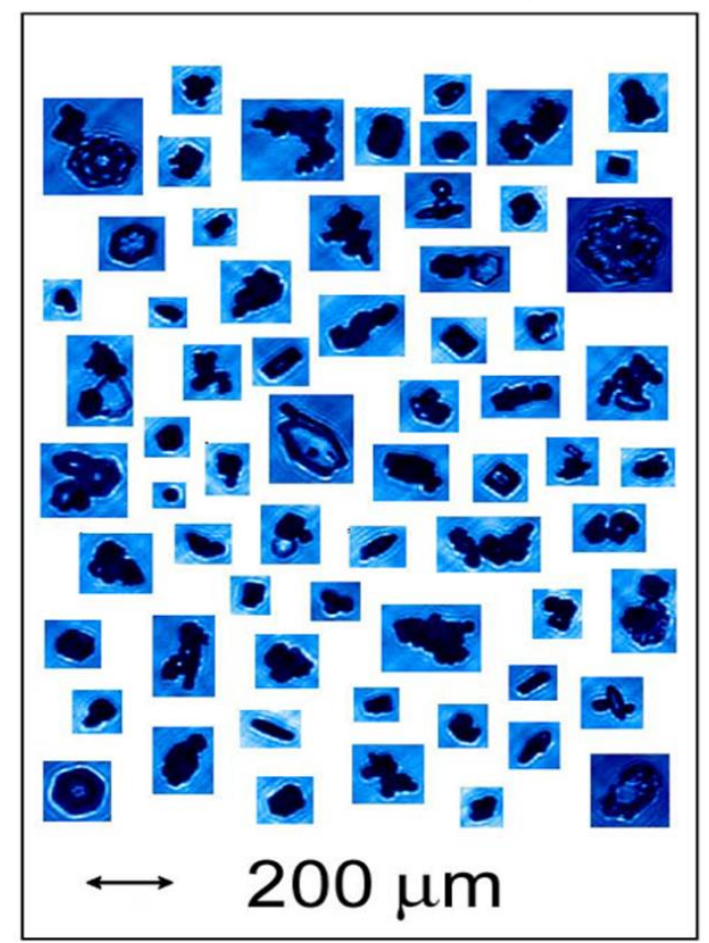

Figure 10. Example of CPI images from the CRYSTAL-FACE project sampled by (left) the UND Citation and (right) NASA WB-57. Vertical profile of radar reflectivity shows relative positions of the aircraft in the anvil. 

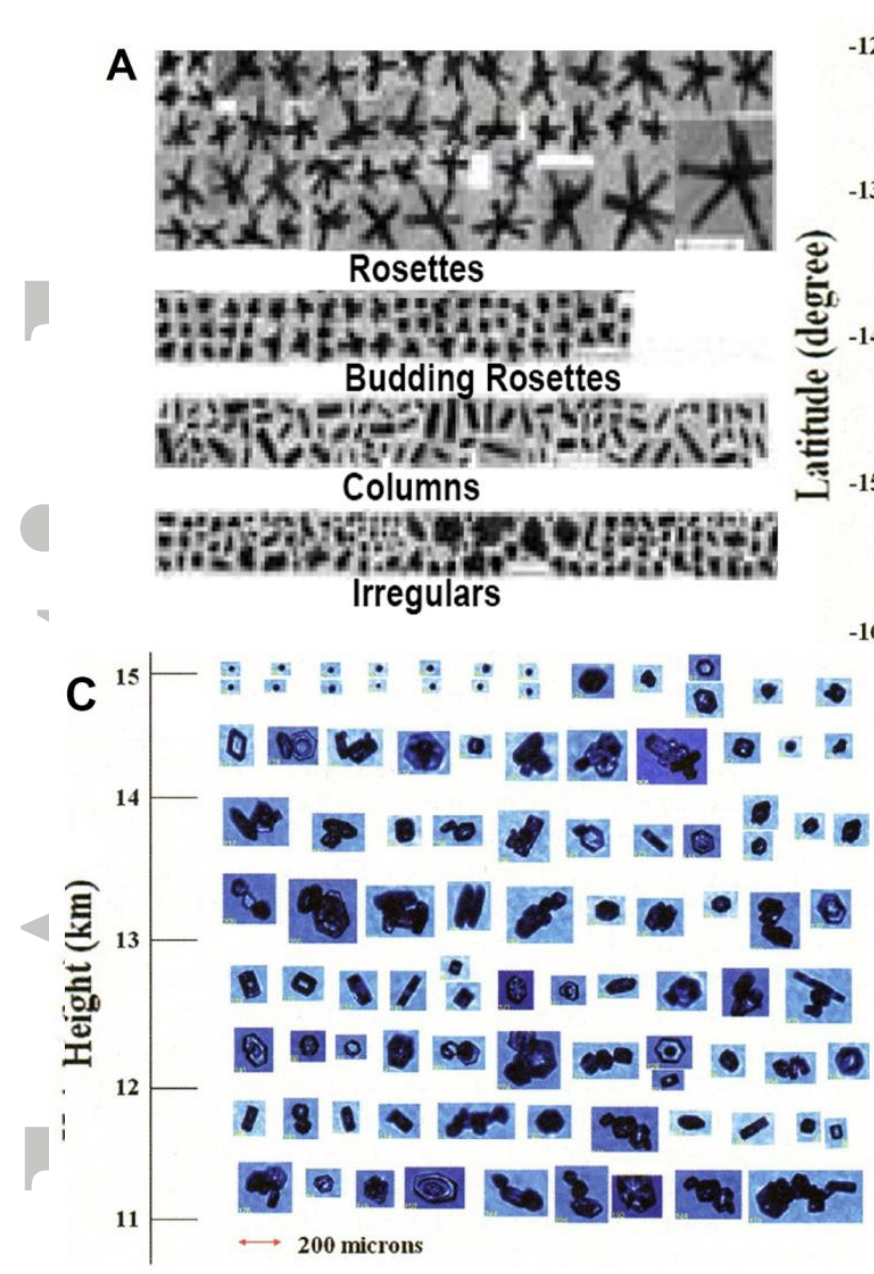
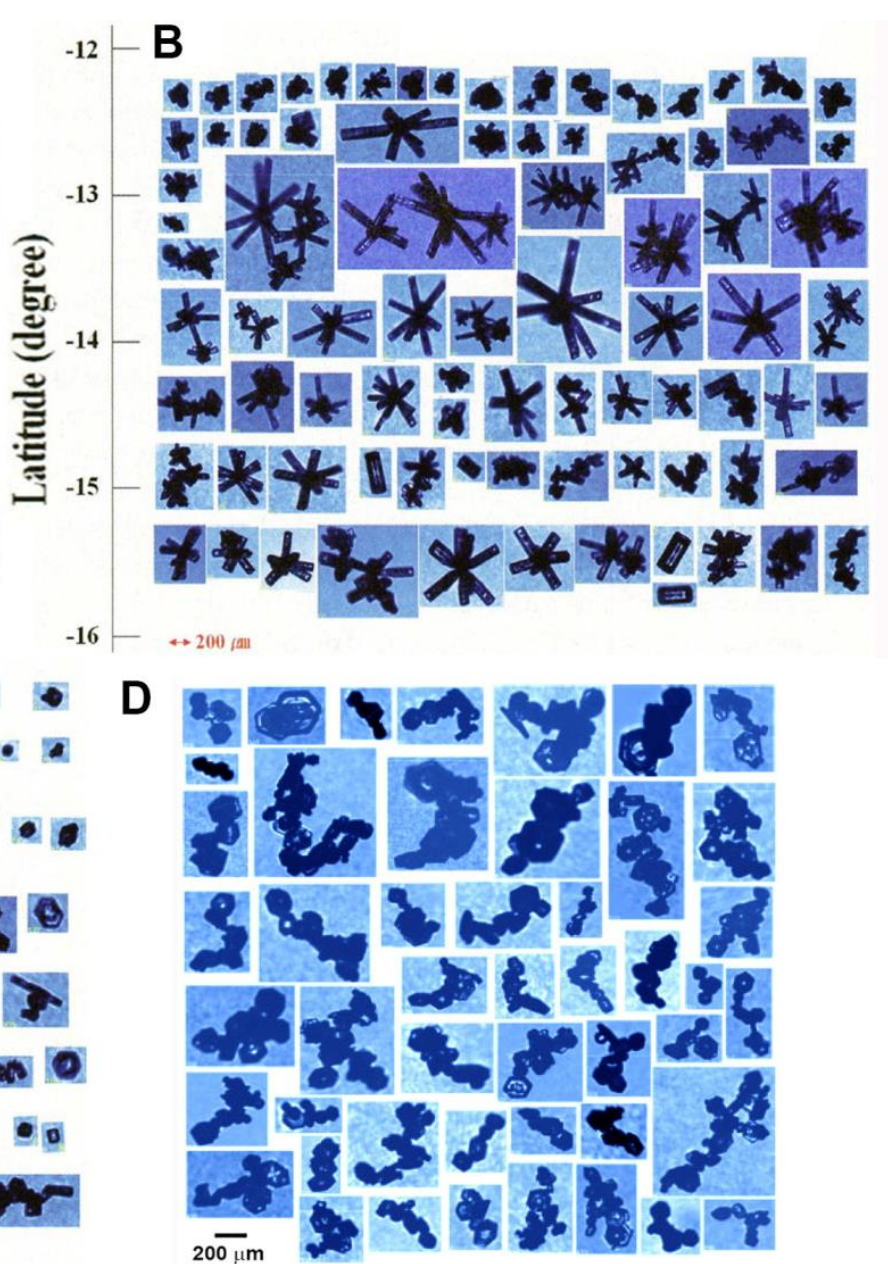

Figure 11. CPI images of particles sampled A: From EMERALD-I sampled by the Egrett in frontal cirrus on 19 September from 10 to $12 \mathrm{~km}\left(-52<\mathrm{T}<-34{ }^{\circ} \mathrm{C}\right)$; B: Aged anvil cirrus that has experienced particle regrowth sampled at $12 \mathrm{~km}\left(\mathrm{~T}=-47^{\circ} \mathrm{C}\right)$ sampled by the

Proteus from TWP-ICE, C: Fresh Tropical Maritime anvil sampled by the Proteus from 11 to

$15 \mathrm{~km}\left(-73^{\circ} \mathrm{C}<\mathrm{T}<-38^{\circ} \mathrm{C}\right)$ during TWP-ICE, and D: Highly electrified anvil cirrus sampled by the Proteus from TWP-ICE. Panel A from Whiteway et al. (2004); Panels B and C from May et al. (2009); Panel D from Um and McFarquhar (2009). 


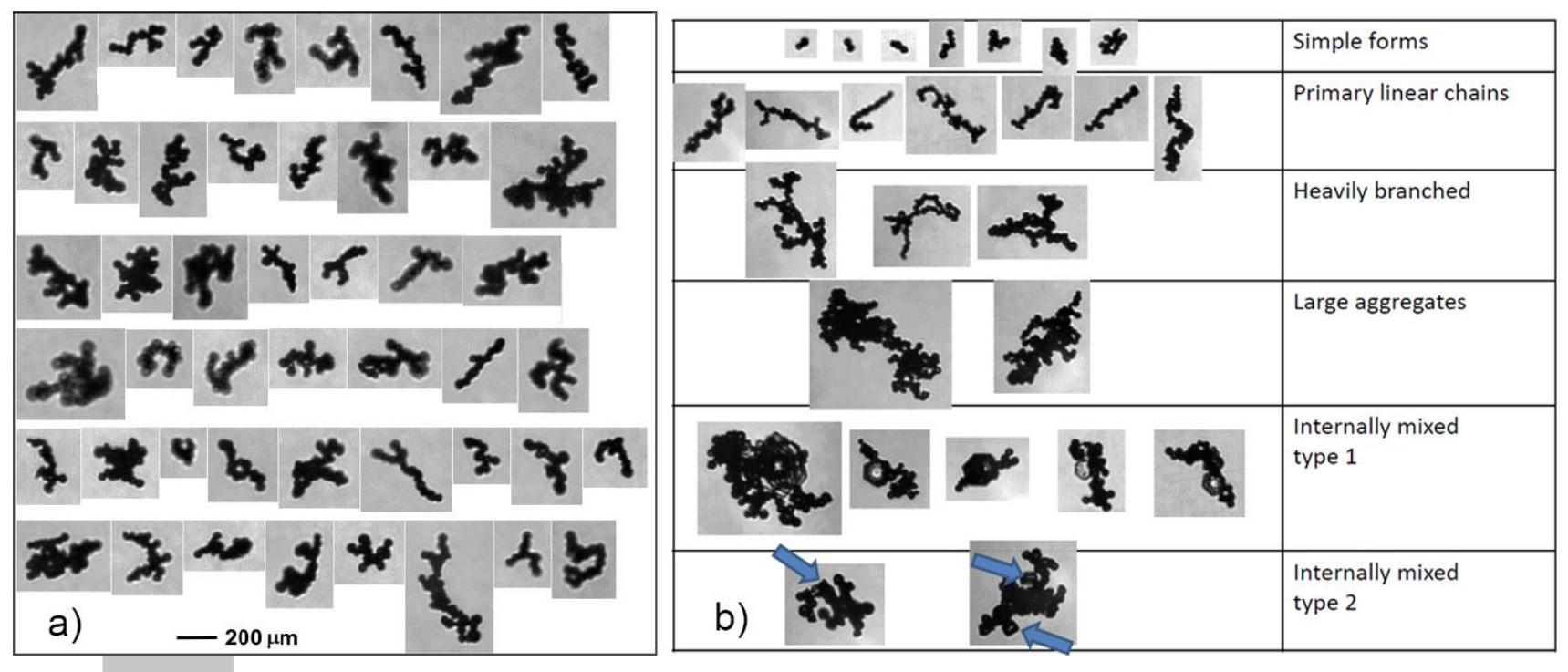

Figure 12. Examples of CPI images, mostly frozen drops in a highly electrified anvil sampled by a GV during DC3, adapted from a) Um et al. (2018) and b) Stith et al. (2014). Arrows in b) point to small faceted crystals. 

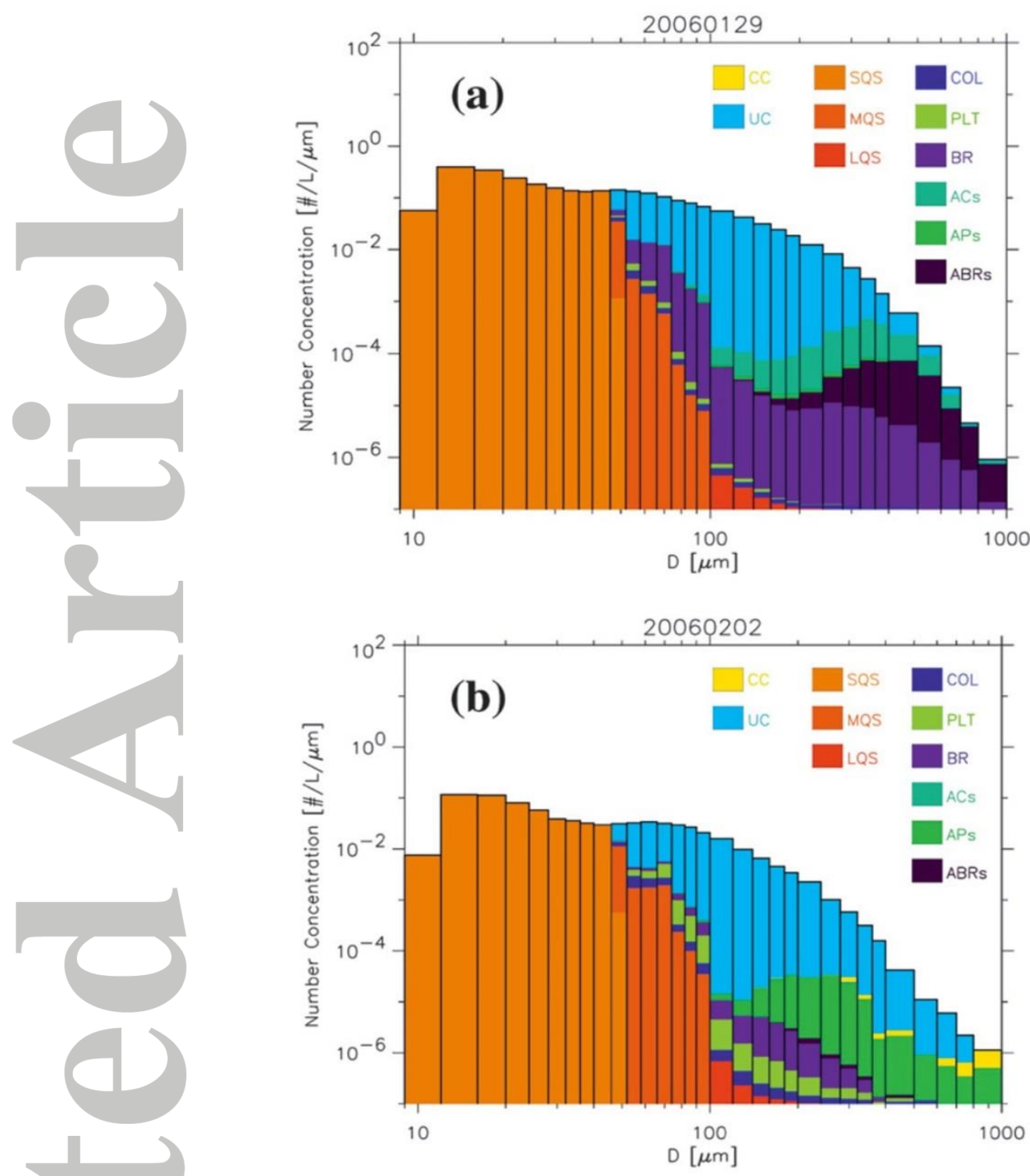

Figure 13. Histograms of particle habits sampled in TWP-ICE and classified using automatic software described in Um and McFarquhar (2009). Panel (a) shows results from aged anvil cirrus. Panel (b) shows results from fresh anvil cirrus. The acronyms of crystal habits are: SQS, MQS, and LQS: small, medium, and large quasi spheres, respectively; COL: columns; PLT: plates; BR: bullet rosettes; AC: aggregates of columns; AP: aggregates of plates; ABR: aggregates of bullet rosettes; CC: capped columns; and UC: unclassified particles. From Protat et al. (2011). 


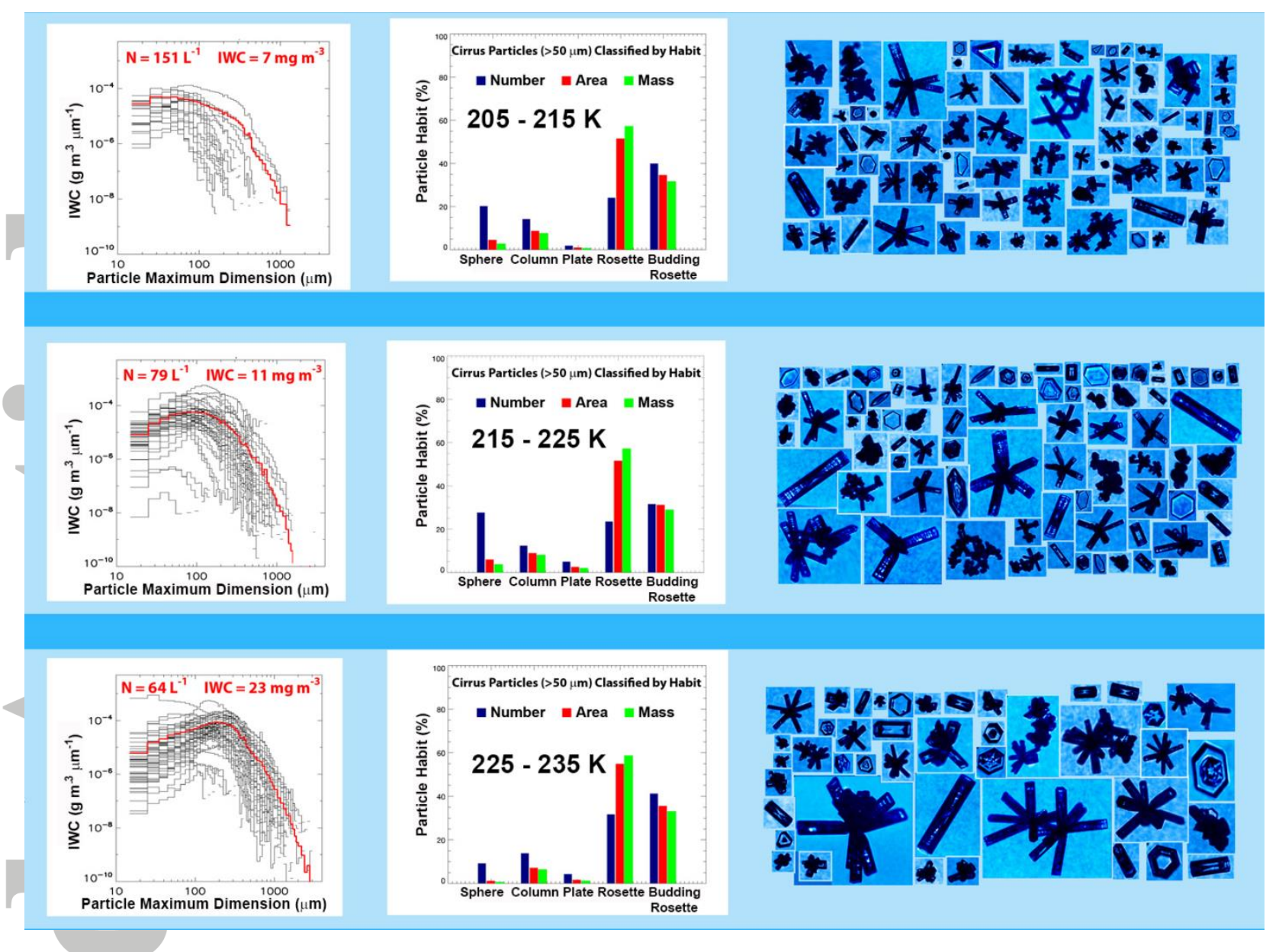

Figure 14. The left set of panels shows a vertical profile of mass size distributions and IWC based on the 2D-S probe from several transects of in situ cirrus clouds during the SPARITCUS project. The red trace in each of the panels shows the mean size distribution at that temperature and mean value of particle concentration $(\mathrm{N})$ and IWC. The middle set of panels shows a vertical profile of particles $>50 \mu \mathrm{m}$ classified by habit. The right set of panels shows representative examples of CPI images within each temperature range. From Lance et

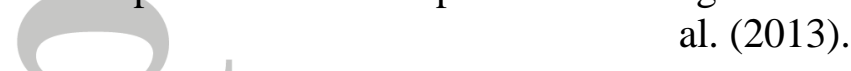




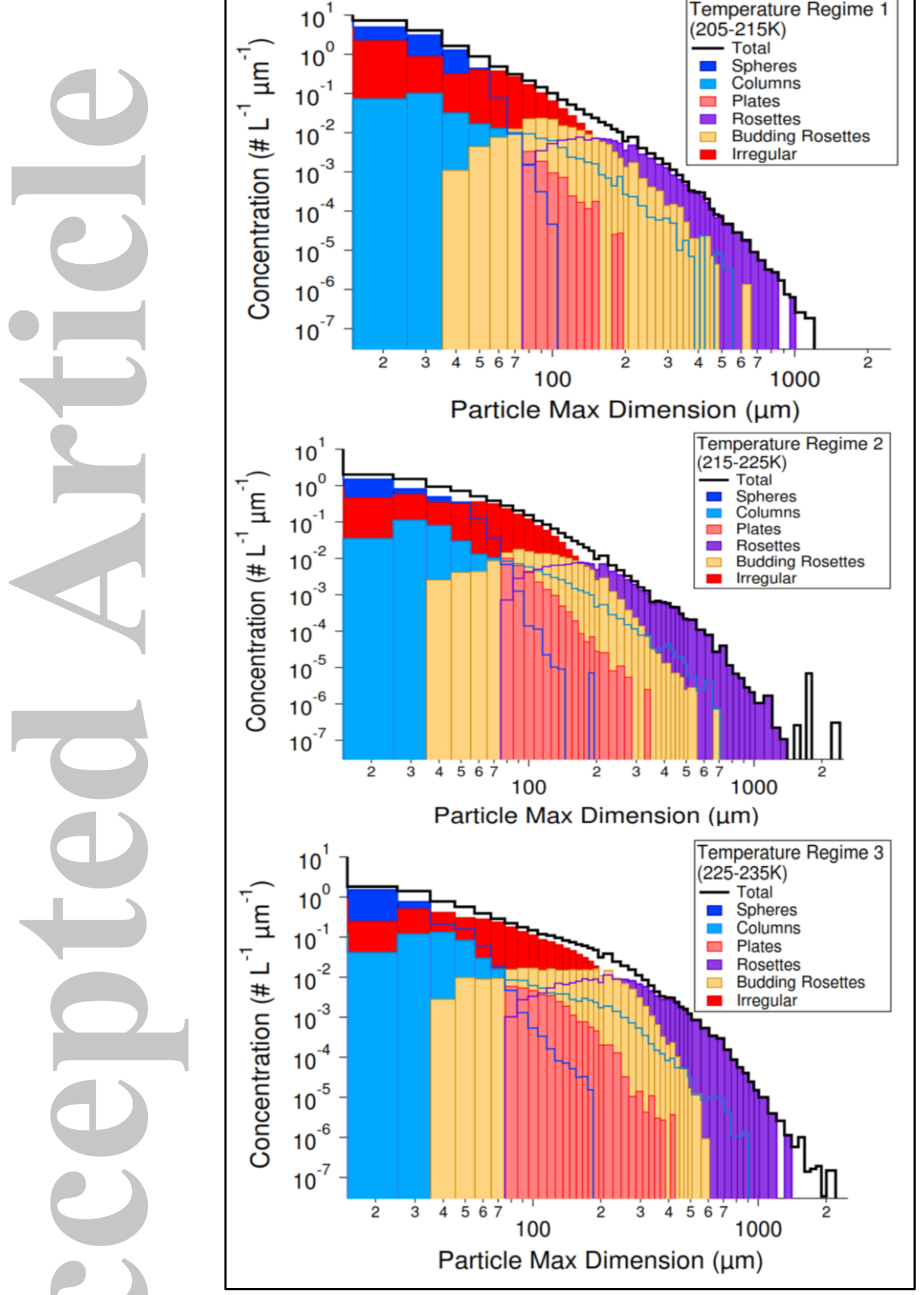

Figure 15. Particle size distributions using SPARTICUS data and classified by habit for the three temperature regimes in Figure 14. From Lance et al. (2013). 


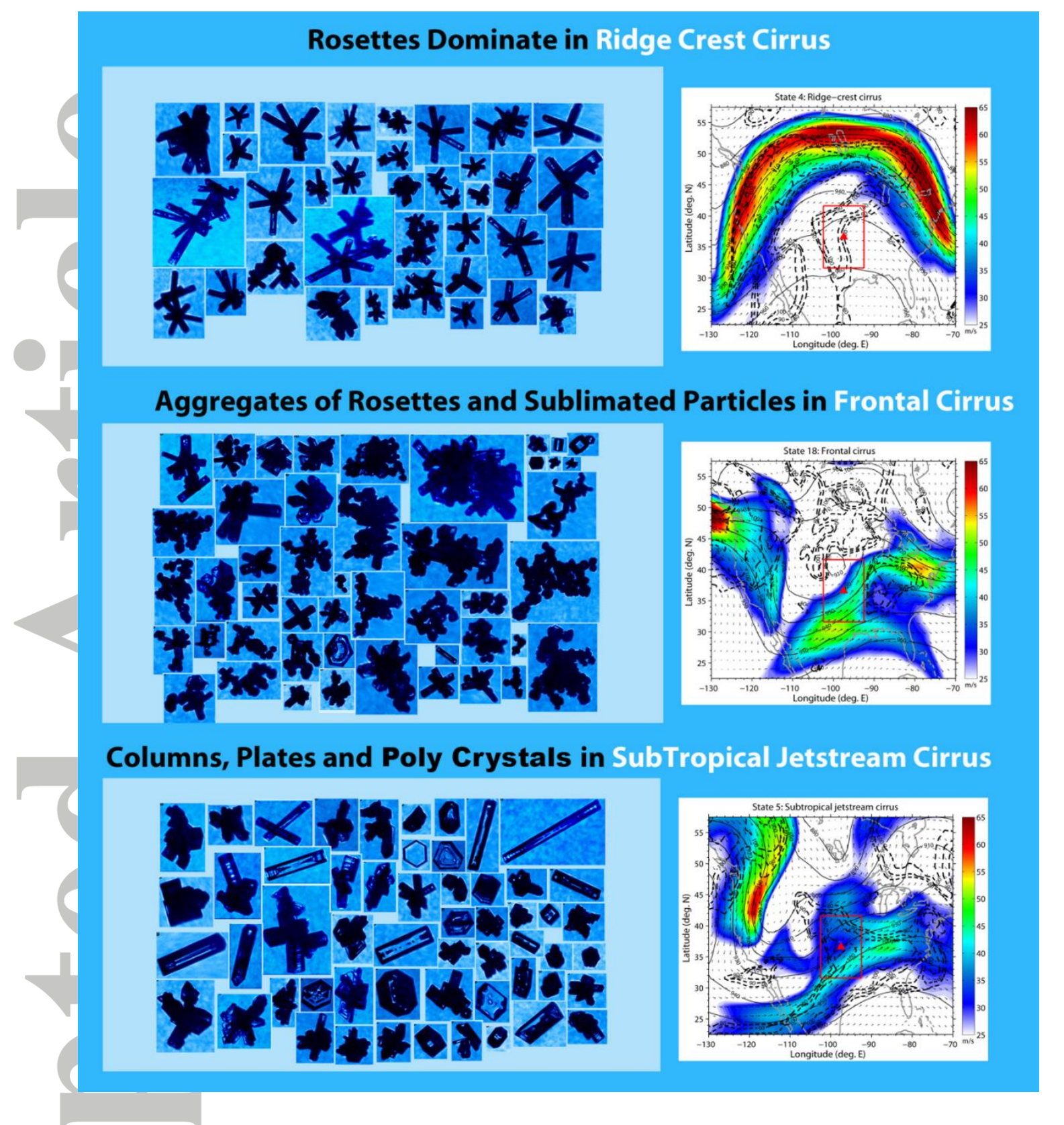

Figure 16. (right panels) Three synoptic states (Ridge Cirrus, Frontal Cirrus and SubTropical Jetstream Cirrus) classified using clustering techniques (adapted from Muhlbauer et al., 2014). The ARM SGP site is highlighted with a red triangle and the red boxes denote the region used for subsetting and analyzing the aircraft data. (left panels) Representative CPI images for each state (from Lance et al., 2013). 


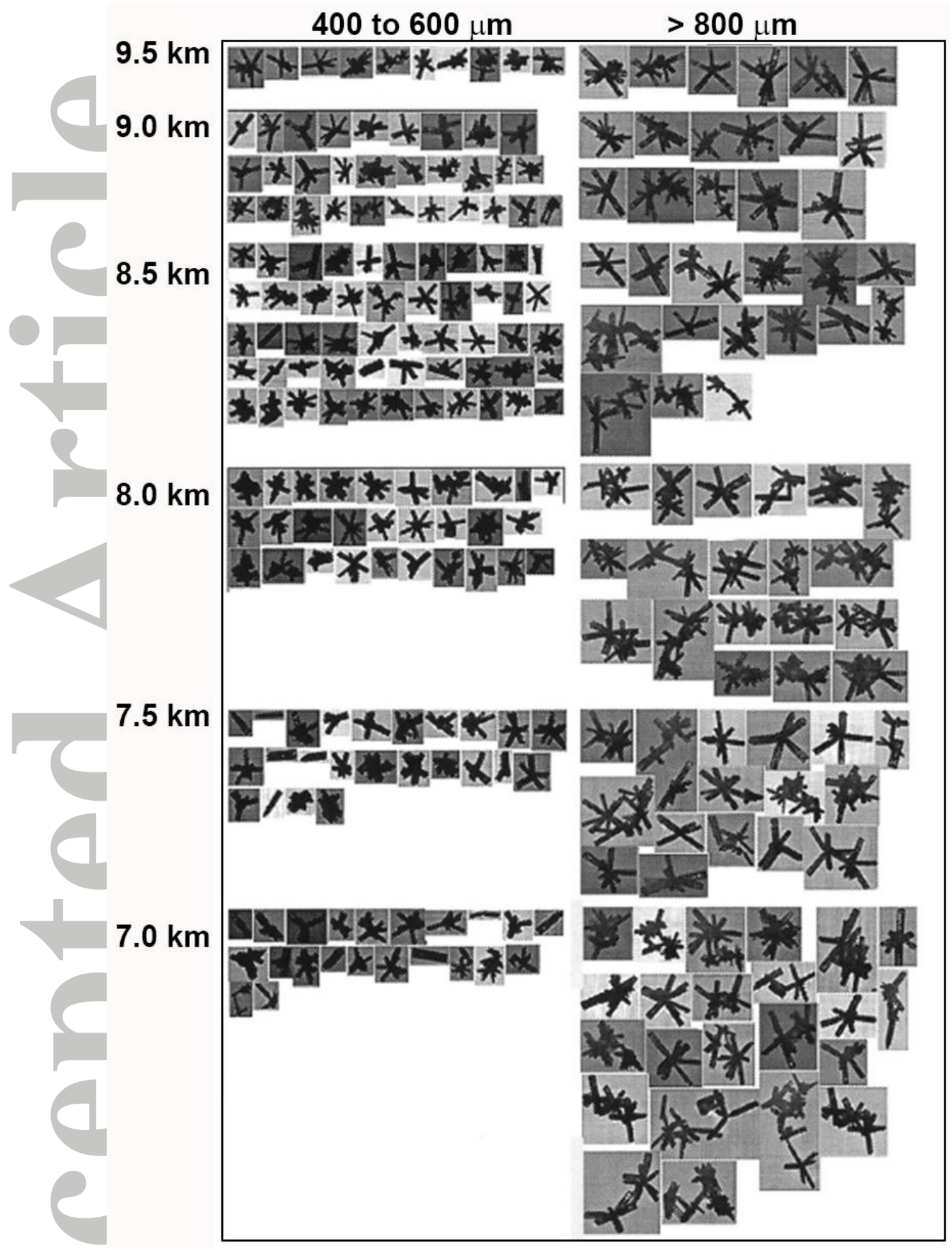

Figure 17. Example of CPI images collected during a Lagrangian spiral descent on 9 Mar 2000 from.$-50 \mathrm{C}$ to $-26{ }^{\circ} \mathrm{C}$ over the ARM site in Oklahoma. Particles are grouped into two size ranges. Adapted from Heymsfield et al. (2002). 

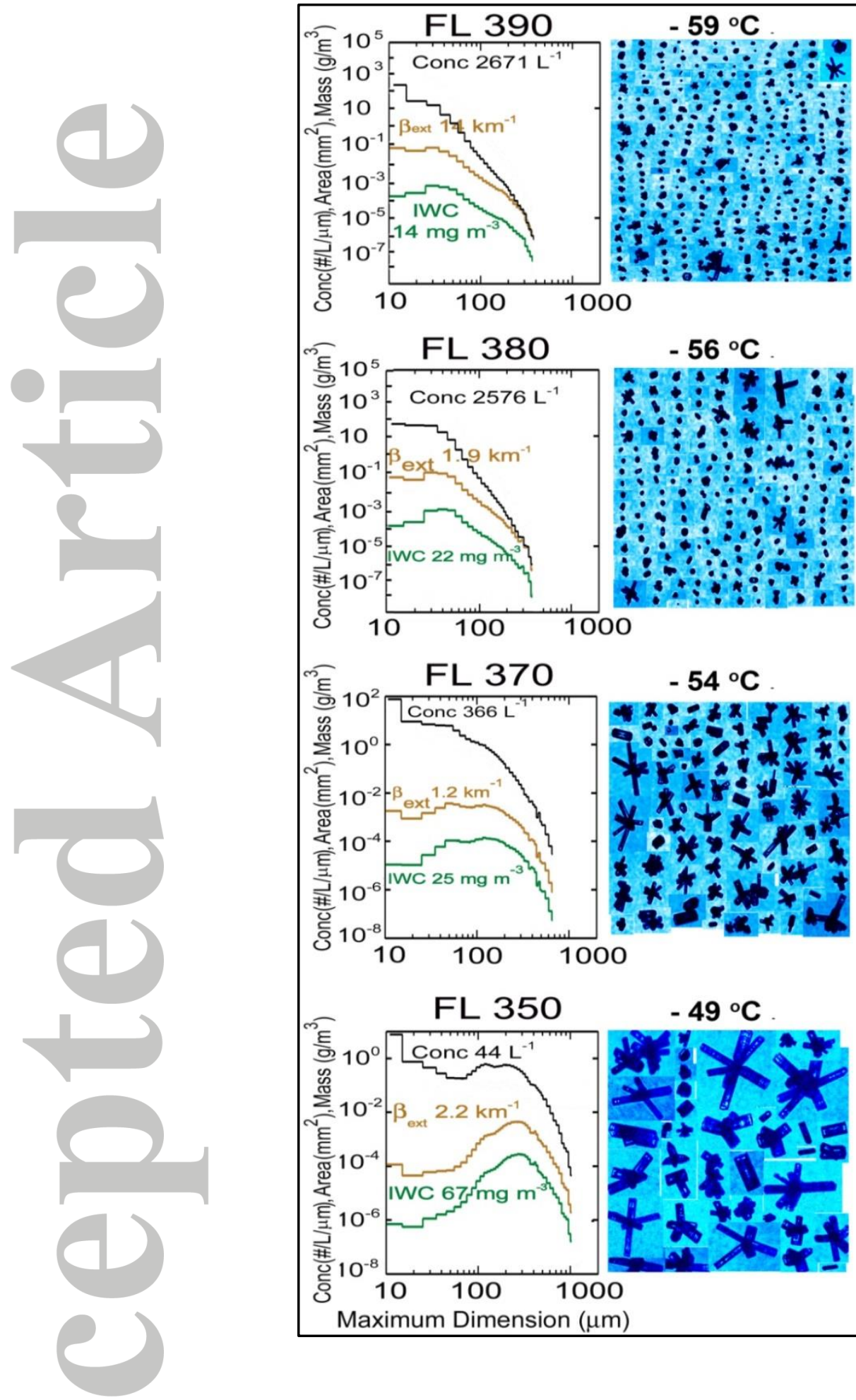

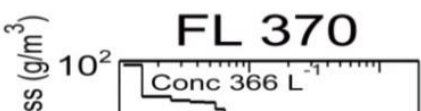

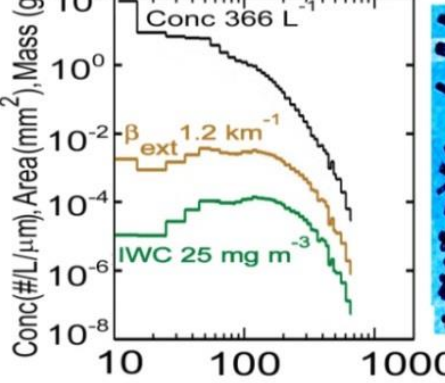

$-54^{\circ} \mathrm{C}$
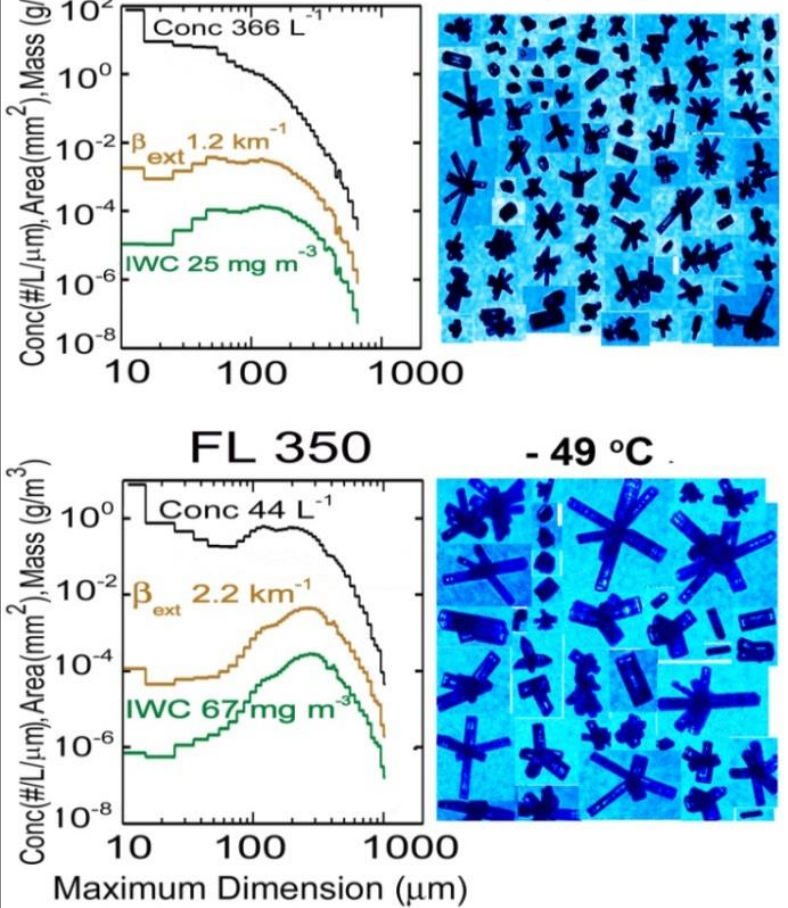

Figure 18. (left panels) 2D-S measurements of a vertical profile of particle size distributions as a function of number, area and mass, and (right panels) representative CPI images of orographic cirrus sampled by the SPEC Learjet on 10 February 2010 during SPARTICUS.

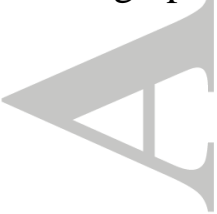



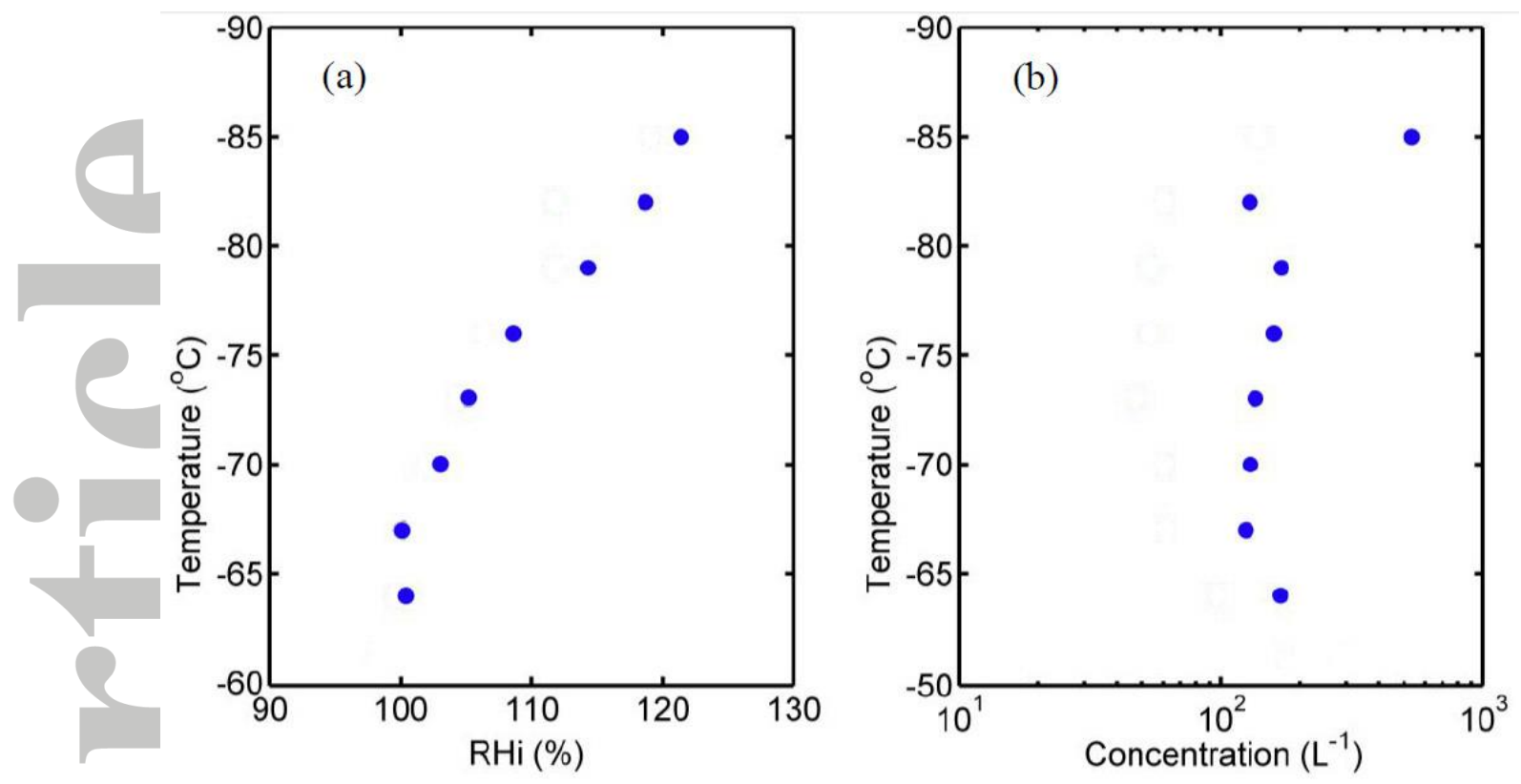

Figure 19. Mean values of (a) $\mathrm{RH}_{\text {ice }}$ and (b) total particle concentration measured by the Global Hawk during ATTREX (adapted from Woods et al., 2018).

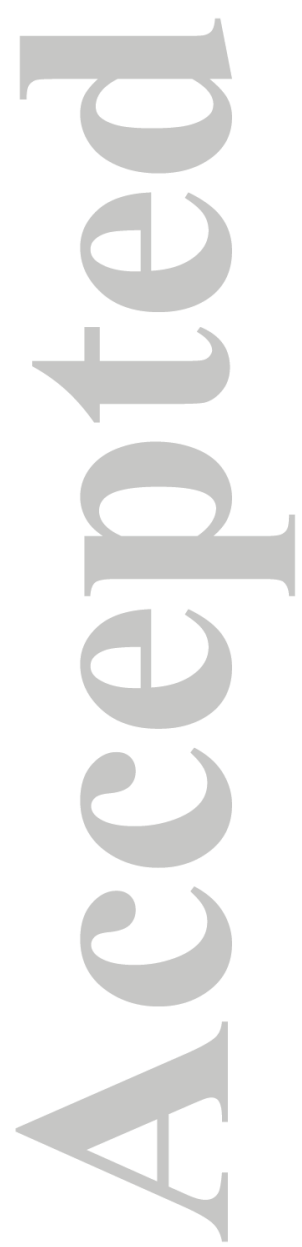




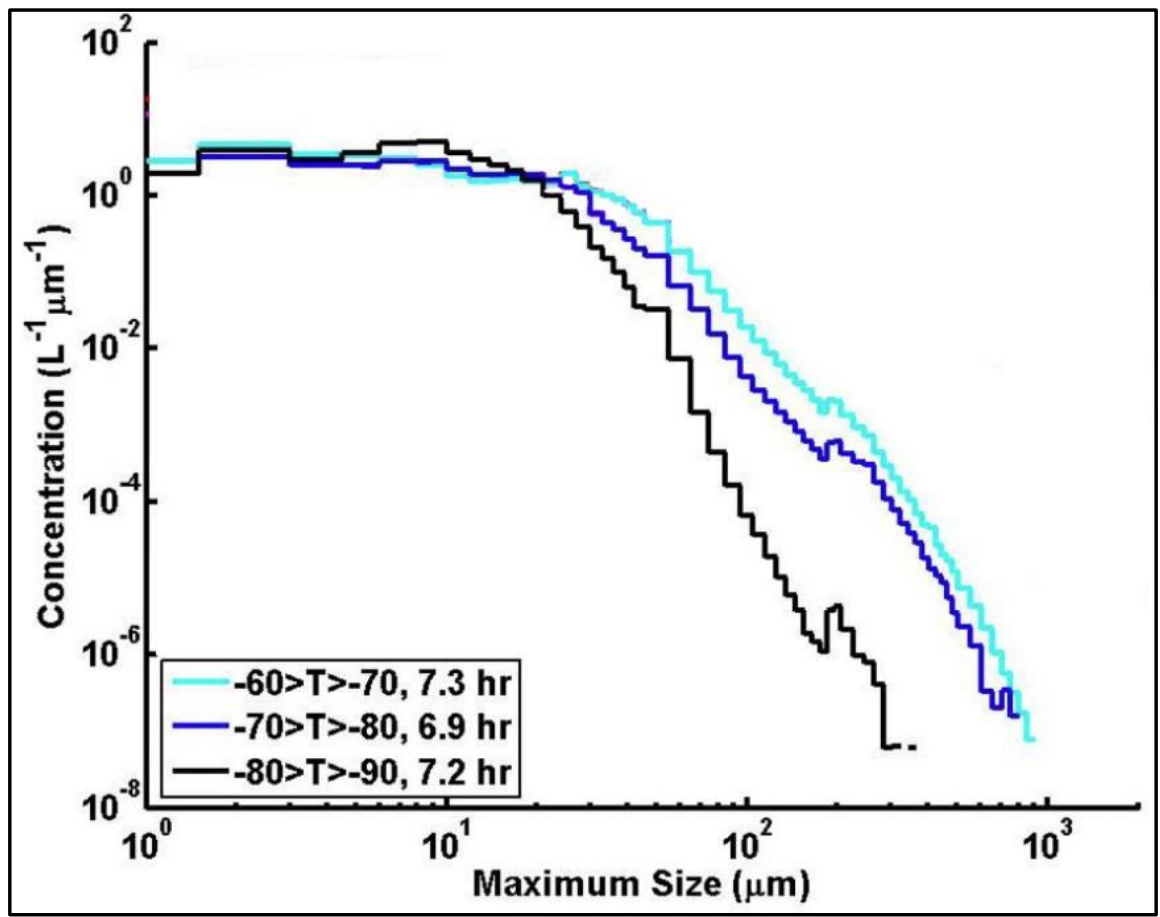

Figure 20. Mean values of particle size distributions measured by the Global Hawk within three temperature ranges during ATTREX (adapted from Woods et al., 2018). The length of the sampling period is shown in hours next to each temperature range. 


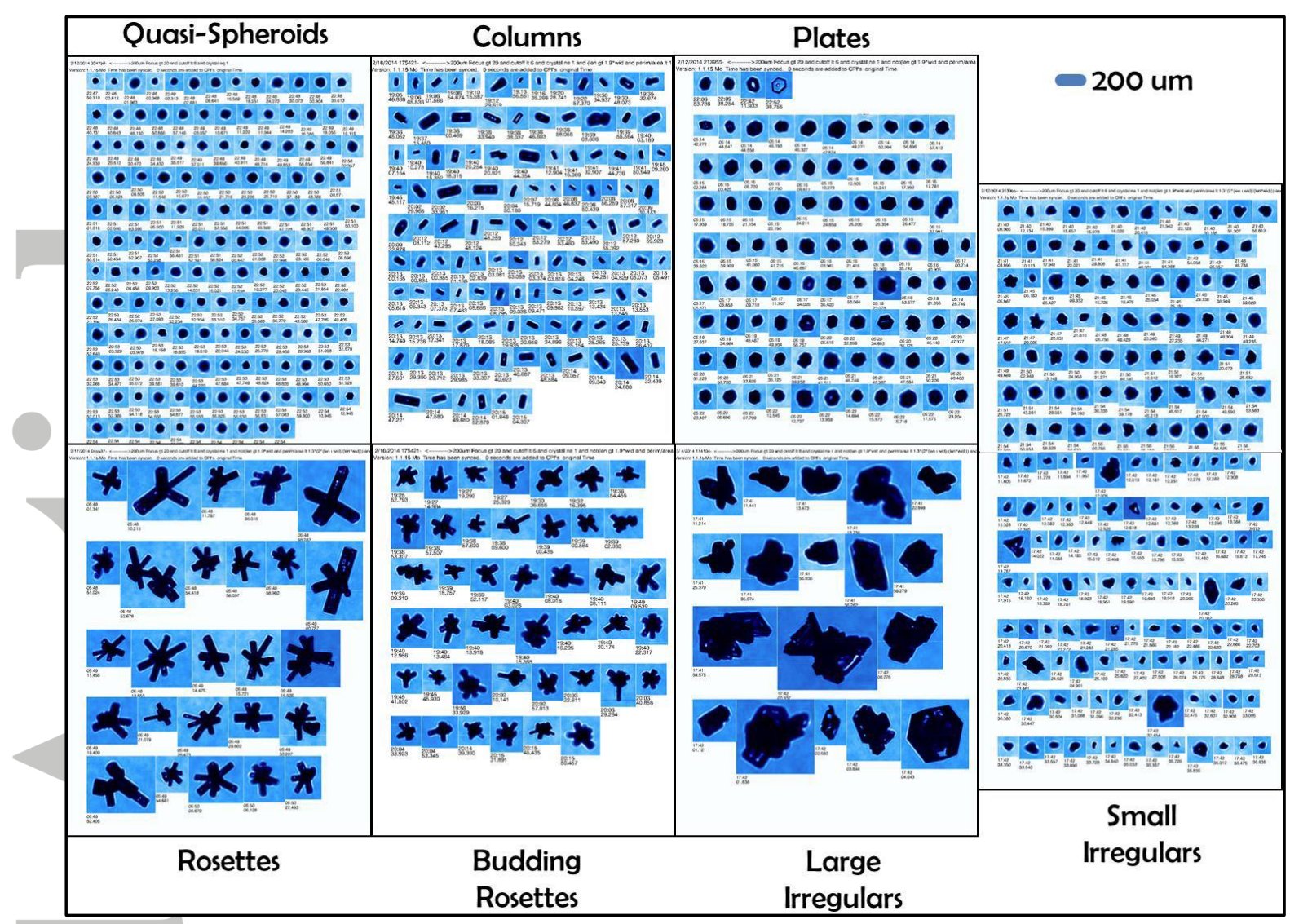

Figure 21. Examples of CPI images sampled in TTL cirrus during the ATTREX project and classified using an automated software program (from Woods et al., 2018).

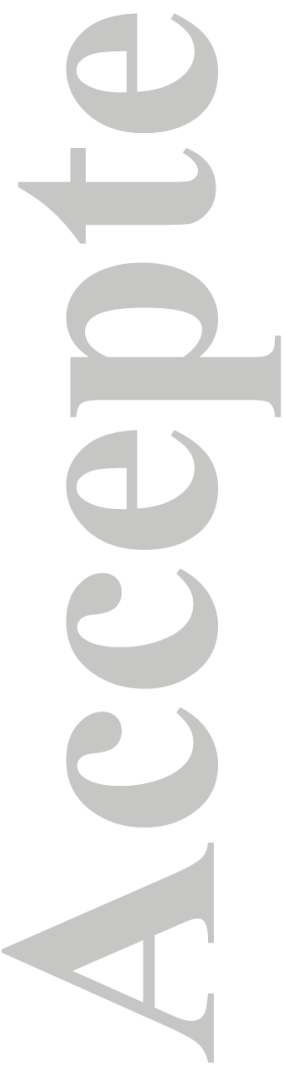

(C) 2019 American Geophysical Union. All rights reserved. 


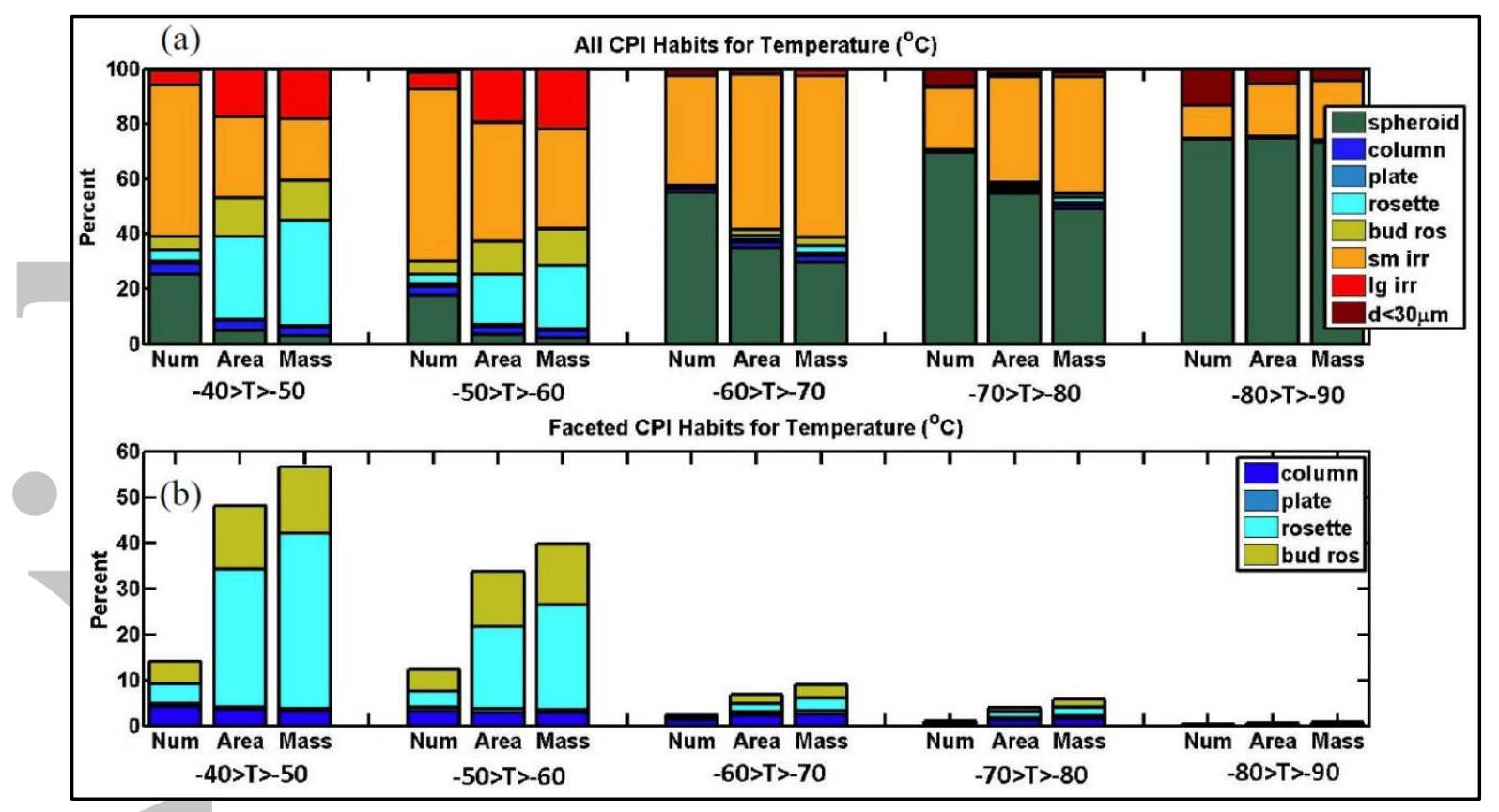

Figure 22. CPI images from the ATTREX project as a function of temperature that are sorted by habit for (a) all images, and (b) only images that are considered to be faceted, which includes rosettes and budding rosettes (from Woods et al., 2018).

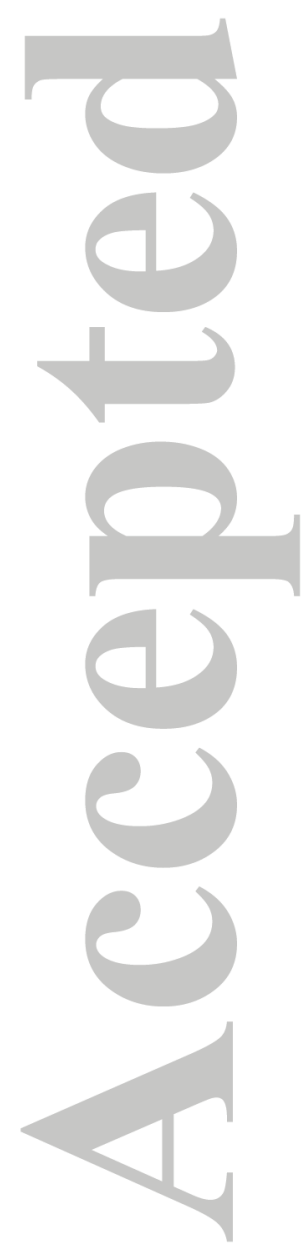



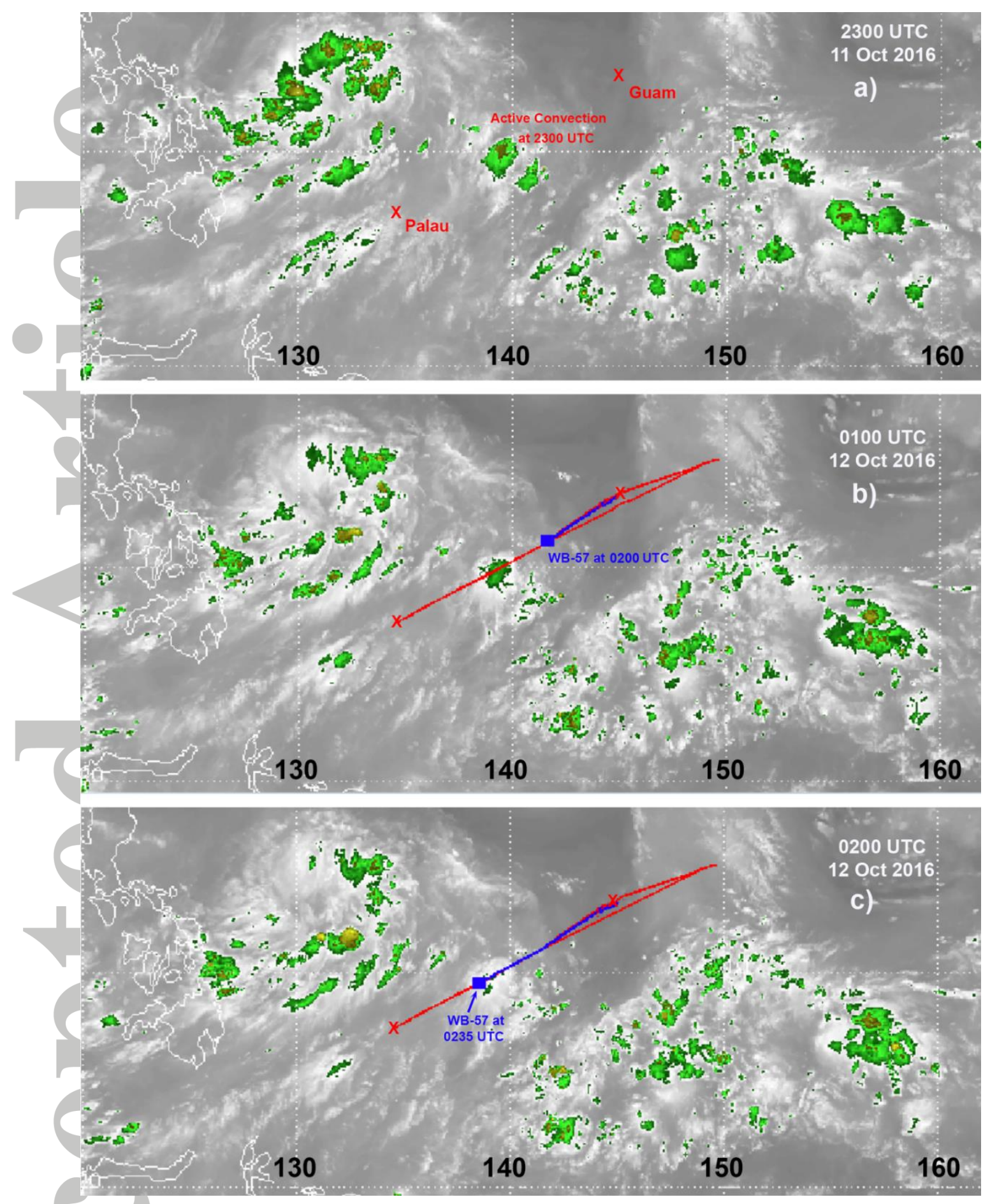

Figure 23. Himawari 8 satellite water vapor imagery of a storm on 11 - 12 October 2016. Image at 2300 shows overshooting top. Images at 0100 and 0200 UTC show aged anvil cirrus that the WB-57 penetrated from 0220 - 0245 UTC. Red flight track shows the outbound and return track to Guam. Blue track shows portions of the track

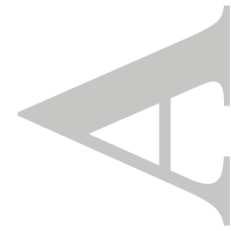
during the satellite observations. 

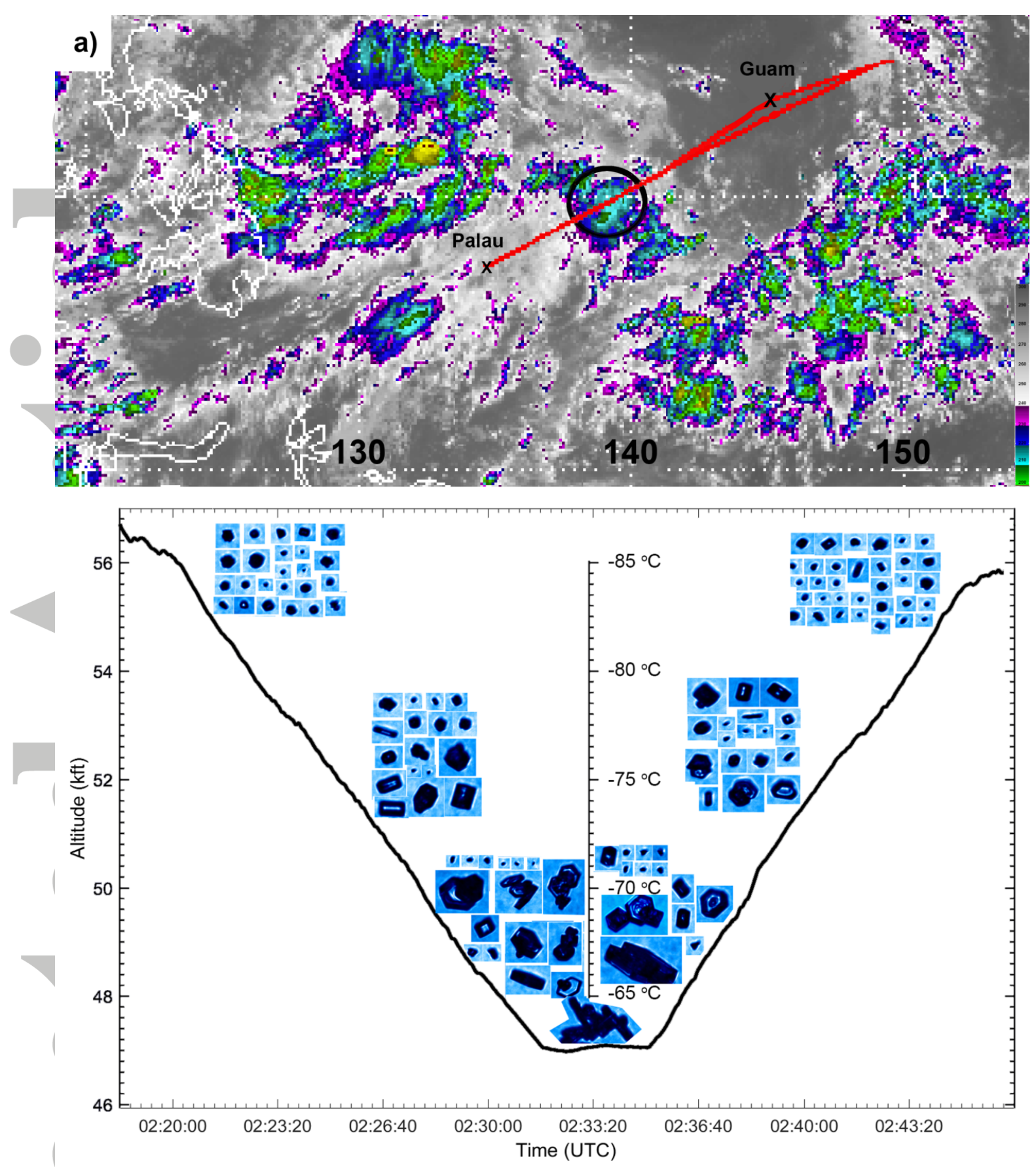

Figure 24. a) Himawari 8 satellite infrared imagery at 0200 UTC and the flight track of the WB-57 from Guam to Palau, and return to Guam. b) Time series of altitude and temperature as the WB-57 descended and then climbed back through the anvil, which is the circled region

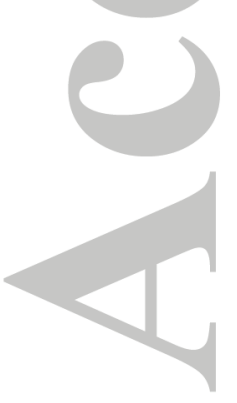
in Fig. 24a. 


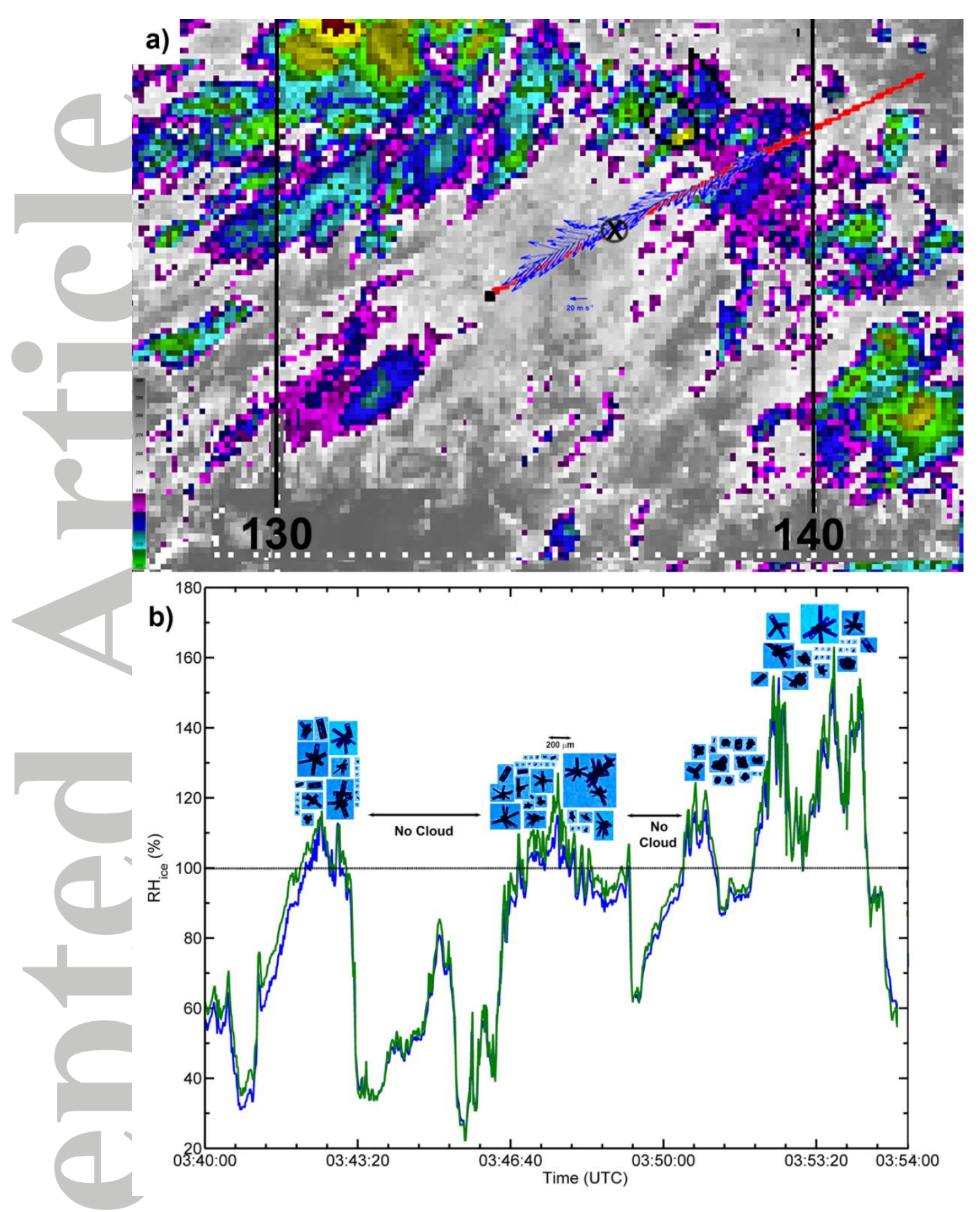

Figure 25. a) Himawari 8 infrared satellite image at 0400 UTC showing the region of cloud along the track where a circled X indicates the region where CPI images of rosettes were sampled from 0340 to 0354 UTC. Wind barbs show mean wind along the flight path. b) Time series of RHice computed from NOAA (Thornberry et al., 2015) (blue trace) and NASA diode laser hygrometer (DLH) (Diskin et al. 2002) (green trace) water vapor instruments, and examples

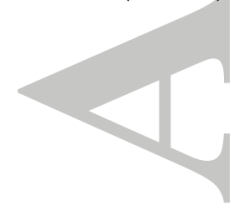
of CPI images. 

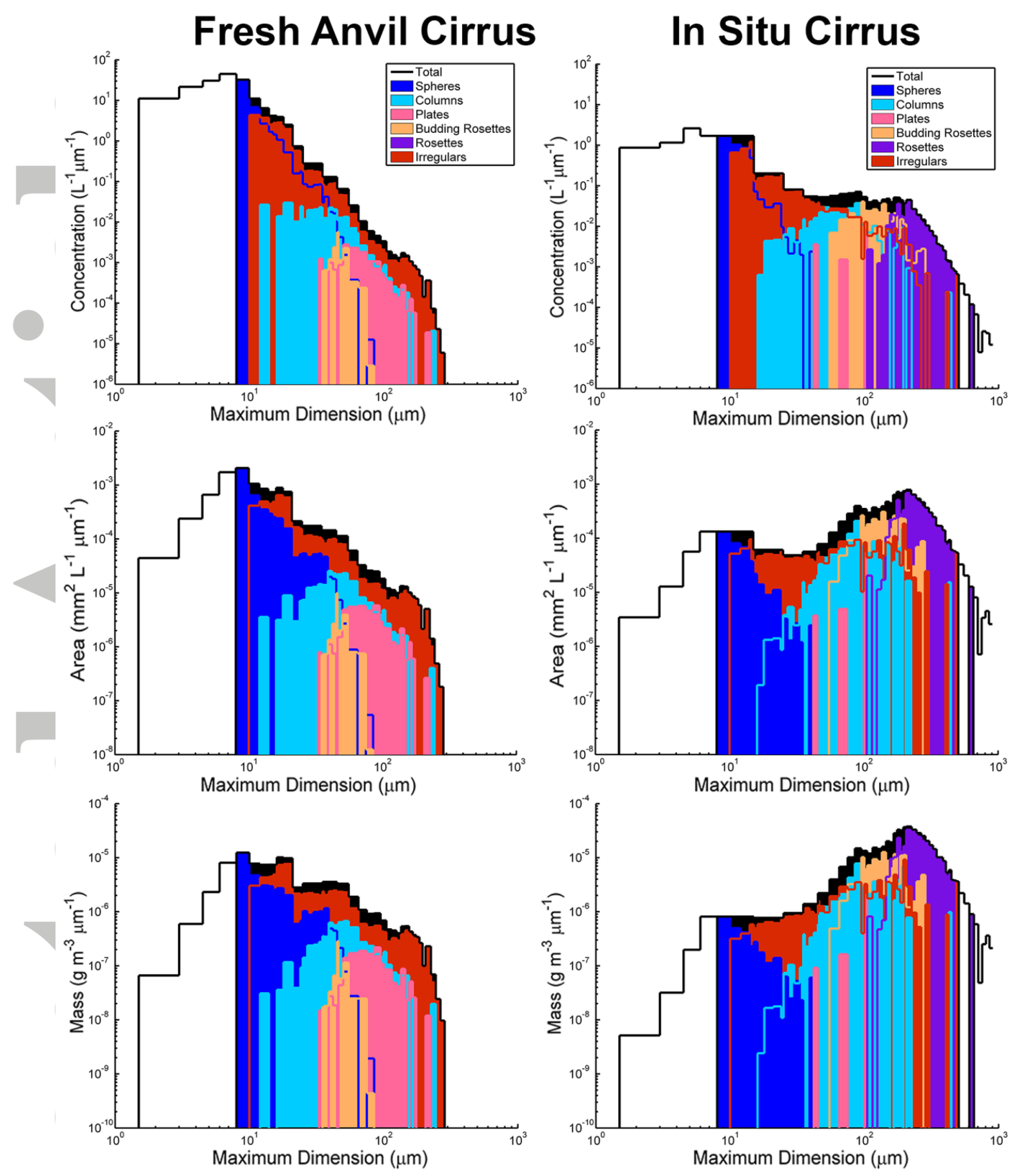

Figure 26. Comparison of CPI derived ice crystal habit PSDs as a function of concentration, area and mass for (left) fresh anvil from the anvil descent/ascent in Fig. 24, and (right) in situ cirrus from the level flight through in situ cirrus (Fig. 25). Size distributions derived from FCDP $(1$ to $10 \mu \mathrm{m})$ and 2D-S (10 to $1000 \mu \mathrm{m})$. 

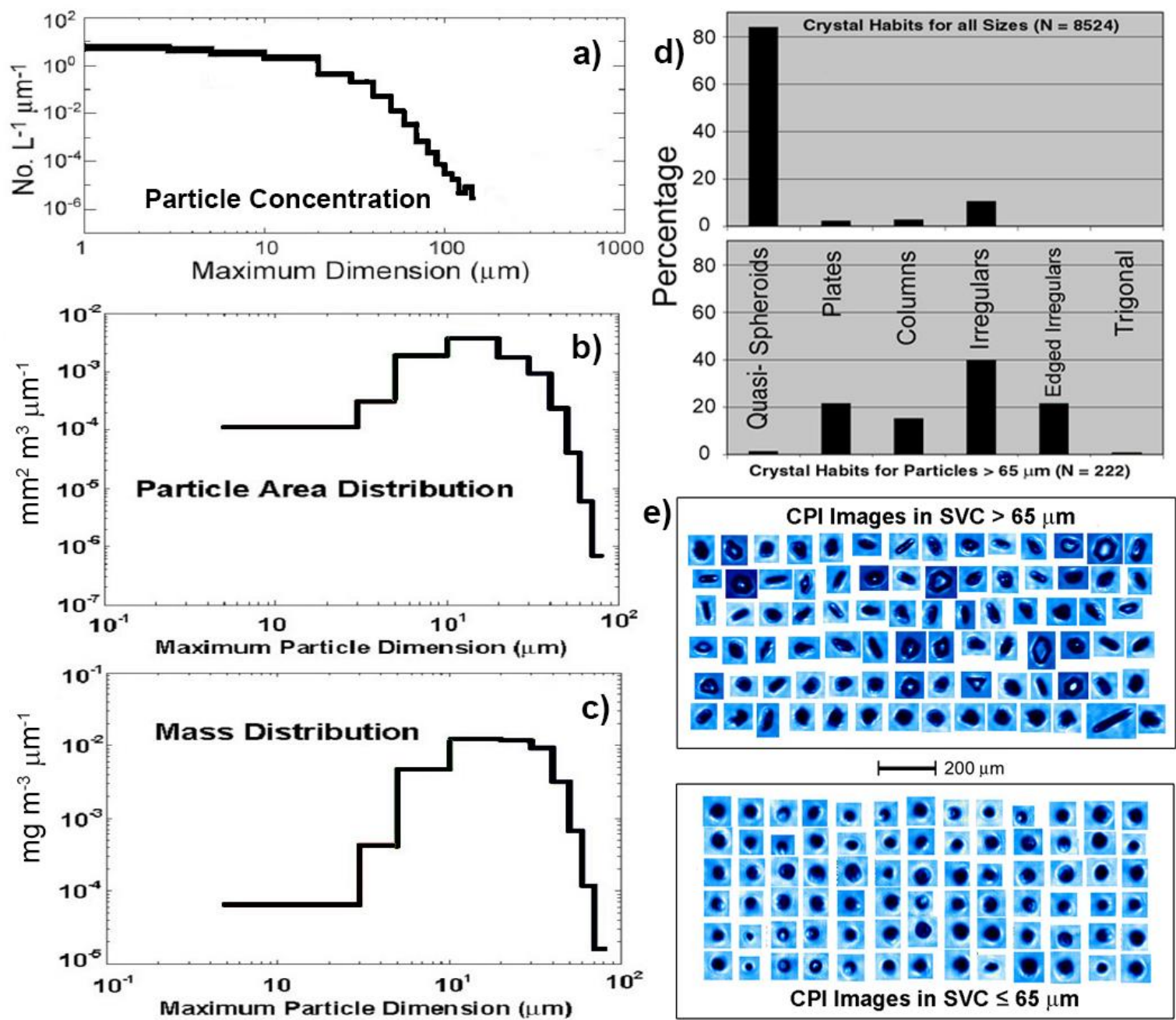

e)

CPI Images in SVC > $65 \mu \mathrm{m}$

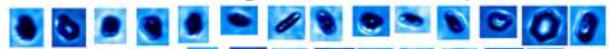

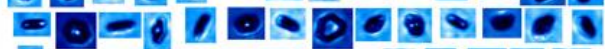

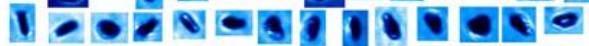

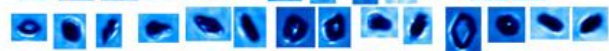

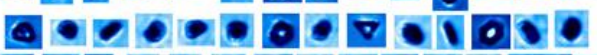

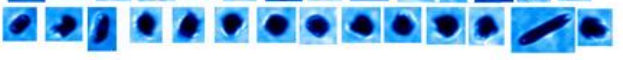

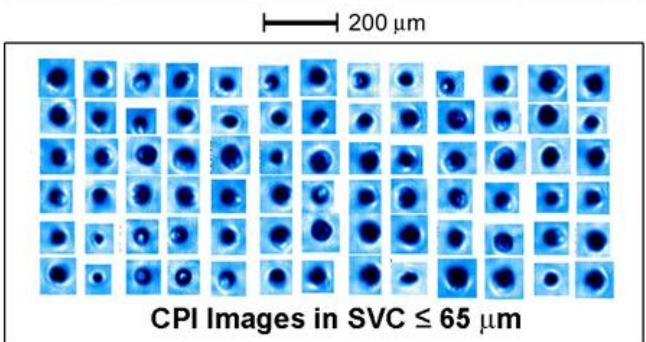

Figure 27. Measurements in SVC showing size distributions of particle a) concentration, b) area, c) mass; d) classification of particle shapes and e) examples of SVC images less than and greater than $65 \mu \mathrm{m}$ (from Lawson et al., 2008). 

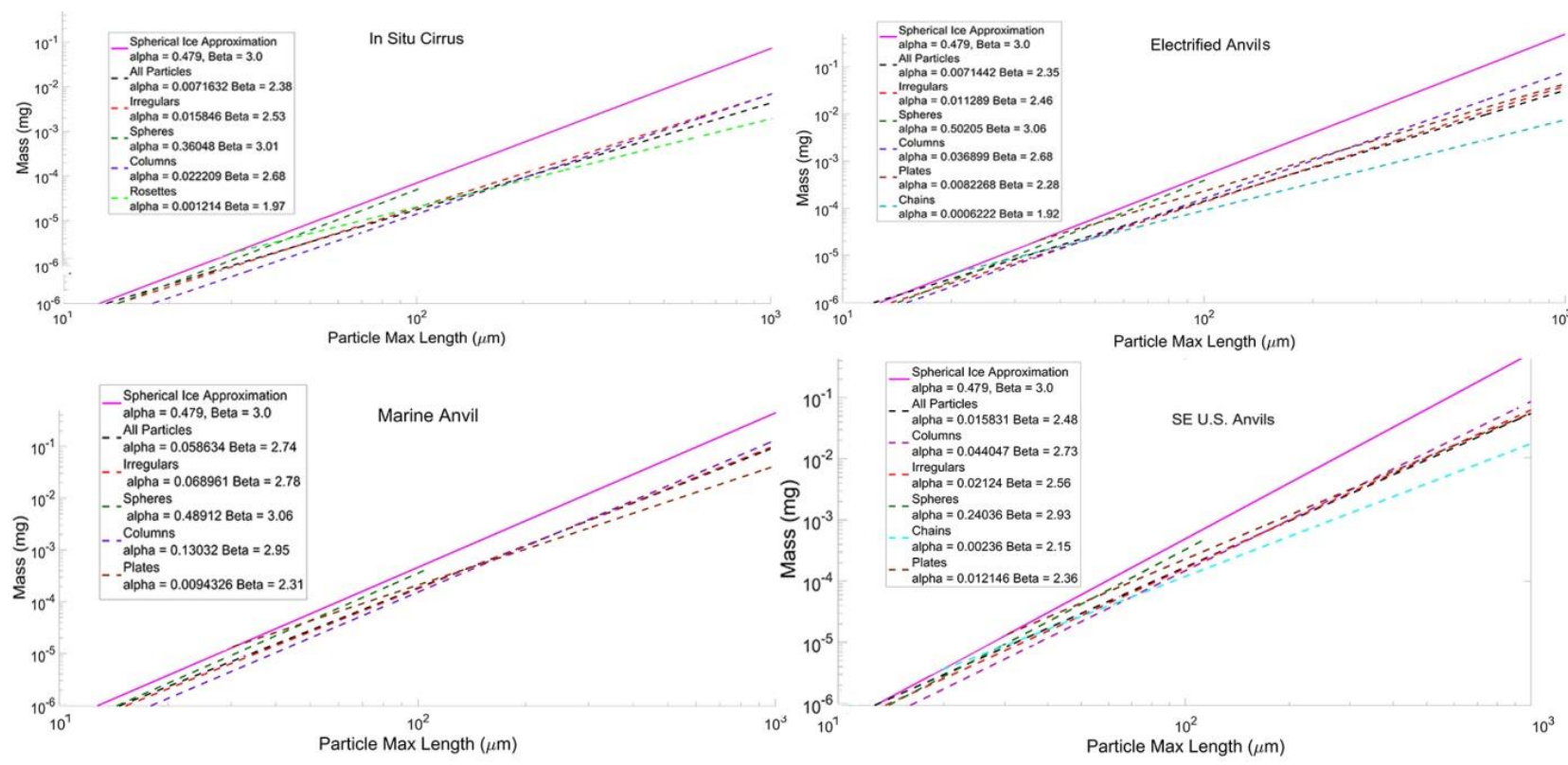

Figure 28. Plots of $m$ versus $d$ for cloud types shown where individual curves represent best fits to CPI particle habits listed in the legend, except for the In Situ Cirrus "All Particles" curve, which also includes 2D-S images $>500 \mu \mathrm{m}$. Units for best-fit equation $m=\alpha d^{\beta}$ are $m(\mathrm{~g})$ and $d(\mathrm{~cm})$. The solid magenta line is for an ice sphere with diameter $d$ and density $0.917 \mathrm{~g} \mathrm{~cm}^{-1}$. The mass of each ice particle is computed from $A$ to $m$ in Baker and Lawson (2006) for $d>50 \mu \mathrm{m}$ and Erfani and Mitchell (2016) Eqn. B8 for $d \leq 50 \mu \mathrm{m}$. 

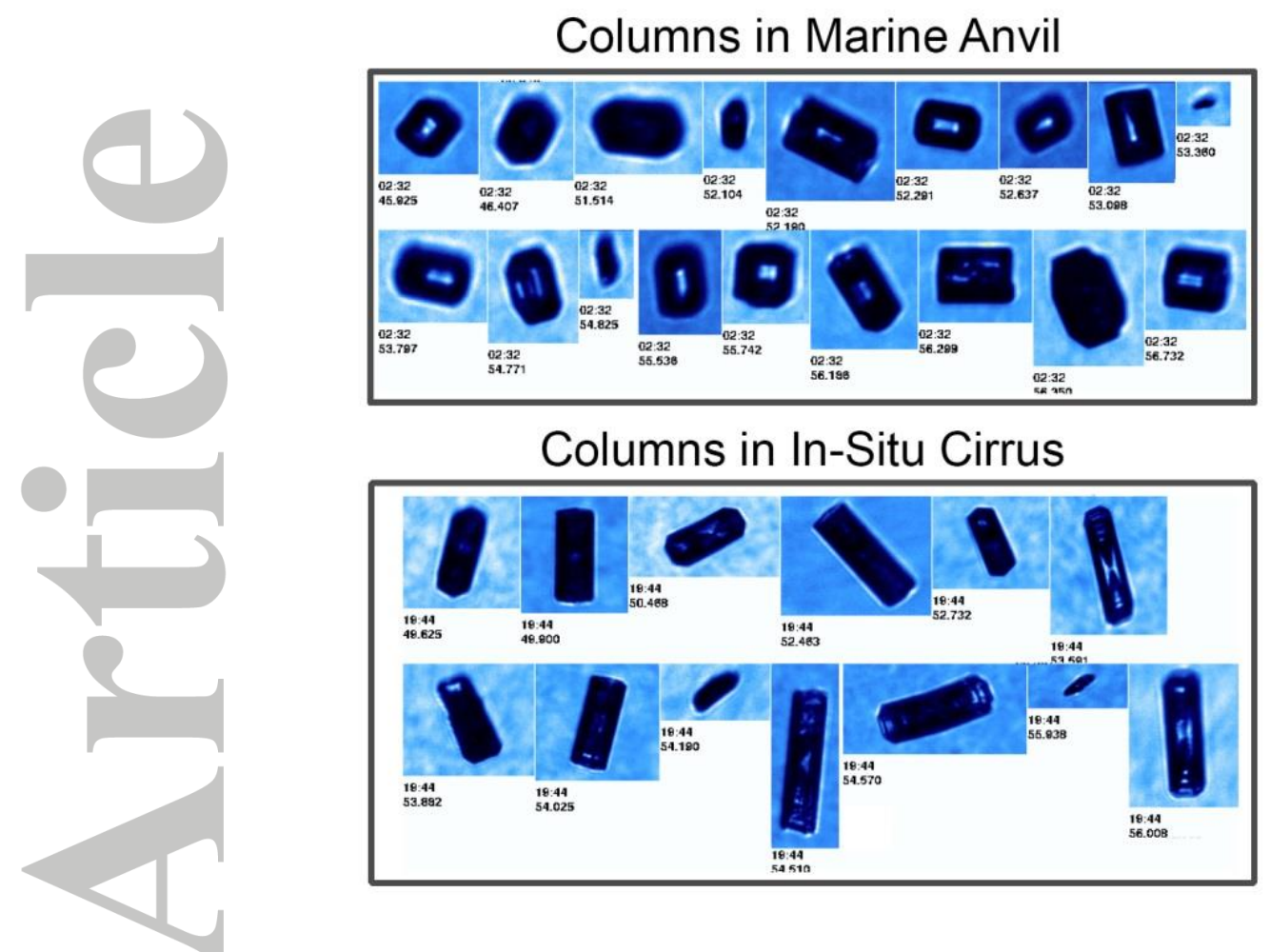

Columns in In-Situ Cirrus

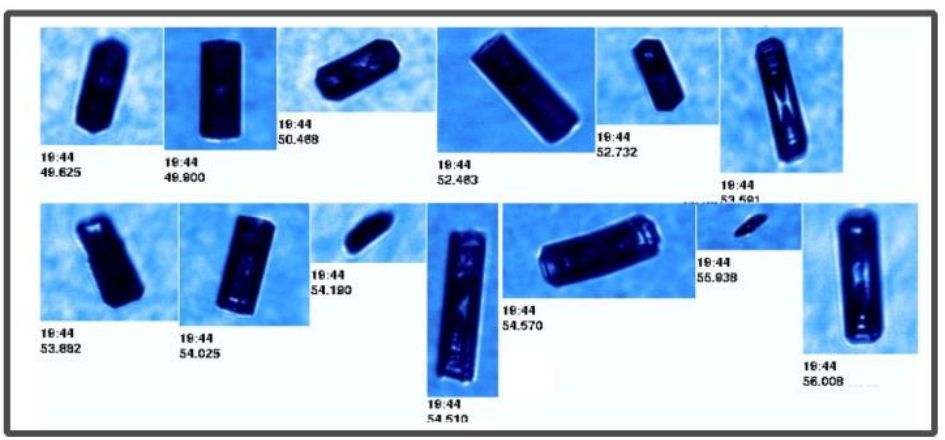

Figure 29. Examples of CPI images of Columns in a Marine Anvil and in situ cirrus.

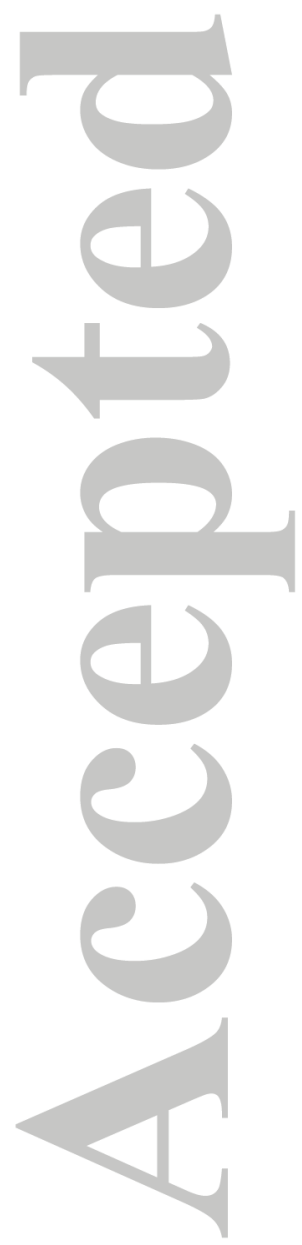




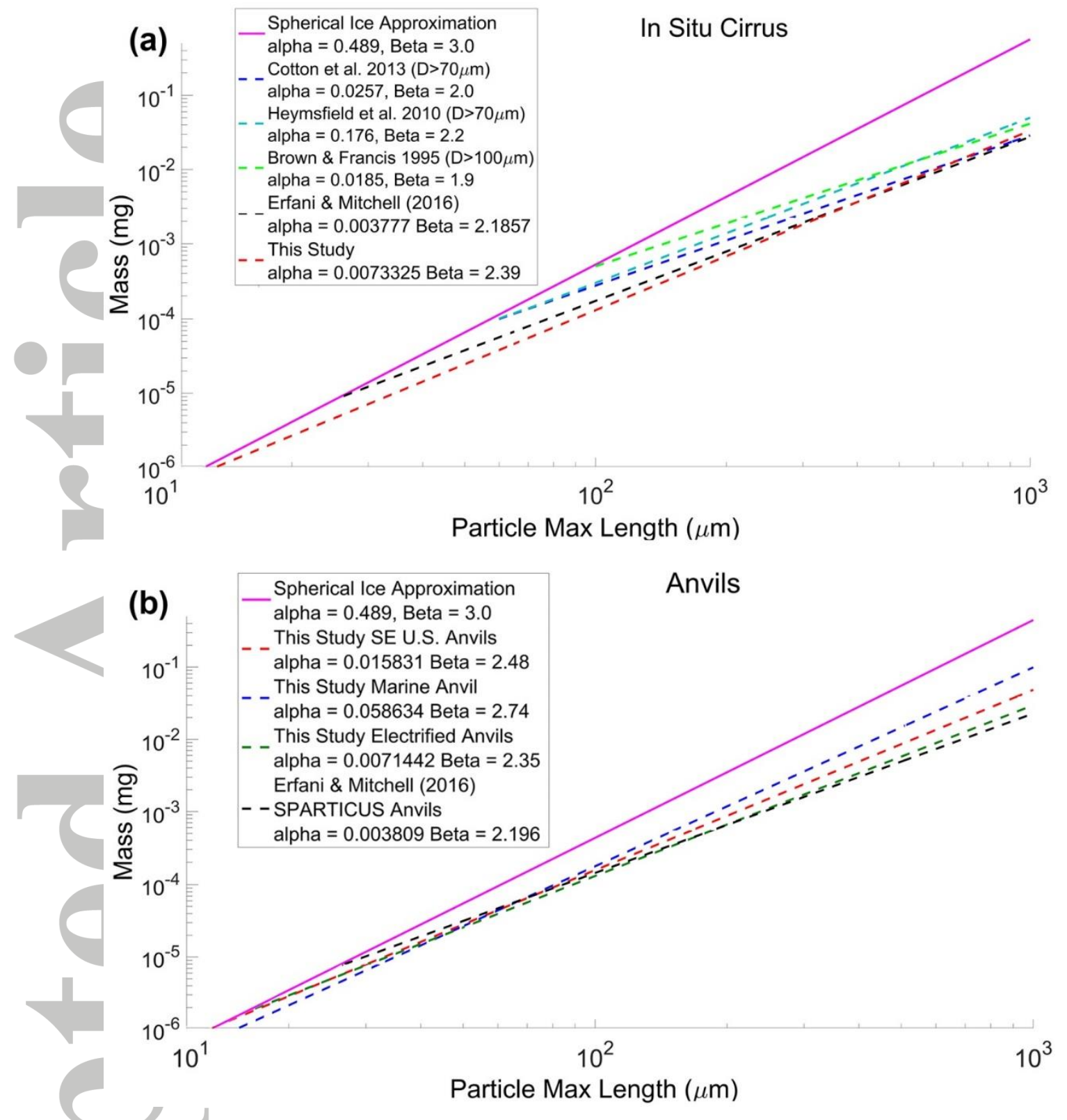

Figure 30. (a) Power-law plots of $m$ versus $d$ for various studies. Units for best-fit equations are $m(\mathrm{~kg})$ and $d(\mathrm{~m})$ from Cotton et al., (2013). Cotton et al., (2013), EM16 and This Study are designated as in situ cirrus. Heymsfield et al., (2010) study is a mixture of in situ and convectively generated cirrus. Brown and Francis (1995) is based on microphotographs of falling ice particles at the surface and equivalent melted drops. All of the lines are truncated where they intersect the value for spherical ice. (b) As in (a) except for Anvils from This Study and SPARTCUS anvils from EM16. 
Table 1. Percentages of CPI particle habits shown for Number, Area and Mass in cirrus formed in situ and three types of anvil cirrus.

\begin{tabular}{|c|c|c|c|c|c|c|c|c|c|c|c|c|}
\hline \multicolumn{13}{|c|}{ NUMBER } \\
\hline Cloud Type & \multicolumn{3}{|c|}{ In Situ Cirrus } & \multicolumn{3}{|c|}{ Marine Anvil } & \multicolumn{3}{|c|}{ SE U.S., Slightly Electrified Anvil } & \multicolumn{3}{|c|}{ Highly Electrified Anvil } \\
\hline Habit & Number & $\%$ by \# & $\begin{array}{l}\text { \% \# excl. } \\
\text { sph\&irr }\end{array}$ & Number & $\%$ by \# & $\begin{array}{l}\text { \% \# excl. } \\
\text { sph\&irr }\end{array}$ & Number & $\%$ by \# & $\begin{array}{l}\text { \% \# excl } \\
\text { sph\&irr }\end{array}$ & Number & $\%$ by \# & $\begin{array}{l}\text { \% \# excl. } \\
\text { sph\&irr }\end{array}$ \\
\hline spheroids & 2114 & 9.78 & & 2451 & 24.15 & & 2037 & 24.73 & & 12674 & 38.20 & \\
\hline columns & 1689 & 7.82 & 23.44 & 668 & 6.58 & 65.30 & 454 & 5.51 & 52.49 & 39 & 0.12 & 3.36 \\
\hline plates & 79 & 0.37 & 1.10 & 283 & 2.79 & 27.66 & 322 & 3.91 & 37.23 & 8 & 0.02 & 0.69 \\
\hline budding rosettes & 2738 & 12.67 & 38.00 & 72 & 0.71 & 7.04 & 2 & 0.02 & 0.23 & 7 & 0.02 & 0.60 \\
\hline rosettes & 2700 & 12.50 & 37.47 & 0 & 0.00 & 0.00 & 0 & 0.00 & 0.00 & 0 & 0.00 & 0.00 \\
\hline irregulars & 12286 & 56.86 & & 6676 & 65.77 & & 5336 & 64.77 & & 19343 & 58.30 & \\
\hline Total & 21606 & 100.00 & 100.00 & 10150 & 100.00 & 100.00 & 8238 & 100.00 & 100.00 & 33176 & 100.00 & 100.00 \\
\hline
\end{tabular}

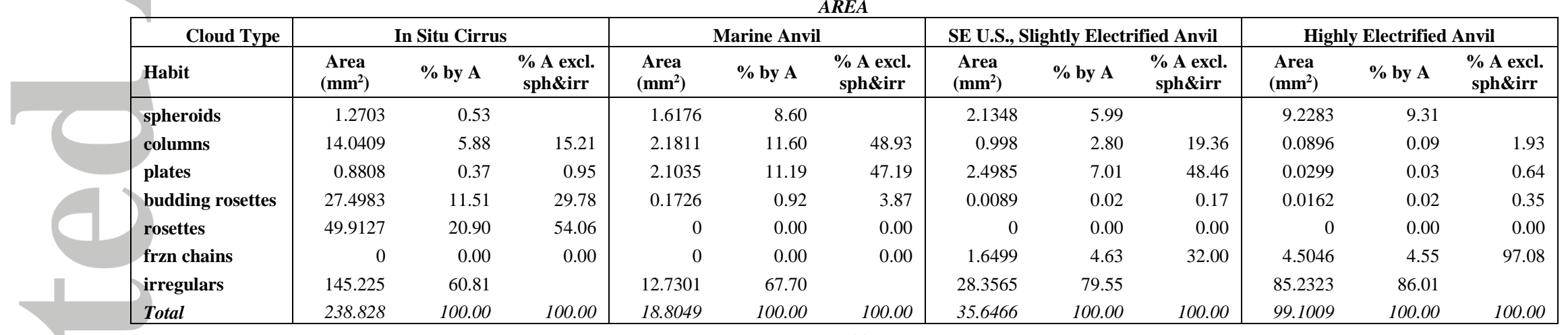

\begin{tabular}{|c|c|c|c|c|c|c|c|c|c|c|c|c|}
\hline \multicolumn{13}{|c|}{ MASS } \\
\hline Cloud Type & \multicolumn{3}{|c|}{ In Situ Cirrus } & \multicolumn{3}{|c|}{ Marine Anvil } & \multicolumn{3}{|c|}{ SE U.S., Slightly Electrified Anvil } & \multicolumn{3}{|c|}{ Highly Electrified Anvil } \\
\hline Habit & $\begin{array}{l}\text { Mass } \\
(\mathbf{m g})\end{array}$ & \% by M & $\begin{array}{c}\% \mathrm{M} \\
\text { excl. } \\
\text { sph\&irr }\end{array}$ & $\begin{array}{l}\text { Mass } \\
(\mathbf{m g})\end{array}$ & $\%$ by M & $\begin{array}{c}\% \text { M } \\
\text { excl. } \\
\text { sph\&irr }\end{array}$ & $\begin{array}{l}\text { Mass } \\
(\mathbf{m g})\end{array}$ & $\%$ by M & $\begin{array}{c}\% \mathrm{M} \\
\text { excl. } \\
\text { sph\&irr }\end{array}$ & $\begin{array}{l}\text { Mass } \\
(\mathbf{m g})\end{array}$ & $\%$ by M & $\begin{array}{c}\% \mathrm{M} \\
\text { excl. } \\
\text { sph\&irr }\end{array}$ \\
\hline spheroids & 0.0262 & 0.20 & & 0.0339 & 4.97 & & 0.0528 & 3.14 & & 0.1927 & 4.64 & \\
\hline columns & 0.7029 & 5.33 & 15.67 & 0.0781 & 11.45 & 45.89 & 0.0316 & 1.88 & 13.82 & 0.0029 & 0.07 & 1.63 \\
\hline plates & 0.0417 & 0.32 & 0.93 & 0.0867 & 12.71 & 50.94 & 0.1058 & 6.28 & 46.28 & 0.0011 & 0.03 & 0.62 \\
\hline budding rosettes & 1.2334 & 9.35 & 27.50 & 0.0054 & 0.79 & 3.17 & 0.0004 & 0.02 & 0.17 & 0.0005 & 0.01 & 0.28 \\
\hline rosettes & 2.5065 & 19.01 & 55.89 & 0 & 0.00 & 0.00 & 0 & 0.00 & 0.00 & 0 & 0.00 & 0.00 \\
\hline frzn chains & 0 & 0.00 & 0.00 & 0 & 0.00 & 0.00 & 0.0908 & 5.39 & 39.72 & 0.1735 & 4.18 & 97.47 \\
\hline irregulars & 8.6772 & 65.80 & & 0.478 & 70.08 & & 1.4026 & 83.29 & & 3.7794 & 91.07 & \\
\hline Total & 13.1879 & 100.00 & 100.00 & 0.6821 & 100.00 & 100.00 & 1.684 & 100.00 & 100.00 & 4.1501 & 100.00 & 100.00 \\
\hline
\end{tabular}

(c) 2019 American Geophysical Union. All rights reserved. 
Table 2. Values of $\alpha$ and $\beta$ in the equation for $m=\alpha d^{\beta}$ as a function of particle habits in cirrus cloud types discussed in the text.

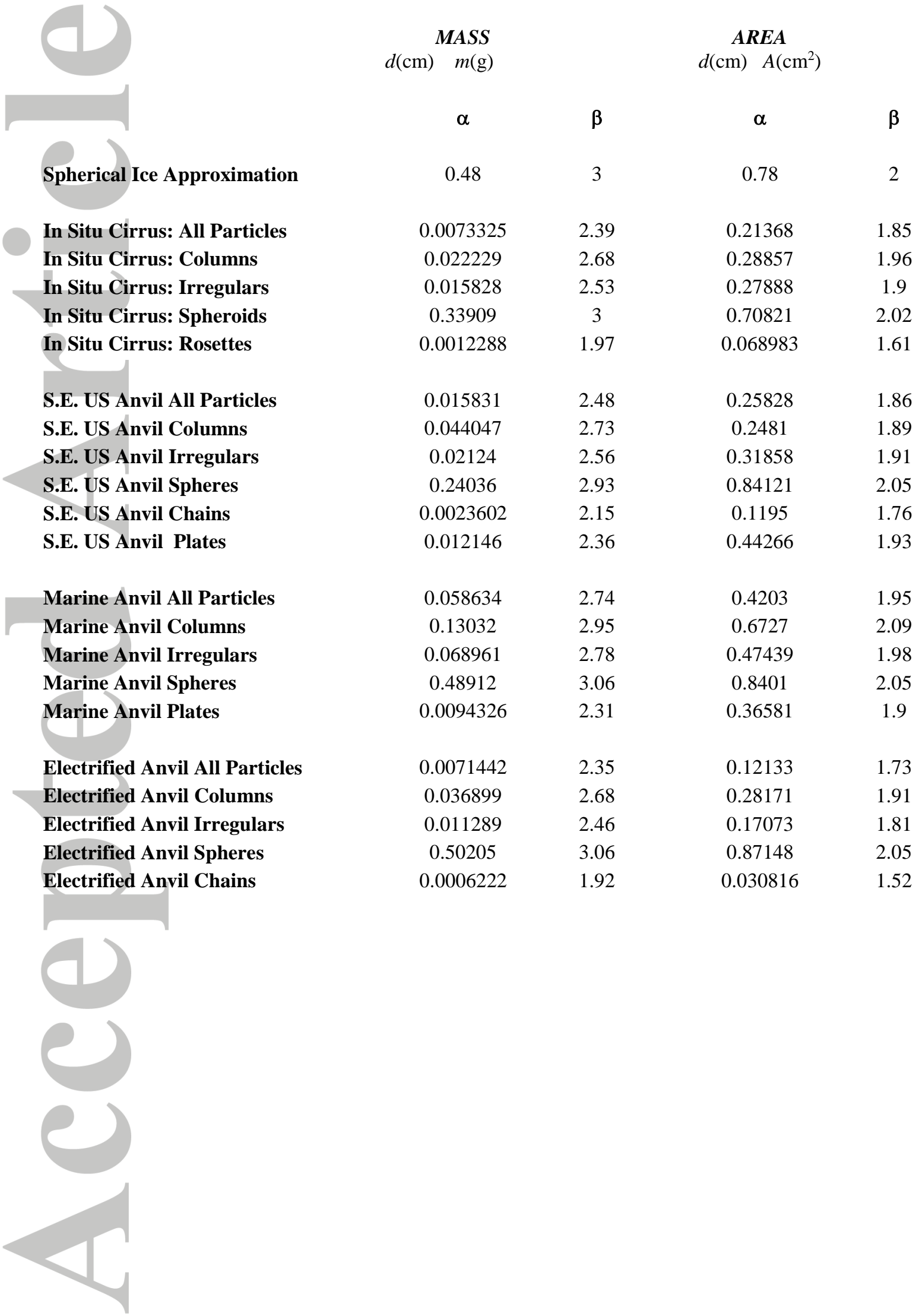


Table 3. Sources of data used in this Section.

\begin{tabular}{|l|l|l|l|}
\hline \multicolumn{4}{|c|}{ DATA SOURCES } \\
\multicolumn{4}{|c|}{ Project } \\
\multicolumn{4}{|c|}{ Flight Date } \\
\hline In Situ Cirrus, WB-57 & POSIDON & $2016-10-12$ & Time Period \\
\hline In Situ Cirrus, Learjet & SPARTICUS & $2010-03-26 \mathrm{a}$ & $19: 39: 00-19: 50: 00$ \\
In Situ Cirrus, Learjet & SPARTICUS & $2010-03-26 \mathrm{a}$ & $19: 51: 00-20: 15: 00$ \\
\hline Marine Anvil, WB-57 & POSIDON & $2016-10-12$ & $03: 42: 00-03: 48: 00$ \\
\hline S.E. US Slightly Electrified Anvil, Learjet & SEAC4RS & $2013-08-12 \mathrm{~b}$ & $19: 48: 00-20: 00: 00$ \\
\hline S.E. US Slightly Electrified Anvil, Learjet & SEAC4RS & $2013-08-30 \mathrm{~b}$ & $18: 48: 00-19: 05: 00$ \\
\hline S.E. US Slightly Electrified Anvil, Learjet & SEAC4RS & $2013-09-11 \mathrm{~b}$ & $20: 10: 31-20: 45: 00$ \\
\hline Continental Highly Electrified Anvil, GV & DC3 & $2012-06-06$ & $22: 19: 12-22: 23: 21$ \\
Continental Highly Electrified Anvil, Learjet & EOS & $2001-06-08$ & $22: 12: 09-22: 59: 50$ \\
\hline
\end{tabular}


Table 4. Percentages of Particle habits as a function of size from Figures 13, 15, and 26.

Fig 13a
\begin{tabular}{c|cccccccccccc} 
Dmin & CC & UC & SQS & MQS & LQS & COL & PLT & BR & ACS & APS & ABRS & Total \\
\hline $\mathbf{1 0}$ & 0.0 & 0.0 & 100 & 0.0 & 0.0 & 0.0 & 0.0 & 0.0 & 0.0 & 0.0 & 0.0 & 100 \\
$\mathbf{2 0}$ & 0.0 & 0.0 & 100 & 0.0 & 0.0 & 0.0 & 0.0 & 0.0 & 0.0 & 0.0 & 0.0 & 100 \\
$\mathbf{3 0}$ & 0.0 & 0.0 & 100 & 0.0 & 0.0 & 0.0 & 0.0 & 0.0 & 0.0 & 0.0 & 0.0 & 100 \\
$\mathbf{4 0}$ & 0.0 & 41.2 & 19.6 & 4.5 & 0.0 & 9.4 & 11.4 & 14.0 & 0.0 & 0.0 & 0.0 & 100 \\
$\mathbf{5 0}$ & 0.0 & 83.4 & 0.0 & 1.6 & 0.0 & 2.5 & 3.1 & 9.4 & 0.0 & 0.0 & 0.0 & 100 \\
$\mathbf{6 0}$ & 0.0 & 86.0 & 0.0 & 1.1 & 0.0 & 1.3 & 1.8 & 9.8 & 0.0 & 0.0 & 0.0 & 100 \\
$\mathbf{7 0}$ & 0.0 & 87.1 & 0.0 & 0.5 & 0.0 & 0.6 & 0.9 & 10.9 & 0.0 & 0.0 & 0.0 & 100 \\
$\mathbf{8 0}$ & 0.0 & 93.2 & 0.0 & 0.1 & 0.0 & 0.1 & 0.1 & 3.0 & 3.6 & 0.0 & 0.0 & 100 \\
$\mathbf{9 0}$ & 0.0 & 96.1 & 0.0 & 0.0 & 0.0 & 0.0 & 0.0 & 1.5 & 2.3 & 0.0 & 0.0 & 100 \\
$\mathbf{1 0 0}$ & 0.0 & 99.5 & 0.0 & 0.0 & 0.0 & 0.0 & 0.0 & 0.1 & 0.3 & 0.1 & 0.0 & 100 \\
$\mathbf{2 0 0}$ & 0.0 & 96.1 & 0.0 & 0.0 & 0.0 & 0.0 & 0.0 & 0.1 & 2.8 & 0.5 & 0.4 & 100 \\
$\mathbf{3 0 0}$ & 0.0 & 84.5 & 0.0 & 0.0 & 0.0 & 0.0 & 0.0 & 0.2 & 11.5 & 2.0 & 1.8 & 100 \\
$\mathbf{4 0 0}$ & 0.0 & 69.0 & 0.0 & 0.0 & 0.0 & 0.0 & 0.0 & 0.5 & 23.0 & 0.0 & 7.6 & 100 \\
$\mathbf{5 0 0}$ & 0.0 & 50.9 & 0.0 & 0.0 & 0.0 & 0.0 & 0.0 & 0.6 & 35.9 & 0.0 & 12.6 & 100 \\
$\mathbf{6 0 0}$ & 0.0 & 51.8 & 0.0 & 0.0 & 0.0 & 0.2 & 0.0 & 1.9 & 30.7 & 0.0 & 15.4 & 100 \\
$\mathbf{7 0 0}$ & 0.0 & 0.0 & 0.0 & 0.0 & 0.0 & 0.0 & 0.0 & 7.7 & 47.3 & 0.0 & 45.0 & 100 \\
$\mathbf{8 0 0}$ & 0.0 & 0.0 & 0.0 & 0.0 & 0.0 & 0.0 & 0.0 & 8.9 & 44.5 & 0.0 & 46.6 & 100 \\
$\mathbf{9 0 0}$ & 0.0 & 0.0 & 0.0 & 0.0 & 0.0 & 0.0 & 0.0 & 8.9 & 44.5 & 0.0 & 46.6 & 100 \\
\end{tabular}

Fig 13b
\begin{tabular}{c|cccccccccccc} 
Dmin & CC & UC & SQS & MQS & LQS & COL & PLT & BR & ACS & APS & ABRS & Total \\
\hline $\mathbf{1 0}$ & 0.0 & 0.0 & 100 & 0.0 & 0.0 & 0.0 & 0.0 & 0.0 & 0.0 & 0.0 & 0.0 & 100 \\
$\mathbf{2 0}$ & 0.0 & 0.0 & 100 & 0.0 & 0.0 & 0.0 & 0.0 & 0.0 & 0.0 & 0.0 & 0.0 & 100 \\
$\mathbf{3 0}$ & 0.0 & 0.0 & 100 & 0.0 & 0.0 & 0.0 & 0.0 & 0.0 & 0.0 & 0.0 & 0.0 & 100 \\
$\mathbf{4 0}$ & 0.0 & 35.9 & 36.6 & 12.0 & 0.0 & 15.6 & 0.0 & 0.0 & 0.0 & 0.0 & 0.0 & 100 \\
$\mathbf{5 0}$ & 0.0 & 69.4 & 0.0 & 4.2 & 0.0 & 7.1 & 9.0 & 10.4 & 0.0 & 0.0 & 0.0 & 100 \\
$\mathbf{6 0}$ & 0.0 & 71.7 & 0.0 & 3.9 & 0.0 & 6.3 & 8.3 & 9.8 & 0.0 & 0.0 & 0.0 & 100 \\
$\mathbf{7 0}$ & 0.0 & 64.6 & 0.0 & 4.5 & 0.0 & 6.5 & 11.1 & 13.4 & 0.0 & 0.0 & 0.0 & 100 \\
$\mathbf{8 0}$ & 0.0 & 90.2 & 0.0 & 0.7 & 0.0 & 0.9 & 2.8 & 3.9 & 0.0 & 1.4 & 0.0 & 100 \\
$\mathbf{9 0}$ & 0.0 & 94.2 & 0.0 & 0.2 & 0.0 & 0.3 & 1.0 & 2.0 & 0.0 & 2.3 & 0.0 & 100 \\
$\mathbf{1 0 0}$ & 0.0 & 99.6 & 0.0 & 0.0 & 0.0 & 0.0 & 0.0 & 0.1 & 0.0 & 0.3 & 0.0 & 100 \\
$\mathbf{2 0 0}$ & 0.0 & 97.3 & 0.0 & 0.0 & 0.0 & 0.0 & 0.0 & 0.1 & 0.0 & 2.4 & 0.3 & 100 \\
$\mathbf{3 0 0}$ & 5.3 & 89.8 & 0.0 & 0.0 & 0.0 & 0.0 & 0.0 & 0.1 & 0.0 & 3.7 & 1.1 & 100 \\
$\mathbf{4 0 0}$ & 41.8 & 54.8 & 0.0 & 0.0 & 0.0 & 0.2 & 0.2 & 0.0 & 0.0 & 2.7 & 0.3 & 100 \\
$\mathbf{5 0 0}$ & 0.0 & 91.5 & 0.0 & 0.0 & 0.0 & 1.2 & 0.0 & 0.0 & 0.0 & 7.3 & 0.0 & 100 \\
$\mathbf{6 0 0}$ & 12.5 & 80.6 & 0.0 & 0.0 & 0.0 & 0.0 & 0.0 & 0.0 & 0.0 & 6.9 & 0.0 & 100 \\
$\mathbf{7 0 0}$ & 25.8 & 64.5 & 0.0 & 0.0 & 0.0 & 0.0 & 0.0 & 0.0 & 0.0 & 9.7 & 0.0 & 100 \\
$\mathbf{8 0 0}$ & 72.2 & 0.0 & 0.0 & 0.0 & 0.0 & 0.0 & 0.0 & 0.0 & 0.0 & 27.8 & 0.0 & 100 \\
$\mathbf{9 0 0}$ & 72.2 & 0.0 & 0.0 & 0.0 & 0.0 & 0.0 & 0.0 & 0.0 & 0.0 & 27.8 & 0.0 & 100 \\
& & & & & & & & & & & & \\
\end{tabular}

Fig 15a
\begin{tabular}{c|ccccccc} 
& $\%$ Habit by Concentration \\
Dmin & Sph & Col & Plt & Ros & Bud & Irr & Total \\
\hline $\mathbf{1 0}$ & 67.2 & 0.5 & 0.0 & 0.0 & 0.0 & 32.3 & 100 \\
$\mathbf{2 0}$ & 67.8 & 0.9 & 0.0 & 0.0 & 0.0 & 31.2 & 100 \\
$\mathbf{3 0}$ & 76.7 & 2.6 & 0.0 & 0.0 & 0.0 & 20.7 & 100 \\
$\mathbf{4 0}$ & 79.2 & 1.9 & 0.0 & 0.0 & 0.1 & 18.9 & 100 \\
$\mathbf{5 0}$ & 51.6 & 2.1 & 0.0 & 0.0 & 0.5 & 45.9 & 100
\end{tabular}

Fig 15b
\begin{tabular}{c|ccccccc} 
Dmin & Sph & Col & Plt & Ros & Bud & Irr & Total \\
\hline $\mathbf{1 0}$ & 90.9 & 0.3 & 0.0 & 0.0 & 0.0 & 8.8 & 100 \\
$\mathbf{2 0}$ & 77.7 & 1.7 & 0.0 & 0.0 & 0.0 & 20.6 & 100 \\
$\mathbf{3 0}$ & 54.8 & 7.5 & 0.0 & 0.0 & 0.0 & 37.7 & 100 \\
$\mathbf{4 0}$ & 53.8 & 9.0 & 0.0 & 0.0 & 0.3 & 37.0 & 100 \\
$\mathbf{5 0}$ & 50.4 & 4.3 & 0.0 & 0.0 & 0.6 & 44.7 & 100
\end{tabular}

Fig $15 c$
\begin{tabular}{c|ccccccc} 
O Habit by Concentration \\
Dmin & Sph & Col & Plt & Ros & Bud & Irr & Total \\
\hline $\mathbf{1 0}$ & 90.7 & 1.1 & 0.0 & 0.0 & 0.0 & 8.2 & 100 \\
$\mathbf{2 0}$ & 84.5 & 2.1 & 0.0 & 0.0 & 0.0 & 13.4 & 100 \\
$\mathbf{3 0}$ & 56.3 & 8.5 & 0.0 & 0.0 & 0.0 & 35.2 & 100 \\
$\mathbf{4 0}$ & 28.3 & 16.0 & 0.0 & 0.0 & 0.4 & 55.4 & 100 \\
$\mathbf{5 0}$ & 27.8 & 13.0 & 0.0 & 0.0 & 1.7 & 57.4 & 100
\end{tabular}

() 2019 American Geophysical Union. All rights reserved. 


\begin{tabular}{c|ccccccc}
$\mathbf{6 0}$ & 16.3 & 2.4 & 0.0 & 0.0 & 1.6 & 79.6 & 100 \\
$\mathbf{7 0}$ & 3.0 & 3.3 & 0.0 & 0.0 & 4.0 & 89.7 & 100 \\
$\mathbf{8 0}$ & 0.8 & 4.3 & 1.5 & 0.8 & 10.6 & 81.9 & 100 \\
$\mathbf{9 0}$ & 0.2 & 5.2 & 1.3 & 2.7 & 16.9 & 73.6 & 100 \\
$\mathbf{1 0 0}$ & 0.0 & 6.7 & 0.8 & 21.1 & 29.6 & 41.8 & 100 \\
$\mathbf{2 0 0}$ & 0.0 & 3.8 & 0.0 & 76.1 & 20.1 & 0.0 & 100 \\
$\mathbf{3 0 0}$ & 0.0 & 3.1 & 0.0 & 84.4 & 12.4 & 0.0 & 100 \\
$\mathbf{4 0 0}$ & 0.0 & 5.5 & 0.0 & 84.7 & 9.7 & 0.0 & 100 \\
$\mathbf{5 0 0}$ & 0.0 & 4.5 & 0.0 & 95.5 & 0.0 & 0.0 & 100 \\
$\mathbf{6 0 0}$ & 0.0 & 0.0 & 0.0 & 95.6 & 4.4 & 0.0 & 100 \\
$\mathbf{7 0 0}$ & 0.0 & 0.0 & 0.0 & 100 & 0.0 & 0.0 & 100 \\
$\mathbf{8 0 0}$ & 0.0 & 0.0 & 0.0 & 100 & 0.0 & 0.0 & 100 \\
$\mathbf{9 0 0}$ & 0.0 & 0.0 & 0.0 & 100 & 0.0 & 0.0 & 100 \\
$\mathbf{1 0 0 0}$ & 0.0 & 0.0 & 0.0 & 0.0 & 0.0 & 0.0 & 0
\end{tabular}

Fig 26a \% Habit by Concentration

\begin{tabular}{l|lllllll} 
Dmin & Sph Col Plt Bud Ros Irr Total \\
\hline 10 & 71.8 & 0.1 & 0.0 & 0.0 & 0.0 & 28.1 & 100
\end{tabular}

\begin{tabular}{l|lllllll}
10 & 71.8 & 0.1 & 0.0 & 0.0 & 0.0 & 28.1 & 100
\end{tabular}

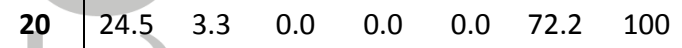

\begin{tabular}{l|lllllll}
30 & 27.3 & 9.7 & 0.2 & 0.3 & 0.0 & 62.5 & 100
\end{tabular}

$\begin{array}{lllllllll}40 & 9.6 & 17.0 & 0.6 & 3.6 & 0.0 & 69.2 & 100\end{array}$

$\begin{array}{lllllllll}50 & 2.1 & 22.4 & 5.6 & 2.9 & 0.0 & 67.0 & 100\end{array}$

\begin{tabular}{l|llllllll}
60 & 0.0 & 25.3 & 17.5 & 2.3 & 0.0 & 54.9 & 100
\end{tabular}

$70 \quad \begin{array}{llllllll}70.2 & 25.5 & 18.1 & 0.0 & 0.0 & 56.2 & 100\end{array}$

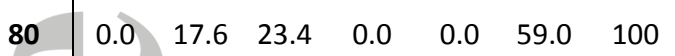

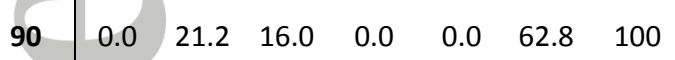

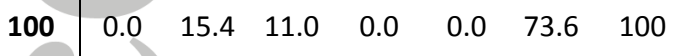

\begin{tabular}{l|llllllll}
200 & 0.0 & 4.5 & 4.1 & 0.0 & 0.0 & 91.4 & 100
\end{tabular}

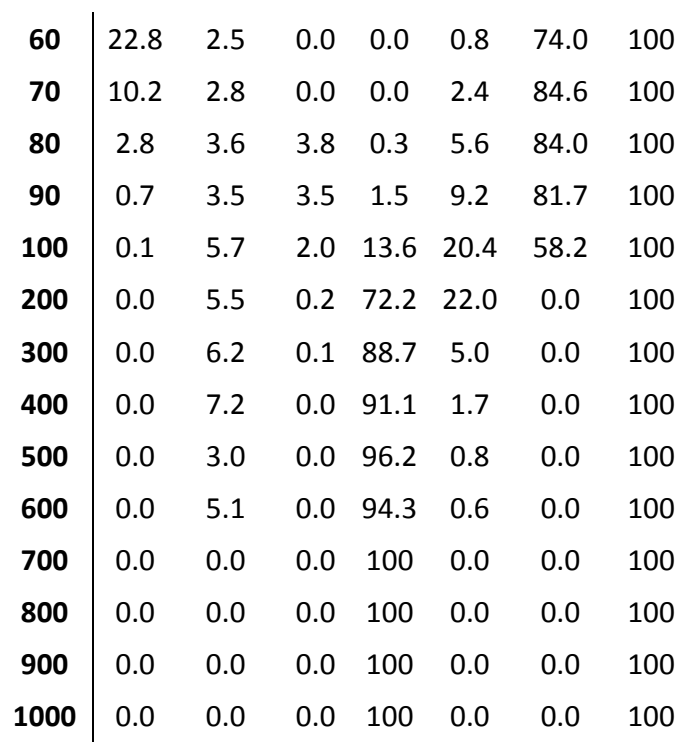

Fig 26b
\begin{tabular}{c|ccccccc} 
26 & \multicolumn{7}{c}{ \% by Area } \\
Dmin & Sph & Col & Plt & Bud & Ros & Irr & Total \\
\hline $\mathbf{1 0}$ & 56.5 & 0.2 & 0.0 & 0.0 & 0.0 & 43.3 & 100 \\
$\mathbf{2 0}$ & 25.5 & 3.9 & 0.0 & 0.0 & 0.0 & 70.6 & 100 \\
$\mathbf{3 0}$ & 26.3 & 10.4 & 0.2 & 0.4 & 0.0 & 62.8 & 100 \\
$\mathbf{4 0}$ & 9.0 & 17.3 & 0.6 & 3.9 & 0.0 & 69.2 & 100 \\
$\mathbf{5 0}$ & 2.1 & 22.8 & 5.9 & 2.7 & 0.0 & 66.4 & 100 \\
$\mathbf{6 0}$ & 0.0 & 25.3 & 17.5 & 2.3 & 0.0 & 54.9 & 100 \\
$\mathbf{7 0}$ & 0.2 & 25.5 & 18.1 & 0.0 & 0.0 & 56.2 & 100 \\
$\mathbf{8 0}$ & 0.0 & 17.6 & 23.4 & 0.0 & 0.0 & 59.0 & 100 \\
$\mathbf{9 0}$ & 0.0 & 21.2 & 16.0 & 0.0 & 0.0 & 62.8 & 100 \\
$\mathbf{1 0 0}$ & 0.0 & 13.2 & 10.0 & 0.0 & 0.0 & 76.7 & 100 \\
$\mathbf{2 0 0}$ & 0.0 & 5.7 & 3.7 & 0.0 & 0.0 & 90.6 & 100
\end{tabular}

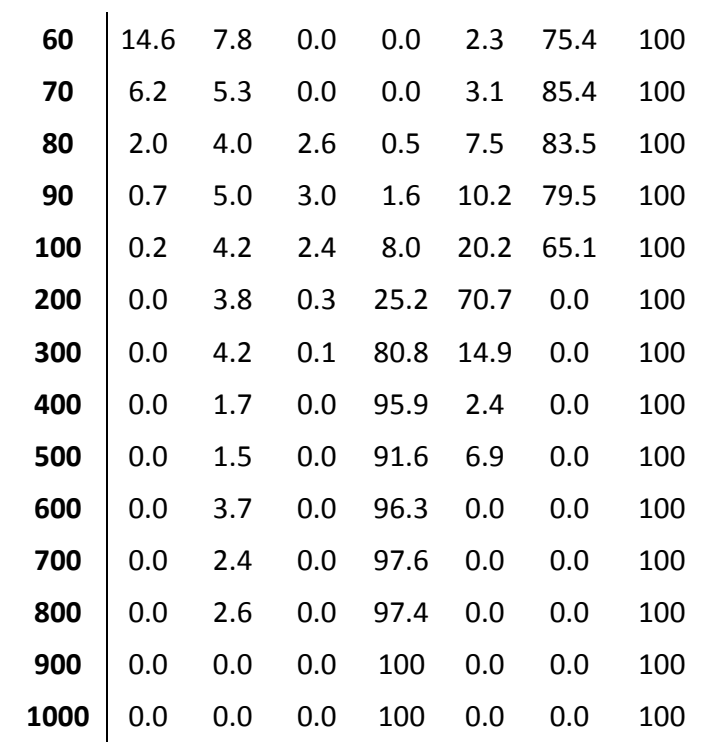

Fig 26c
\begin{tabular}{c|ccccccc} 
Dmin & Sph & Col & Plt & Bud & Ros & Irr & Total \\
\hline $\mathbf{1 0}$ & 48.9 & 0.3 & 0.0 & 0.0 & 0.0 & 50.8 & 100 \\
$\mathbf{2 0}$ & 26.1 & 4.2 & 0.0 & 0.0 & 0.0 & 69.7 & 100 \\
$\mathbf{3 0}$ & 25.8 & 10.6 & 0.2 & 0.4 & 0.0 & 62.9 & 100 \\
$\mathbf{4 0}$ & 8.7 & 17.4 & 0.6 & 4.0 & 0.0 & 69.2 & 100 \\
$\mathbf{5 0}$ & 2.0 & 22.9 & 6.0 & 2.7 & 0.0 & 66.3 & 100 \\
$\mathbf{6 0}$ & 0.0 & 25.3 & 17.5 & 2.3 & 0.0 & 54.9 & 100 \\
$\mathbf{7 0}$ & 0.2 & 25.5 & 18.1 & 0.0 & 0.0 & 56.2 & 100 \\
$\mathbf{8 0}$ & 0.0 & 17.6 & 23.4 & 0.0 & 0.0 & 59.0 & 100 \\
$\mathbf{9 0}$ & 0.0 & 21.2 & 16.0 & 0.0 & 0.0 & 62.8 & 100 \\
$\mathbf{1 0 0}$ & 0.0 & 12.8 & 9.8 & 0.0 & 0.0 & 77.4 & 100 \\
$\mathbf{2 0 0}$ & 0.0 & 5.9 & 3.6 & 0.0 & 0.0 & 90.4 & 100
\end{tabular}

Fig 26e

\% Habit by Area
Fig $26 f$

\% Habit by Mass 


\begin{tabular}{c|ccccccc} 
Dmin & Sph & Col & Plt & Bud & Ros & Irr & Total \\
\hline $\mathbf{1 0}$ & 48.8 & 0.1 & 0.0 & 0.0 & 0.0 & 51.1 & 100 \\
$\mathbf{2 0}$ & 9.5 & 4.0 & 0.0 & 0.0 & 0.0 & 86.5 & 100 \\
$\mathbf{3 0}$ & 2.7 & 15.1 & 0.0 & 0.0 & 0.0 & 82.2 & 100 \\
$\mathbf{4 0}$ & 0.0 & 32.8 & 2.3 & 0.0 & 0.0 & 64.9 & 100 \\
$\mathbf{5 0}$ & 0.0 & 47.1 & 0.0 & 6.4 & 0.0 & 46.5 & 100 \\
$\mathbf{6 0}$ & 0.0 & 31.3 & 2.4 & 23.5 & 0.0 & 42.8 & 100 \\
$\mathbf{7 0}$ & 0.0 & 42.4 & 0.0 & 32.0 & 0.0 & 25.5 & 100 \\
$\mathbf{8 0}$ & 0.0 & 52.2 & 0.0 & 23.4 & 0.0 & 24.4 & 100 \\
$\mathbf{9 0}$ & 0.0 & 20.9 & 0.0 & 75.8 & 0.0 & 3.3 & 100 \\
$\mathbf{1 0 0}$ & 0.0 & 11.8 & 1.6 & 44.7 & 25.5 & 16.4 & 100 \\
$\mathbf{2 0 0}$ & 0.0 & 0.8 & 0.0 & 6.8 & 87.7 & 4.6 & 100 \\
$\mathbf{3 0 0}$ & 0.0 & 0.0 & 0.0 & 0.0 & 100 & 0.0 & 100 \\
$\mathbf{4 0 0}$ & 0.0 & 4.5 & 0.0 & 0.0 & 78.3 & 17.2 & 100 \\
$\mathbf{5 0 0}$ & 0.0 & 0.0 & 0.0 & 0.0 & 0.0 & 0.0 & 0 \\
$\mathbf{6 0 0}$ & 0.0 & 0.0 & 0.0 & 0.0 & 100 & 0.0 & 100
\end{tabular}

\begin{tabular}{c|ccccccc} 
Dmin & Sph & Col & Plt & Bud & Ros & Irr & Total \\
\hline $\mathbf{1 0}$ & 42.8 & 0.2 & 0.0 & 0.0 & 0.0 & 56.9 & 100 \\
$\mathbf{2 0}$ & 8.4 & 5.2 & 0.0 & 0.0 & 0.0 & 86.4 & 100 \\
$\mathbf{3 0}$ & 2.4 & 17.1 & 0.0 & 0.0 & 0.0 & 80.6 & 100 \\
$\mathbf{4 0}$ & 0.0 & 33.2 & 1.8 & 0.0 & 0.0 & 65.1 & 100 \\
$\mathbf{5 0}$ & 0.0 & 45.4 & 0.0 & 7.7 & 0.0 & 47.0 & 100 \\
$\mathbf{6 0}$ & 0.0 & 31.3 & 2.4 & 23.5 & 0.0 & 42.8 & 100 \\
$\mathbf{7 0}$ & 0.0 & 42.4 & 0.0 & 32.0 & 0.0 & 25.5 & 100 \\
$\mathbf{8 0}$ & 0.0 & 52.2 & 0.0 & 23.4 & 0.0 & 24.4 & 100 \\
$\mathbf{9 0}$ & 0.0 & 20.9 & 0.0 & 75.8 & 0.0 & 3.3 & 100 \\
$\mathbf{1 0 0}$ & 0.0 & 10.9 & 1.0 & 40.7 & 31.6 & 15.9 & 100 \\
$\mathbf{2 0 0}$ & 0.0 & 0.6 & 0.0 & 7.6 & 87.7 & 4.1 & 100 \\
$\mathbf{3 0 0}$ & 0.0 & 0.0 & 0.0 & 0.0 & 100 & 0.0 & 100 \\
$\mathbf{4 0 0}$ & 0.0 & 4.4 & 0.0 & 0.0 & 76.0 & 19.6 & 100 \\
$\mathbf{5 0 0}$ & 0.0 & 0.0 & 0.0 & 0.0 & 0.0 & 0.0 & 0 \\
$\mathbf{6 0 0}$ & 0.0 & 0.0 & 0.0 & 0.0 & 100 & 0.0 & 100
\end{tabular}

\begin{tabular}{c|ccccccc} 
Dmin & Sph & Col & Plt & Bud & Ros & Irr & Total \\
\hline $\mathbf{1 0}$ & 38.4 & 0.4 & 0.0 & 0.0 & 0.0 & 61.2 & 100 \\
$\mathbf{2 0}$ & 7.7 & 6.0 & 0.0 & 0.0 & 0.0 & 86.3 & 100 \\
$\mathbf{3 0}$ & 2.2 & 17.9 & 0.0 & 0.0 & 0.0 & 79.9 & 100 \\
$\mathbf{4 0}$ & 0.0 & 33.3 & 1.6 & 0.0 & 0.0 & 65.1 & 100 \\
$\mathbf{5 0}$ & 0.0 & 45.0 & 0.0 & 7.9 & 0.0 & 47.1 & 100 \\
$\mathbf{6 0}$ & 0.0 & 31.3 & 2.4 & 23.5 & 0.0 & 42.8 & 100 \\
$\mathbf{7 0}$ & 0.0 & 42.4 & 0.0 & 32.0 & 0.0 & 25.5 & 100 \\
$\mathbf{8 0}$ & 0.0 & 52.2 & 0.0 & 23.4 & 0.0 & 24.4 & 100 \\
$\mathbf{9 0}$ & 0.0 & 20.9 & 0.0 & 75.8 & 0.0 & 3.3 & 100 \\
$\mathbf{1 0 0}$ & 0.0 & 10.7 & 0.8 & 39.9 & 32.8 & 15.9 & 100 \\
$\mathbf{2 0 0}$ & 0.0 & 0.5 & 0.0 & 7.7 & 87.7 & 4.0 & 100 \\
$\mathbf{3 0 0}$ & 0.0 & 0.0 & 0.0 & 0.0 & 100 & 0.0 & 100 \\
$\mathbf{4 0 0}$ & 0.0 & 4.4 & 0.0 & 0.0 & 75.5 & 20.1 & 100 \\
$\mathbf{5 0 0}$ & 0.0 & 0.0 & 0.0 & 0.0 & 0.0 & 0.0 & 0 \\
$\mathbf{6 0 0}$ & 0.0 & 0.0 & 0.0 & 0.0 & 100 & 0.0 & 100
\end{tabular}

(c) 2019 American Geophysical Union. All rights reserved. 